University of Louisville

ThinkIR: The University of Louisville's Institutional Repository

Electronic Theses and Dissertations

$12-2010$

\title{
The role of MUC1 splice variants in dry eye and inflammation.
}

Yoannis Imbert-Fernandez

University of Louisville

Follow this and additional works at: https://ir.library.louisville.edu/etd

\section{Recommended Citation}

Imbert-Fernandez, Yoannis, "The role of MUC1 splice variants in dry eye and inflammation." (2010). Electronic Theses and Dissertations. Paper 659.

https://doi.org/10.18297/etd/659

This Doctoral Dissertation is brought to you for free and open access by ThinkIR: The University of Louisville's Institutional Repository. It has been accepted for inclusion in Electronic Theses and Dissertations by an authorized administrator of ThinkIR: The University of Louisville's Institutional Repository. This title appears here courtesy of the author, who has retained all other copyrights. For more information, please contact thinkir@louisville.edu. 
THE ROLE OF MUC1 SPLICE VARIANTS IN DRY EYE AND INFLAMMATION

\author{
By \\ Yoannis Imbert-Fernandez \\ B.S., University of Havana, 1998 \\ M.S., University of Louisville, 2008
}

\begin{abstract}
A Dissertation
Submitted to the Graduate Faculty of the School of Medicine of the University of Louisville in Partial Fulfillment of the Requirements for the Degree of

Doctor of Philosophy

Department of Biochemistry and Molecular Biology University of Louisville, School of Medicine Louisville, KY
\end{abstract}

December 2010 
Copyright 2010 by Yoannis Imbert-Fernandez

All rights reserved 

THE ROLE OF MUC1 SPLICE VARIANTS IN DRY EYE AND INFLAMMATION

By

Yoannis Imbert-Fernandez

B.S., University of Havana, 1998

M.S., University of Louisville, 2008

A Dissertation Approved on

November 11,2010

by the following Thesis Committee:

Dr. Carrolyn M. Klifge (Mentor)

\begin{tabular}{c}
\hline Dr. William W. Yoúng \\
\hline Dr. Bdrbara J. Clark \\
\hline Dr. Jill Suttles \\
\hline Dr. George N. Hajishengallis \\
\hline
\end{tabular}

Dr. Mark D. Brennan 


\section{DEDICATION}

This dissertation is dedicated to my parents for their unconditional love and support; also to my husband and best friend, Ernest Fernandez, without whose love, encouragement, and support, I would not have finished this thesis. Furthermore, this thesis goes to my daughter Veronica and my son Reynold, for giving me so much strength and making me a better person. Last, but not least, this dissertation is also dedicated to my sister Yoania Cannon for the love and trust she has always given me. 


\section{ACKNOWLEDGMENTS}

I would like to express my sincerest gratitude to my mentor, Dr. Carolyn M. Klinge, for her support, guidance, and dedication. Her vast knowledge and expertise has been invaluable for my scientific growth. I am heartily thankful to my former mentor, Dr. William W. Young, for his encouragement, support, and patience. He provided me with direction and became my source of inspiration. I would also like to thank the rest of my committee members, Dr. Marcia M. Jumblatt, Dr. Barbara J. Clark, Dr. Jill Suttles, Dr. Mark D. Brennan, and Dr. George N. Hajishengallis for their assistance and comments. Special thanks go to my laboratory colleagues for their support over the years. 


\begin{abstract}
THE ROLE OF MUC1 SPLICE VARIANTS IN DRY EYE DISEASE AND INFLAMMATION

Yoannis Imbert-Fernandez

November 11, 2010
\end{abstract}

Mucin 1 (MUC1) is a plasma membrane-bound glycoprotein that plays a protective role in corneal epithelial cells. Two full-length splice variants of $\mathrm{MUC1}$ : $\mathrm{MUC1} / \mathrm{B}$ and MUC1/A, that differ by the inclusion of $27 \mathrm{bp}$ from intron 1 and a SNP in MUC1/A, but have identical C-terminal cytoplasmic domain (CD) sequences, were identified in human conjunctival tissue. I tested the hypothesis that MUC1 splice variants are key immunoregulators that act on the ocular surface to protect the ocular surface from inflammation and that their expression correlates with dry eye status. The expression of MUC1/A and MUC1/B splice variant was examined in non-Sjögren's aqueous deficient and evaporative dry eye patients and compared to normal controls. The frequency of MUC1/A gene expression was lower in patients with non-Sjögren's aqueous deficient dry eye compared to controls, indicating a link between MUC1/A and the symptoms associated with dry eye disease. Overexpression of MUC1/A and MUC1/B in COS-7 cells resulted in equal protein expression and plasma membrane localization. MUC1/B and MUC1/A splice variants differed in their ability to modulate the TNF $\alpha$-induced inflammatory responses. The MUC1/B splice variant, and not MUC1/A, inhibited the 
induction of IL-1 $\beta$ and IL-8 expression by TNF $\alpha$ at $4 \mathrm{~h}$. In contrast, MUC1/A stimulated TNF $\alpha$-driven IL- 8 mRNA and protein expression after $24 \mathrm{~h}$ of treatment. MUCl/B, but not $\mathrm{MUC1} / \mathrm{A}$, inhibited TNF $\alpha$-induced luciferase activity from an NF- $\kappa \mathrm{B}$ reporter. Both MUC1/B and MUC1/A blocked the induction of miR-21 by TNF $\alpha$. In addition, MUC1/A, but not MUC1/B, increased basal expression of TGF $\beta$. These data demonstrate for the first time that $\mathrm{MUC1} / \mathrm{A}$ and $\mathrm{MUC1} / \mathrm{B}$ are genetic susceptibility factors with different anti-inflammatory activities. 


\section{TABLE OF CONTENTS}

DEDICATION.

iii

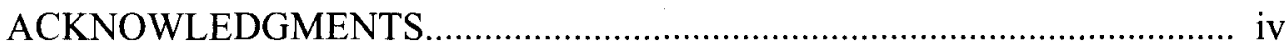

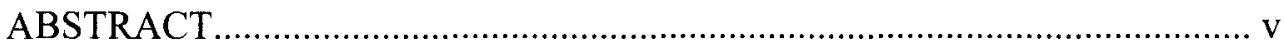

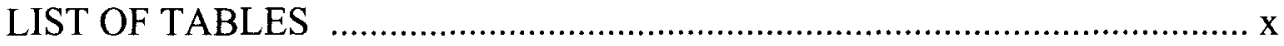

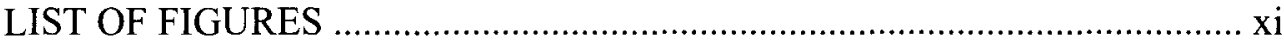

\section{CHAPTER}

I. INTRODUCTION TO DRY EYE DISEASE

The definition and classification of dry eye disease ......................... 1

The lacrimal functional unit ..........................................................

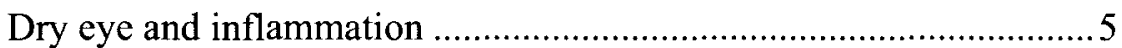

Animal models of dry eye ..................................................... 6

Etiology and risks factors for dry eye disease ............................. 7

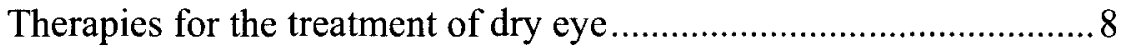

II. SIGNIFICANCE OF MUC1 IN DRY EYE DISEASE AND INFLAMMATION

Introduction to mucins ............................................................ 10

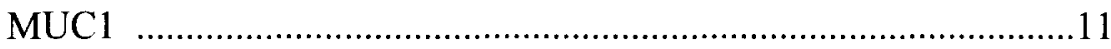

The role of $\mathrm{MUC1}$ in the regulation of cell signaling.......................14

Regulation of MUC1 gene expression .........................................15

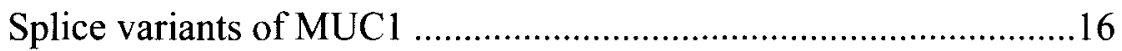

Dissertation specific aims and hypotheses...................................18 
III. MUC1 SPLICE VARIANTS IN HUMAN OCULAR SURFACE TISSUES: POSSIBLE DIFFERENCES BETWEEN DRY EYE PATIENTS AND NORMAL CONTROLS

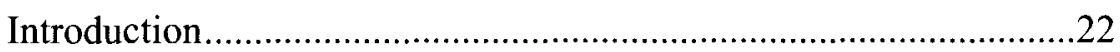

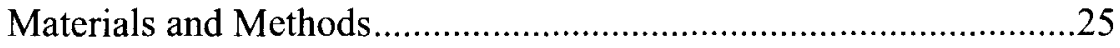

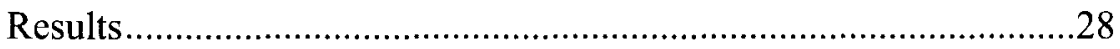

MUC1 real-time RT-PCR ……………………………...................

RT-PCR of MUC1 splice variants in whole ocular surface tissues ...31

RT-PCR screening of conjunctival swab samples from dry eye subjects and normal controls for MUC1 splice variants.....................32

Screening dry eye and normal control conjunctival swab samples for SNP status as a measure of tandem repeat size class ..........................37

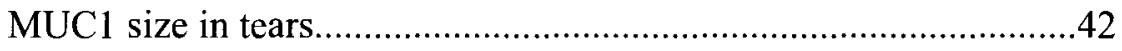

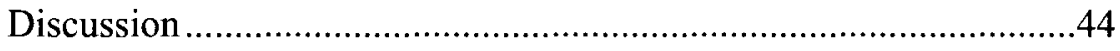

MUC1 variants in ocular tissues ......................................................4

MUC1 splice variant, tandem repeat number, and dry eye disease ...46

IV. MUC1 AND ESTROGEN RECEPTOR $\alpha$ GENE POLYMORPHISMS IN DRY EYE PATIENTS

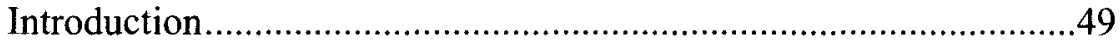

Materials and Methods....................................................................50

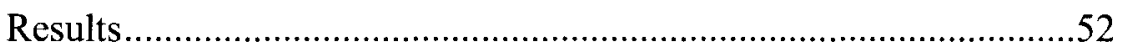

Correlation between $\mathrm{MUCl}$ splice variant pattern

and SNP genotype

MUC1 SNP genotype frequencies among normal controls and dry eye groups

Correlation between MUC1 splice variant pattern and VNTR size class 
ER $\alpha$ SNP genotype frequencies among normal controls and dry eye groups

Discussion .58

$\mathrm{ER} \alpha$ SNP genotype frequencies among Caucasians. .58

MUC1 SNP genotype frequencies among Caucasians .60

Possible relationships of MUC1 variants in dry eye disease .62

V. MUC1/A AND MUC1/B SPLICE VARIANTS DIFFERENTIALLY REGULATE INFLAMMATORY CYTOKINE EXPRESSION

Introduction .65

Materials and Methods .66

Results.

Expression of MUC1/A and MUC1/B splice variants in COS-7 cells .72

Regulation of the inflammatory response by MUC1/A and MUC1/B.

MUC1/A increases basal TGF $\beta$ mRNA and protein expression

Regulation of NF- $\kappa B$-Luciferase reporter by $\mathrm{MUC1} / \mathrm{A}$ and $\mathrm{MUCl} / \mathrm{B}$

Regulation of microRNA miR-21 by $\mathrm{MUCl} / \mathrm{A}$ and $\mathrm{MUCl} / \mathrm{B}$.

MUCl ectodomain release. .83

Discussion .85

VI. RESEARCH IMPLICATIONS .................................................99

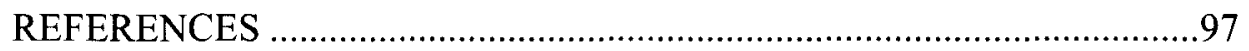

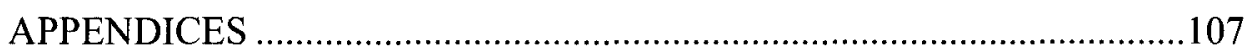

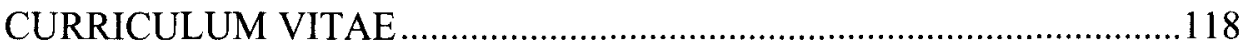




\section{LIST OF TABLES}

$\begin{array}{ll}\text { TABLE PAGE } & \text { PA }\end{array}$

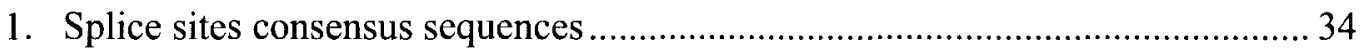

2. Comparison of frequencies of MUC1 SNP rs 4072037

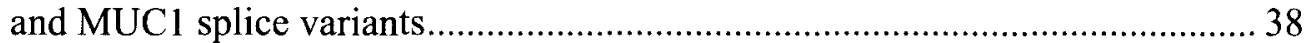

3. MUC1 SNP genotype frequencies among

normal controls and dry eye subjects .......................................................... 54

4. ER $\alpha$ SNP genotype frequencies among

normal controls and dry eye subjects 


\section{LIST OF FIGURES}

1. The core mechanisms causing dry eye disease ......................................... 4

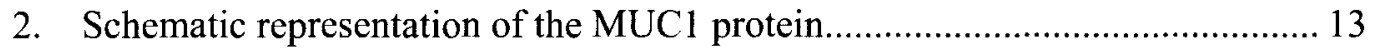

3. Schematic representation of the MUCl/A and MUC1/B splice variants.

4. Proposed model for MUCl splice variants as key factors in the development of dry eye disease

5. MUC1 splice variants

6. Expression of MUC1 in human ocular surface tissues as determined by real-time RT-PCR

7. RT-PCR of MUC1 splice variants in whole ocular surface tissues.

8. Amino acid sequence of the peptide predicted to be encoded by the splice variant MUC1/YI.

9. RT-PCR to detect MUC1 splice variants in conjunctival epithelial swab samples

10. Relationships among MUC1/A and MUC1/B splice site status, SNP rs4072037 status, MUC1 tandem repeat number, AlwNI sensitivity, and proposed susceptibility to dry eye

11. AlwNI digests of PCR products from conjunctival epithelial swab samples

12. Western blot of tears with DF3 anti-MUC1

13. Western blot analysis of tears with DF3 anti-MUC1

14. Comparison of MUC1 SNP genotype and VNTR allele size as determined by Southern blotting 
15. Expression of MUC1/A and MUC1/B in COS-7 cells

16. Expression of MUC1/A and MUC1/B

does not affect cell viability

17. Surface expression of MUC1/A and MUC1/B in COS-7 cells 76

18. MUC1/A and MUC1/B differentially regulate

IL-1 $\beta$ and IL-8 expression 78

19. MUC1/A stimulates TGF $\beta$ expression 80

20. Effect of MUC1/A and MUC1/B overexpression in TNF $\alpha$-induced NF- $\kappa \mathrm{B}$ activation 82

21. MUC1/A and MUC1/B inhibit TNF $\alpha$-induced miR-21 expression 84

22. MUClectodomain release in COS-7 cells transfected with $\mathrm{MUC1} / \mathrm{A}$ or $\mathrm{MUC1} / \mathrm{B}$ and treated with TNF $\alpha$ 86

23. MUC1, ER $\alpha$ and ER $\beta$ are expressed in HSG and hTCE-D cells 109

24. MUC1, ER $\alpha$ and $E R \beta$ interact in lung cancer cells. 110

25. TNF $\alpha$ treatment in HSG cells up-regulates COX-2, IL- $1 \beta$, IL- 8 and ICAM- 1 at the mRNA level

26. TNF $\alpha$ treatment increases MUC1 expression 114

27. MUC1/B overexpression decreases IL- 8 stimulation by TNF $\alpha$ 115 


\section{CHAPTER I- INTRODUCTION TO DRY EYE DISEASE}

\section{The Definition and Classification of Dry Eye Disease}

Dry eye disease or keratoconjunctivitis sicca (KCS) is a common disorder of the tear film and ocular surface, affecting more than 10 million people in this country (1). Dry eye is one the most common diseases seen in the ophthalmologic clinic, and it is significantly more prevalent among women than men (2). Whereas dry eye is not typically a sight-threatening disease, it is characterized by symptoms of irritation and discomfort and therefore it decreases the patient quality of life considerably (3).

For many years, dry eye was defined as a disorder of the tear film due to tear deficiency or excessive tear evaporation that results in inflammation and epithelial damage (4). This definition, however, was vague and did not include the word "disease" which could be interpreted as if dry eye syndrome was not a real disease but a disturbance. The dry eye workshop (DEWS) reviewed and broadened the definition and classification of dry eye in 2007. The new definition is as follows: "Dry eye is a multifactorial disease of the tears and ocular surface that results in symptoms of discomfort, visual disturbance, and tear film instability with potential damage to the ocular surface. It is accompanied by increased osmolarity of the tear film and inflammation of the ocular surface" (5). This new definition incorporates the concept of a "core mechanism" driven by tear hyperosmolarity and tear film instability that causes damage to the surface epithelium and triggers inflammation (6). 
The tear film is responsible for lubricating, nourishing and protecting the ocular surface and is composed of secretions from three major sources: the lacrimal glands which secrete the aqueous tear fluid and a number of associated proteins; the meibomian glands which secrete lipids that retard evaporation from the ocular surface; and conjunctival goblet cells and non-goblet conjunctival epithelial cells that secrete mucins that contribute to the viscoelastic properties of the tear film $(7 ; 8)$. Deficiency in any of the tear film components can contribute to the pathology of dry eye disease (7).

Based on etiology, dry eye disease has been classified into two major categories: aqueous tear-deficient and evaporative dry eye (5). Aqueous tear-deficient dry eye, as the name denotes, is characterized by a decrease in tears due to a failure of tear secretion by the lacrimal glands (9). Aqueous tear-deficient dry eye is subdivided into two categories: Sjögren's aqueous deficient and non-Sjögren's aqueous deficient. Sjögren's aqueous deficient is a chronic autoimmune disease in which the lacrimal and salivary glands are targeted by an autoimmune process leading to cell death (10). As a consequence hyposecretion of the tears and saliva is observed in these patients. In contrast, evaporative dry eye is characterized by normal lacrimal gland function and excessive water loss from the ocular surface. Evaporative dry eye is commonly associated with abnormal lipid composition of the tears due to meibomian gland dysfunction $(9 ; 11 ; 12)$.

\section{The Lacrimal Functional Unit (LFU)}

In the light of new knowledge, dry eye disease is recognized as a disturbance of the "Lacrimal Functional Unit (LFU)" and not just a problem of the tear film and the 
lacrimal gland (6). The LFU is an integrated system that is composed of the lacrimal glands, the ocular surface (conjunctiva, cornea and meibomian glands), the eyelids and the sensory and motors nerves that connect them (5). This functional unit controls the dynamics of the tear film in response to environmental, endocrine, and cortical signals. The overall function of the LFU is "to maintain the integrity of the tear film, the transparency of the cornea and the quality of the image displayed onto the retina" (5). Consequently, damage to any of the components of the LFU will alter the system homeostasis resulting in abnormal tear film and hence dry eye disease. Changes in the tear composition and stability due to dysfunction of the LFU leads to tear hyperosmolarity, tear instability and ocular surface inflammation which are considered the core mechanisms in the etiology of all subtypes of dry eye disease (5).

Increased tear osmolarity was first reported decades ago (13), and it is now recognized as the central mechanism triggering surface inflammation, damage and symptoms of discomfort. Tear hyperosmolarity is a consequence of either low aqueous tear flow and/or excessive evaporation. In some forms of dry eye, tear film stability is the initiating event rather than tear hyperosmoloratity (14). Both tear hyperosmolarity and tear film instability are shown in Figure 1 as the initiators of a cascade of inflammatory responses mediated via activation of mitogen-activated protein kinase (MAPK) and nuclear factor-kappaB (NF-kB) pathways. These inflammatory events in turn lead to progressive cell death, as has been demonstrated for goblet cells (15). Goblet cell loss and the subsequent decrease in the mucin MUC5AC, is observed in every form of dry eye $(16 ; 17)$, and it feeds back into the cycle. As dry eye disease progresses, other factors can enter the cycle and further amplify these initiating events. 


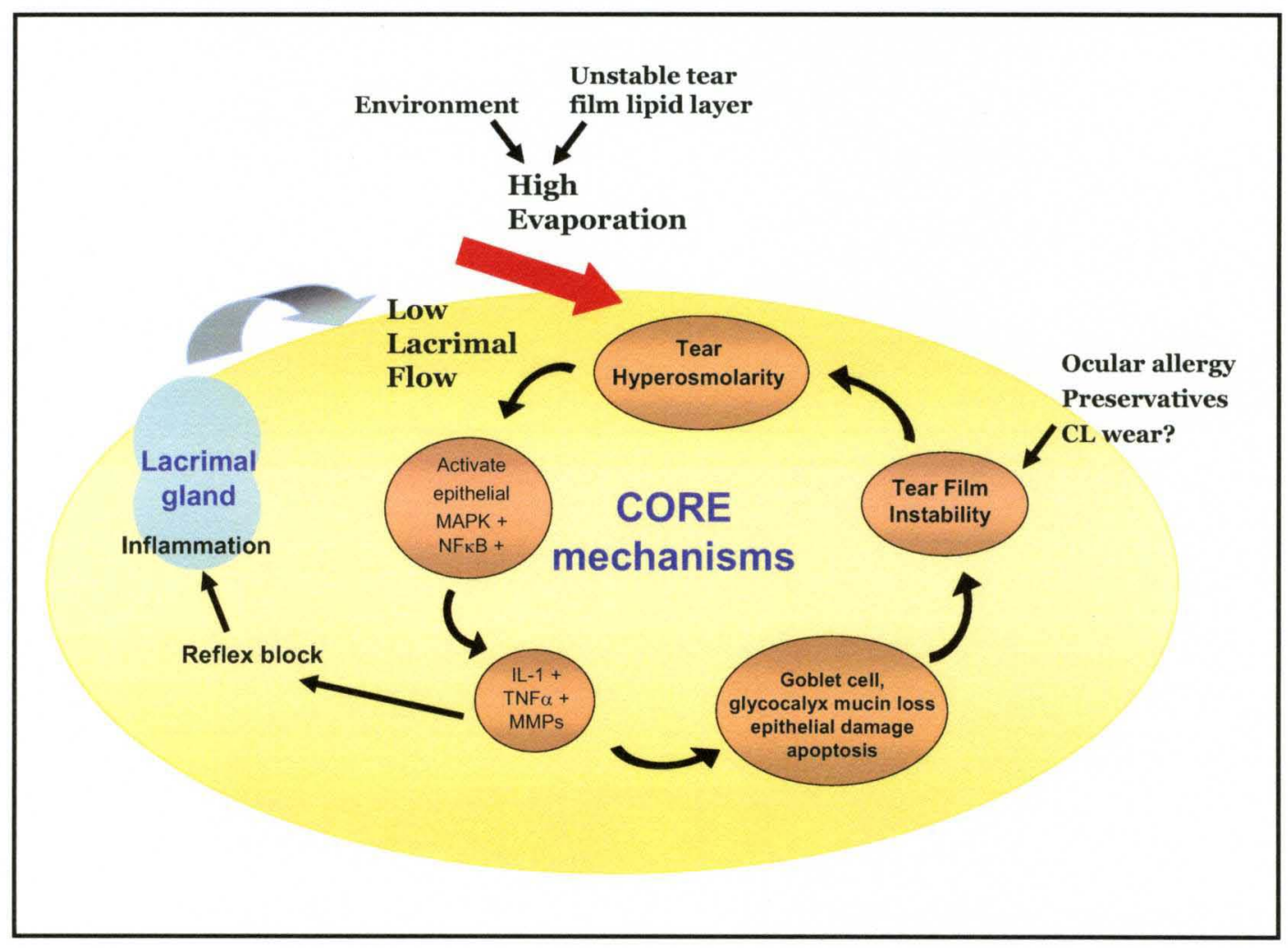

Figure 1. The core mechanisms causing dry eye disease. Adapted from the 2007 Report of the International DEWS. The figure shows the inter-connection of events occurring in dry eye that are driven by tear hyperosmolarity and tear film instability. Tear hyperosmolarity caused by reduced tear flow and/or decreased tear evaporation induces the activation of an inflammatory signaling cascade at the ocular surface that results in the release of inflammatory mediators into the tears. Cellular damage triggers cell death by apoptosis, loss of goblet cells, and disturbance of mucin expression, leading to tear film instability. This instability increases even further the ocular surface hyperosmolarity and closes the vicious circle. Tear film instability can also be initiated as an independent event of tear hyperosmolarity. Factors that contribute to tear film instability include ocular allergy, topical preservative use, and contact lens (CL) wear. The epithelial damage caused by dry eye stimulates corneal nerve endings, leading to symptoms of discomfort and eventually to inflammation of the lacrimal gland. 


\section{Dry Eye and Inflammation}

Chronic inflammation is a common denominator in all forms of dry eye disease, and immunosuppressive drugs such as cyclosporine and steroids have been reported to improve symptoms and signs of dry eye (18). Both cellular and soluble mediators have been demonstrated to play a role in the ocular surface inflammation that develops during the course of dry eye.

The exact mechanisms responsible for the development of ocular surface inflammation in dry eye have not been firmly established. However, extensive evidence supports the idea that inflammation is initiated by a stress response of the surface epithelial cells to increased tear osmolarity and/or desiccation. Tear hyperosmolarity stress in turn, activates a variety of signaling pathways, including MAPK pathways, in particular p38 and c-Jun N-terminal kinases (JNK), and NF-kB in the ocular surface epithelia $(19 ; 20)$. These activated kinases are responsible for the regulation of a wide number of genes involved in the inflammatory response. Pro-inflammatory cytokines, e.g., interleukin-1beta (IL-1 $\beta$ ), tumor necrosis factor alpha (TNF $\alpha$ ), IL-8, and matrix metalloproteinases (MMPs) are among the inflammatory mediators elevated during the inflammatory response by the corneal epithelium (21-24). In addition, increased expression of immune activation molecules including intracellular adhesion molecule 1 (ICAM-1) and HLA-DR has been reported in both Sjögren's and non-Sjögren's aqueous deficient dry eye $(25 ; 26)$. Cytokines released from activated epithelial cells cause lymphocytic infiltration and increased apoptosis of epithelial-secreting cells (27), subsequently leading to a cycle of chronic inflammation and ocular surface injury. For 
that reason inflammation is seen as both the cause and the consequence of cell damage accompanying dry eye.

\section{Animals Models of Dry Eye Disease}

In an effort to understand the causative mechanisms leading to the pathogenesis of dry eye several animal models have been generated. These animal models have provided important clues in identifying the underlying molecular pathways contributing to the development of dry eye disease.

Although dogs can spontaneously develop dry eye disease and therefore would seem to be ideal to study the development and progression of dry eye, this animal model is limited for two primary reasons: 1) canine dry eye is a naturally-occurring (low frequency) disease and thus, it is difficult to generate enough dogs with dry eye to conduct experiments; 2) dogs are people's beloved pets. Rabbits, rats and mice are the preferred animal models of dry eye disease. The current animal models are generated by: 1) inducing lacrimal insufficiency, which mimics Sjögren's dry eye; 2) removal or obstruction of the lacrimal or meibomian glands; 3) mechanical damage, i.e., inserting a lid specula for a period of time to prevent blinking; and 4) blockage of neuronal stimulation for tear secretion, e.g., using scopolamine which blocks the cholinergic receptors in the lacrimal gland and results in decreased aqueous production (reviewed in (28)).

Due to the availability of several knockout and transgenic mice that mimic autoimmune disorders, the mouse model has become the preferred model to study Sjögren's syndrome (29). The nonobese diabetic (NOD) mouse model has been 
extensively used to study Sjögren's syndrome (30). These mice show infiltration of CD4+ Th1 cells in the lacrimal glands and submandibular glands. Although one limitation of this model is the fact that the tear secretion is only reduced by $30 \%$ compared to the wild-type animals, the NOD mice is one of the only two models that show any decrease in tear secretion (31). The transforming growth factor $\beta$ (TGF $\beta$ ) knockout mouse is another model of lacrimal gland inflammation. These mice develop "crusty eyes" that eventually close as the disease progresses (32), the presence of lymphocytes in the lacrimal glands has been confirmed in these animals. Unfortunately, although TGF $\beta$ knock-out mice is a good model to study Sjögren's syndrome, these animals have a very short lifespan, i.e., they die between 3 and 4 weeks post-natal, which greatly limits their use. In addition, these mice develop inflammation in several vital organs which in turn compromise dry eye study $(29 ; 32)$.

There is no doubt that environmental conditions play an important role in the development of dry eye. There are several animal models of dry eye generated by subjecting mice to continuous air flow exposure or keeping the mice in air controlled chambers to mimic environmental stress conditions (29).

In summary, the currently available animal models of dry eye mirror different subtypes of dry eye disease. However, because of the multi-factorial nature of dry eye disease, has it has been difficult to incorporate all the complexity of this chronic disease in a single animal model. 


\section{Etiology and Risk Factors for Dry Eye Disease}

As indicated above, the causes of dry eye are obscure, but established risk factors for dry eye disease include female sex, older age, postmenopausal hormone replacement therapy (HRT) (33), a diet low in omega-3 fatty acids (34), and vitamin A deficiency $(35)$.

The role of sex hormones in ocular surface homeostasis has been recognized and the underlying mechanism(s) by which hormonal status may contribute to dry eye is currently being investigated. It was initially hypothesized that estrogens were the key hormone protecting against dry eye disease. However, the role of estrogens in protecting against dry eye was questioned after studies demonstrated that women who use HRT are at increased risk of dry eye disease (33). Instead, androgen deficiency may be the critical etiologic factor in the pathogenesis of aqueous-deficient and evaporative dry eye disease during menopause. Androgen levels decrease in post-menopausal women (1), and androgen deficiency has been correlated with dry eye in androgen insufficiency syndrome (36) and anti-androgen medication treatment (37). Androgens have been shown to play a crucial role in maintaining an anti-inflammatory state of the LFU by constitutively suppressing inflammation of the lacrimal gland. Androgens inhibit lacrimal gland inflammation by up-regulating the anti-inflammatory cytokine TGF $\beta$ (38). In addition, androgens increase the secretion of the meibomian glands which produce the lipids found in the tear film (39). The complex role of sex hormones in ocular surface health needs further study. 


\section{Therapies for the Treatment of Dry Eye}

There has been progress in our understanding of the pathophysiology of dry eye that has allowed a shift in dry eye management from simply lubricating and hydrating the ocular surface to treatments that stimulate natural production of tears, maintain ocular surface epithelial barrier function, and inhibit inflammation at the ocular surface. Current therapies for patients with dry eye disease include the use of lubricants, tear stimulants, tear retention procedures, anti-inflammatory therapies and biological tear substitutes (5). These therapies are designed to improve the patient's ocular comfort and quality of life but do not yet eliminate the underlying pathology of the disease since the precise etiology of dry eye remains unknown and is likely multi-factorial. It is possible that future therapies will focus on replacing or providing specific tear components that have an important role in maintaining ocular surface integrity. Further research will be needed to identify these key factors and to provide better diagnostic tools to measure their concentrations in tears. 


\section{CHAPTER II- SIGNIFICANCE OF MUC1 IN DRY EYE DISEASE}

\section{Introduction to Mucins}

Mucins are high molecular weight O-glycosylated proteins localized on the apical border of epithelial cells (40) including the ocular surface as well as the respiratory and intestinal tracts (41). Mucins play a central role in the protection, lubrication and hydration of epithelial surfaces. The overall function of mucins is to help preserve the integrity of surfaces that are constantly exposed to foreign substances and pathogens. In recent years it has become clear that the functions of mucins are more complex than simply forming a protective barrier. The structure and localization of mucins enables them to play important roles in processes including cell-cell communication, cellextracellular matrix interactions, and intracellular signaling. It is well established that mucins are important for the maintenance of a healthy ocular surface (42), as highlighted by the finding of several examples of mucin alterations in dry eye disease $(16 ; 43 ; 44)$.

At present, at least 20 mucins are members of the human MUC gene family (45). They are named MUCs 1, 2, 3, etc., according to the order in which they were characterized. Mucins are subclassified into two classes: soluble, gel-forming mucins and membrane-tethered mucins. The major ocular mucins are expressed differently by the ocular surface cells, i.e. soluble mucins are expressed exclusively by conjunctival goblet cells and membrane-tethered mucins are expressed mainly by non-goblet epithelia (reviewed in $(42 ; 46))$. 
One common feature in all mucins is the presence of a variable number of tandem repeats (VNTR) in the extracelullar domain: the "mucin domain" (for a review see $(41 ; 47))$. The VNTR contains multiple serine and threonine residues that serve as Oglycosylation sites. The extensive O-glycosylation of the VNTR accounts for $\sim 50-80 \%$ of the mucin mass (47). Moreover, the type and extent of mucin glycosylation accounts for the biochemical and biophysical properties of each mucin. Based on their glycosylation status, mucins regulate important cellular processes including cell adhesion, cell-cell interaction, and immunological responses (48-50). Another important characteristic of the mucins is the presence of cysteine-rich regions in the $\mathrm{N}$ - and $\mathrm{C}$ terminal domains. These cysteine-rich regions allow disulfide bond formation resulting in huge multimers that assemble to form mucus in the gastrointestinal and respiratory tracts $(51)$.

In recent years, the membrane-bound mucins have received increased attention for their role in regulating intracellular signaling. Membrane-bound mucins have a relatively short cytoplasmic domain (CD) that acts as a docking site for components of several cytoplasmic signaling pathways thereby providing signals in response to alterations in the local environment (52). Among the membrane-tethered mucins, MUC1 is the best characterized with regard to cell signaling.

\section{MUC1}

MUC1, also designated MUC1/REP or $\mathrm{MUC1} / \mathrm{B}$, was the first cloned transmembrane mucin and is expressed at the ocular surface (44). Structurally, MUC1 contains two domains of functional significance (Fig. 2); 1) the $>250 \mathrm{kDa}$ N-terminal 
extracellular domain (MUCI-N) which contains the 20 aa VNTR that are extensively Oglycosylated (53) and 2) the $\sim 25 \mathrm{kDa}$ C-terminal domain (MUC1-CD) which includes a 58 aa extracellular domain, a 28 aa transmembrane domain, and a 72 aa cytoplasmic tail (MUC1.CT) that is highly conserved across species (54). The VNTR is the largest domain of $\mathrm{MUC1}$ and does not share significant homology with other mucin genes (55). The MUC1 protein is translated as a single polypeptide; however, as a result of an autoproteolytic event in the endoplasmic reticulum, the MUC1-N and MUC1-CD subunits are generated (56). The MUC1-N and MUC1-CD domains remain tightly associated at the plasma membrane through non-covalent interactions. On normal epithelial cells, the MUC1 heterodimer localizes at the apical border (40). However, in carcinoma cells that have lost polarity, MUC1 is highly overexpressed and its localization is no longer restricted to the apical border, thus allowing it to interact with adjacent proteins which impacts the cell biology and survival of tumor cells.

MUC1 is overexpressed in $>90 \%$ of breast tumors and also in most types of ovarian, lung, colon and pancreatic carcinomas, as well as in inflammatory diseases $(55 ; 57)$. MUC1 has long been known as a tumor associated protein and its expression has been linked to enhanced cell growth, tumorigenicity, metastasis, and inhibition of oxidative stress-induced apoptosis (58). These oncogenic effects are attributed to the interaction between the MUCl CD and signaling molecules including epidermal growth factor (EGFR), $\beta$-catenin, p53, and estrogen receptor $\alpha(\mathrm{ER} \alpha)$ [reviewed in $(58 ; 59)]$. Recent work by Kufe's group demonstrates that MUC1-CD accumulates in the cytoplasm as oligomers that translocate into the nucleus by a mechanism involving importin $\beta$ and 


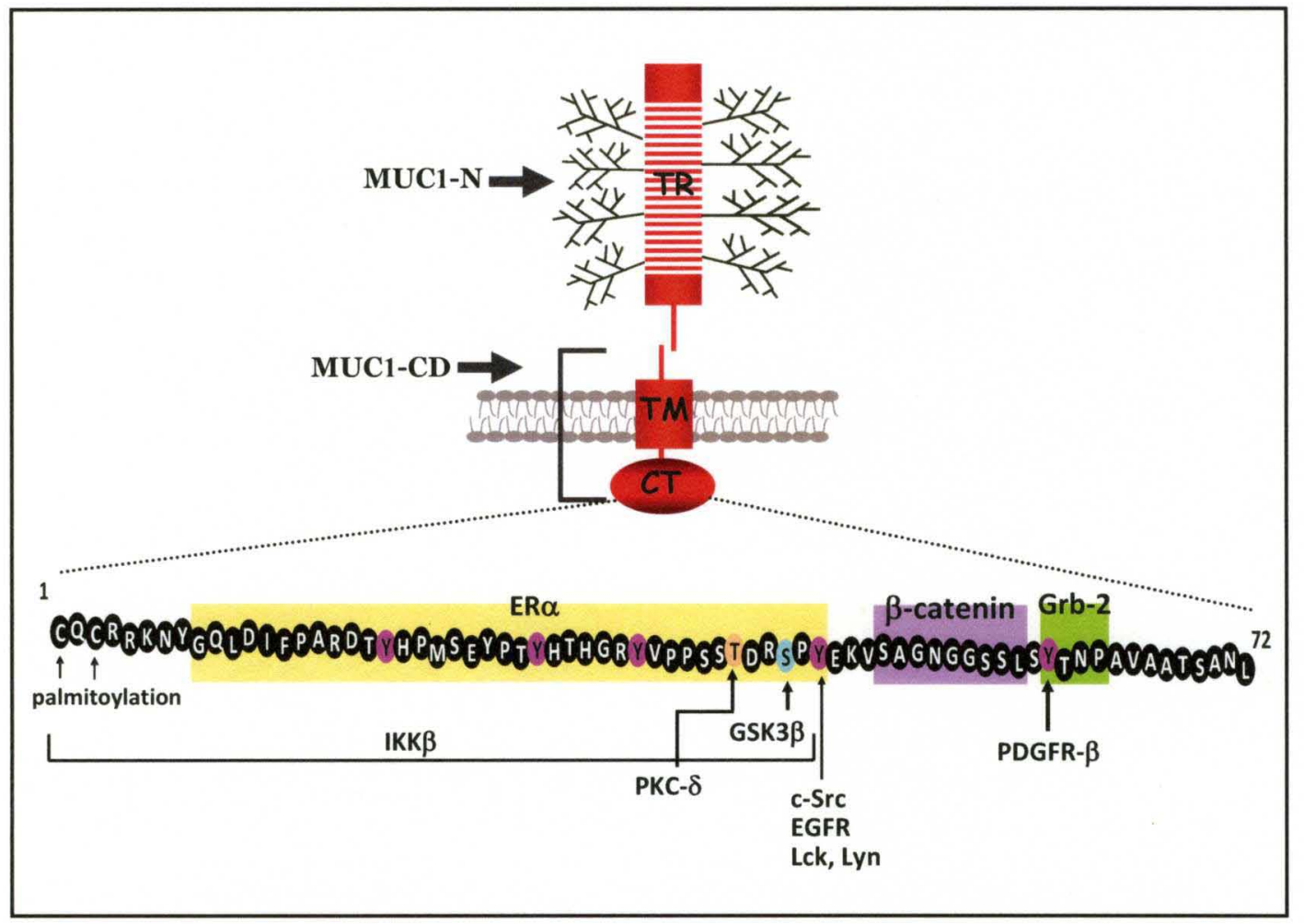

Figure 2. Schematic representation of the MUC1 protein. Autoproteolytic cleavage yields the two subunits of MUC1: the MUC1-N terminal domain (MUC1-N) and the Cterminal domain (MUC1-CD). The MUC1-N extracellular subunit contains $\sim 40-80$ tandem repeats of 20 aa (shown as TR) that are O-glycosylated. The MUC1-CD consists of a short extracellular region (58 aa), a transmembrane domain (TM, 28 aa), and the cytoplasmic tail (CT) composed of 72 aa (also known as MUC1.CT). The sequence of the CT is depicted at the bottom of the figure and some of the MUC1 interacting proteins are shown. 
nucleoporin p62 (60). As shown in Fig. 2, MUC1 is palmitoylated at the CQC motif. MUC1 palmitoylation regulates its recycling without affecting endocytosis (61).

\section{The Role of MUC1 in the Regulation of Cell Signaling}

Regulation of cell signaling by MUC1 occurs when the MUC1-CD associates with signal transduction mediators that include $\beta$-catenin, $\mathrm{p} 53$, inhibitors of $\mathrm{I} \kappa \mathrm{B}$ kinase (IKK), and ER $\alpha$. As a result of this association MUC1-CD can translocate to the nucleus and regulate target gene transcription (57). $\mathrm{MUCl}$ also regulates extracellular signaling by the interaction of intercellular adhesion molecule 1 (ICAM-1) as a ligand for MUC1 that initiates a calcium signaling response which leads to reorganization of the cytoskeleton and increased cell migration (62-64). It has been demonstrated that binding to Pseudomonas aeruginosa, or its flagellin protein, promotes phosphorylation of serine residues on the MUC1-CD leading to the activation of the ERK pathway.

Of special interest to the research described in this dissertation is the role of MUC1 in regulating inflammatory responses. MUC1 gene ablation experiments in mice resulted in increased inflammatory responses in the airways and a predisposition to develop conjunctivitis indicating an anti-inflammatory role of MUC1 $(65 ; 66)$. For example, in one study using a model of bacterial lung infection, the lungs in the Muc1 ${ }^{-1-}$ mice showed decreased colonization of P.aeruginosa (65). Higher levels of tumor necrosis factor alpha (TNF $\alpha)$ and interleukin 8 (IL-8), proinflammatory mediators were detected in bronchoalveolar lavage fluid of the $\mathrm{Mucl}^{-/-}$mice compared to wild-type littermates (65). Similar findings were reported in primary human bronchial epithelial cells where RNAi knockdown of MUC1 expressed resulted in an increase in flagellin- 
induced- IL-8 production (65). It was recently reported that MUC1 can inhibit the activation of Toll-like receptors (67). In addition, MUC1 expression in resting T lymphocytes can inhibit the activation of $\mathrm{T}$ cells (68). Taken together, these results suggest that MUCl acts as an anti-inflammatory agent which is relevant to the pathogenesis of dry eye. In contrast to these reports, there is recent evidence that MUC1 can activate the NF-KB pathway in human cancer cell lines including MCF-7 and HeLa cells as well as in normal mammary epithelial cells (MCF-10A) (69), indicating a possible pro-inflammatory role of MUC1. Therefore, the role of MUCl in inflammation is controversial and requires further investigation.

\section{Regulation of MUC1 Gene Expression}

Given the importance of MUC1 in maintaining cellular homeostasis, it is critical to understand how MUC1 expression is regulated. In humans, the MUC1 gene spans 4 to $7 \mathrm{~kb}$ on chromosome 1q21-24. Studies of the MUCl promoter revealed the location of the typical TATA box 25 nucleotides upstream of the transcriptional start site $(70 ; 71)$. Numerous binding sites for transcriptional regulators are present in the promoter of MUC1, including specificity protein-1 (Sp1), activator protein 1 (AP-1), nuclear factor 1 (NF-1), NF-кB, ER, and Signal Transducers and Activators of Transcription (STAT) transcription factors (70-72).

Many of the regulatory elements in the MUC1 promoter have been functionally characterized. The region containing the Spl cis-element was shown to be important to drive transcriptional activity of a reporter gene in $M U C 1$-expressing epithelial cell lines (73). The STAT binding element in the MUCl gene mediates the interferon $\gamma$ 
(IFN $\gamma$ )-driven upregulation of MUC1 $(72 ; 74)$. Moreover, STAT3 has been shown to bind to the MUC1 promoter in response to interleukin 6 (IL-6) in human mammary epithelial cells (72). MUC1 is upregulated in response to TNF $\alpha$ treatment via NF- $\mathrm{KB}$ activation and binding to the $-589 /-580$ element (74). The regulation of MUCl by progesterone (PR) has been reported, and multiple putative estrogen and PR response elements have been identified in the human MUC1 promoter (71). In mice, Muc1 expression has been shown to be regulated by both progesterone and $17 \beta$-estradiol $\left(E_{2}\right)$ $(75 ; 76)$, with $E_{2}$ specifically stimulating Mucl expression in the uterus. However, direct binding of ER $\alpha, E R \beta, P R-A$ or PR-B to the Muc1 promoter has not been demonstrated (77). Therefore, further studies will be necessary to elucidate the role of hormones in the regulation of MUC1 gene expression. At the post-translational level, $\mathrm{MUCl}$ is been shown to be downregulated by microRNA miR-125b (78).

\section{Splice Variants of MUC1}

MUC1 pre-mRNA undergoes alternative splicing generating several different variants, with at least twelve splice variants having been described to date (79). Thus far, no functional differences have been attributed to any individual splice variant. Early work by Hilken's group revealed that the alternative retention of $27 \mathrm{bp}$ from the intron at the start of exon 2 gives rise to the MUC1/A splice variant (Fig. 3) (80). The selection of splice variant $\mathrm{MUC1} / \mathrm{A}$ or $\mathrm{MUC1} / \mathrm{B}$ is controlled by a $\mathrm{G}$ to $\mathrm{A}$ single nucleotide polymorphism (SNP) (rs4072037) that is located 8 nucleotides downstream from the start

of exon 2 of MUC1. The presence of G at the rs4072037 SNP generates the MUC1/A splice variant, whereas having $\mathrm{A}$ at the SNP site gives rise to the $\mathrm{MUC1} / \mathrm{B}$ form. In 


\section{MUC1/A and MUC1/B SPLICE VARIANTS}

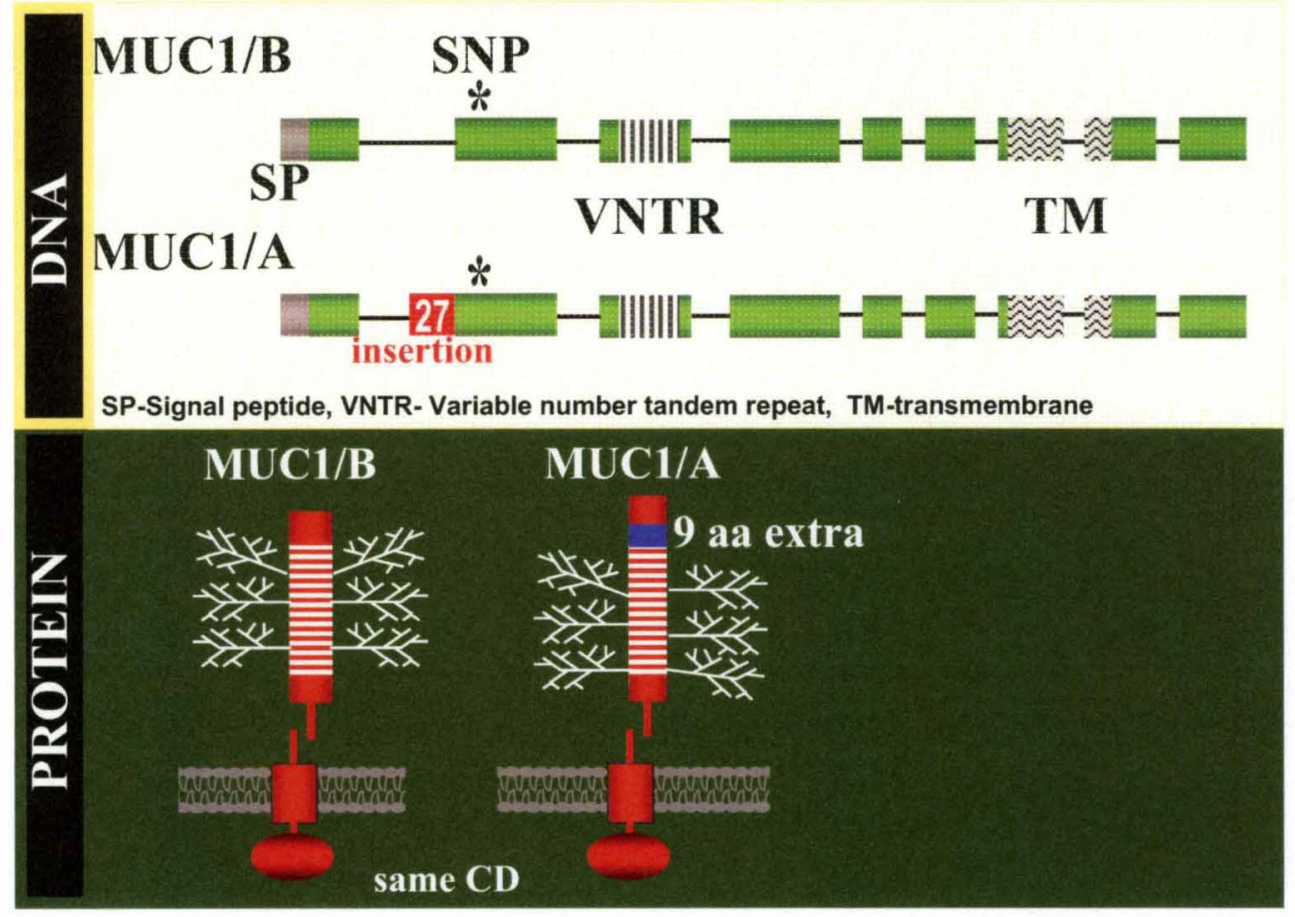

Figure 3. Schematic representation of the MUC1/A and MUC1/B splice variants. The upper panel shows the MUC1/A and MUC1/B isoforms at the DNA level. Each box represents an exon for a total of 9 exons. MUC1/A and MUC1/B differ by the insertion of 27 nucleotides between exons 1 and 2. The SNP present in exon 2 determines the choice of splicing. The regions containing the sequences for the signal peptide, VNTR, and transmembrane domain (TM) are shown in between the two variants. The lower panel is a representation of the protein resulting from MUC1/A and MUC1/B splice variants. The additional 9 aa resulting from the 27 nucleotide insertion is shown in blue in the extracellular domain of MUC1/A. 
addition to the MUC1/A and MUC1/B splicing choice, the SNP rs4072037 has also been associated with the length of the VNTR $(80 ; 81)$ although this association does not occur in $100 \%$ of the cases (44). Specifically, the G allele (MUC1/A) is correlated with larger size VNTRs and A allele (MUC1/B) is associated with smaller size VNTR. According to the Ensembl database, the frequencies of the GG, G/A and AA genotypes in the Caucasian population are 18,49 and $33 \%$, respectively

As compared to MUC1/B, the MUC1/A protein contains an extra stretch of 9 aa that are located on the amino terminal side of the tandem repeat region (Fig. 3). Whether these additional 9 aa in MUC1/A affect MUC1 function is unknown; however, analysis of the MUC1/A protein sequence predicts a change in the signal peptide cleavage site $(82 ; 83)$ which can potentially affect the protein trafficking and localization.

In addition to $\mathrm{MUC1} / \mathrm{A}$ and $\mathrm{MUCl} / \mathrm{B}$ splice variants, $\mathrm{MUC1}$ transcripts that have lost the tandem repeat region (MUC1/Y, MUC1/Yalt and $\mathrm{MUCl} / \mathrm{Z}(\mathrm{X})$ ) or transcripts lacking the transmembrane domain (MUC1/SEC) have also been described (84-86). As part of my dissertation research described in Chapter III, the expression of six MUC1 variants in human ocular surface tissues was reported (79).

\section{Dissertation Specific Aims and Hypotheses}

As reviewed in Chapter I, dry eye disease is a complex set of diseases of unknown cause that affects at least 10 million people in the U.S. (87). At present, there are no biochemical markers that can predict a patient's susceptibility to dry eye disease. The current therapies against dry eye disease are directed at alleviating the symptoms rather than eliminating the problem. Therefore, uncovering possible genetic susceptibility 
factors may lead to a better diagnosis as well as novel and personalized therapies that will improve or even eliminate dry eye disease. MUC1 plays an important role in protecting the ocular surface by sensing the surrounding environment, preventing the adhesion and access of foreign molecules onto ocular surface epithelia, and possibly by regulating inflammation (88). My initial results shown in Chapter III indicated that MUC1 splice variants may be differentially expressed in dry eye patients compared to normal controls. This striking pattern prompted me to focus my dissertation research on the role of MUC1 splice variants as susceptibility factors involved in the development of dry eye. My working model is that $\mathrm{MUC1} / \mathrm{A}$ and $\mathrm{MUC1} / \mathrm{B}$ splice variants are genetic predisposing factors for the development of dry eye, although they are not sufficient to cause disease (Fig. 4). Chapters III and IV summarize the research that links MUC1/A and MUC1/B expression to the development of dry eye disease. The expression of MUC1/A or MUC1/B at the ocular surface will either protect or enhance, respectively, the ocular surface damage after the patient encounters a second "hit". It is very likely that one mechanism by which MUC1 splice variants are involved in dry eye development is by regulating inflammatory responses differently; therefore, in Chapter $\mathrm{V}$, experiments that test that possibility are described. The long term goal of the studies described in this dissertation was to elucidate the molecular mechanisms involved in the pathogenesis of dry eye disease and to ascertain how MUC1 splice variants contribute to the symptoms and pathology of dry eye disease. I tested the hypothesis that MUC1 splice variants are key immuno-regulators that act on the ocular surface to protect the ocular surface from inflammation and that their expression correlates with dry eye status. 
The specific aims of this dissertation were:

Aim 1: To determine the frequencies of individuals expressing MUC1/A only, MUC1/B only, and MUC1/A-MUC1/B in patients diagnosed with evaporative dry eye, non-Sjogren's aqueous deficient dry eye, and control volunteers.

Aim 2: Determine whether MUC1/A and MUC1/B splicing variants differentially modulate inflammatory responses.

Aim 3: Elucidate the molecular mechanisms through which MUC1 splice variants regulate inflammatory responses.

It is important to note here that these aims were modified from my Exam IIB. Aim 2 of this proposal corresponds to Aim 4 of my Exam IIB. Aim 3 was not on the original proposal. Aim 3 evolved from the results that I obtained while addressing Aim 2. On February 13, 2008, I defended my Exam IIB dissertation proposal and I was advised to prioritize experiments for Aim 4. Because the cloning of MUC1/A took longer than anticipated, I did not have time to address Aims 2 and 3. However, I generated some preliminary data that is included as "Appendix I" in this dissertation. The aims that were not addressed in this dissertation are shown below.

Initial Aim 2: Determine if MUC1 interacts directly and functionally with ER $\alpha$ and/or $E R \beta$ in human submandibular gland (HSG) and ocular surface epithelial cell lines.

Initial Aim 3: Elucidate the anti-inflammatory role of MUC1, ER $\alpha$ and/or ER $\beta$ in human submandibular gland and human ocular surface epithelial cell lines. 


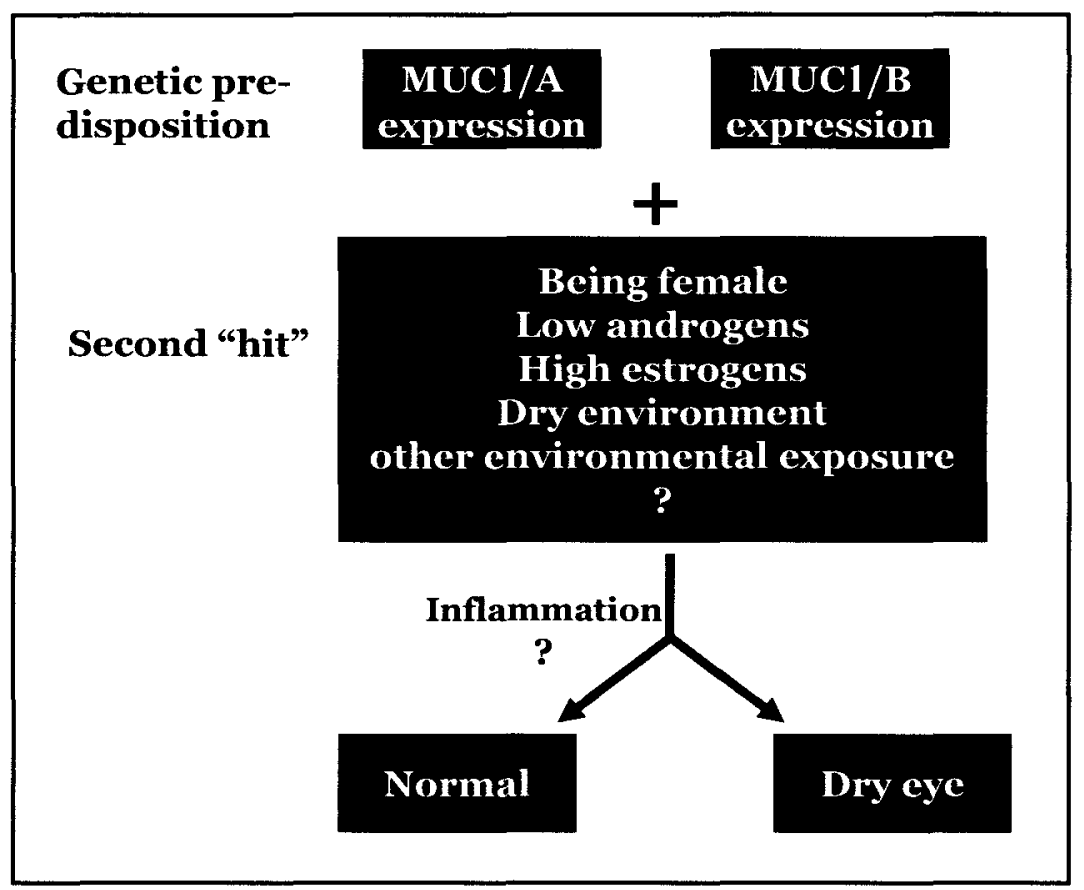

Figure 4. Proposed model for MUC1 splice variants as key factors in the development of dry eye disease. MUC1/B expression correlates with non-Sjögren's and evaporative dry eye disease. Thus, my research tests the hypothesis that $\mathrm{MUCl} / \mathrm{A}$ and $\mathrm{MUC1} / \mathrm{B}$ are genetic factors that will either protect from (MUC1/A) or contribute to (MUC1/B) the development of dry eye. Other predisposing factors such as gender, hormonal status, or dry environment act in combination with the MUC1 status to result in either a normal or damaged ocular surface. Other environmental exposures, e.g., cigarette smoke, air quality, and air pollution, may also affect dry eye disease. Inflammation is one of the core mechanisms causing dry eye disease, and it possible that $\mathrm{MUCl} / \mathrm{A}$ and $\mathrm{MUCl} / \mathrm{B}$ can differentially regulate the inflammatory response. 


\section{CHAPTER III- MUC1 SPLICE VARIANTS IN HUMAN OCULAR SURFACE TISSUES: POSSIBLE DIFFERENCES BETWEEN DRY EYE PATIENTS AND NORMAL CONTROLS}

The text of this chapter was published in Exp. Eye Research; 83(3):493-501 (2006)

\section{Introduction}

The normal human tear film lubricates and protects the ocular surface against pathogens and environmental challenges. Mucins are large, highly O-glycosylated proteins that function at the ocular surface to facilitate lubrication, retain water, and provide a barrier against pathogen invasion $(42 ; 46)$. Many of the viscoelastic properties of mucins are provided by the large amount of carbohydrate found on mucins. One of the transmembrane mucins, MUC1, is present on corneal and conjunctival epithelial cells (89) and in the tears (90). The majority of the O-glycosylation sites of $\mathrm{MUCl}$ are present in a highly polymorphic core region containing a variable number of tandem repeats (VNTR). Each repeat of 20 amino acids bears 5 potential sites for O-glycosylation. MUC1 alleles can be divided into size classes that contain small (30-45) or large (60-90) numbers of repeats.

Alternative splicing generates multiple forms of mRNA from a single pre-mRNA and is a major mechanism for generating proteome complexity $(91 ; 92)$. At least twelve splice variants of MUC1 have been described in human tumor tissue (Fig. 5). These 


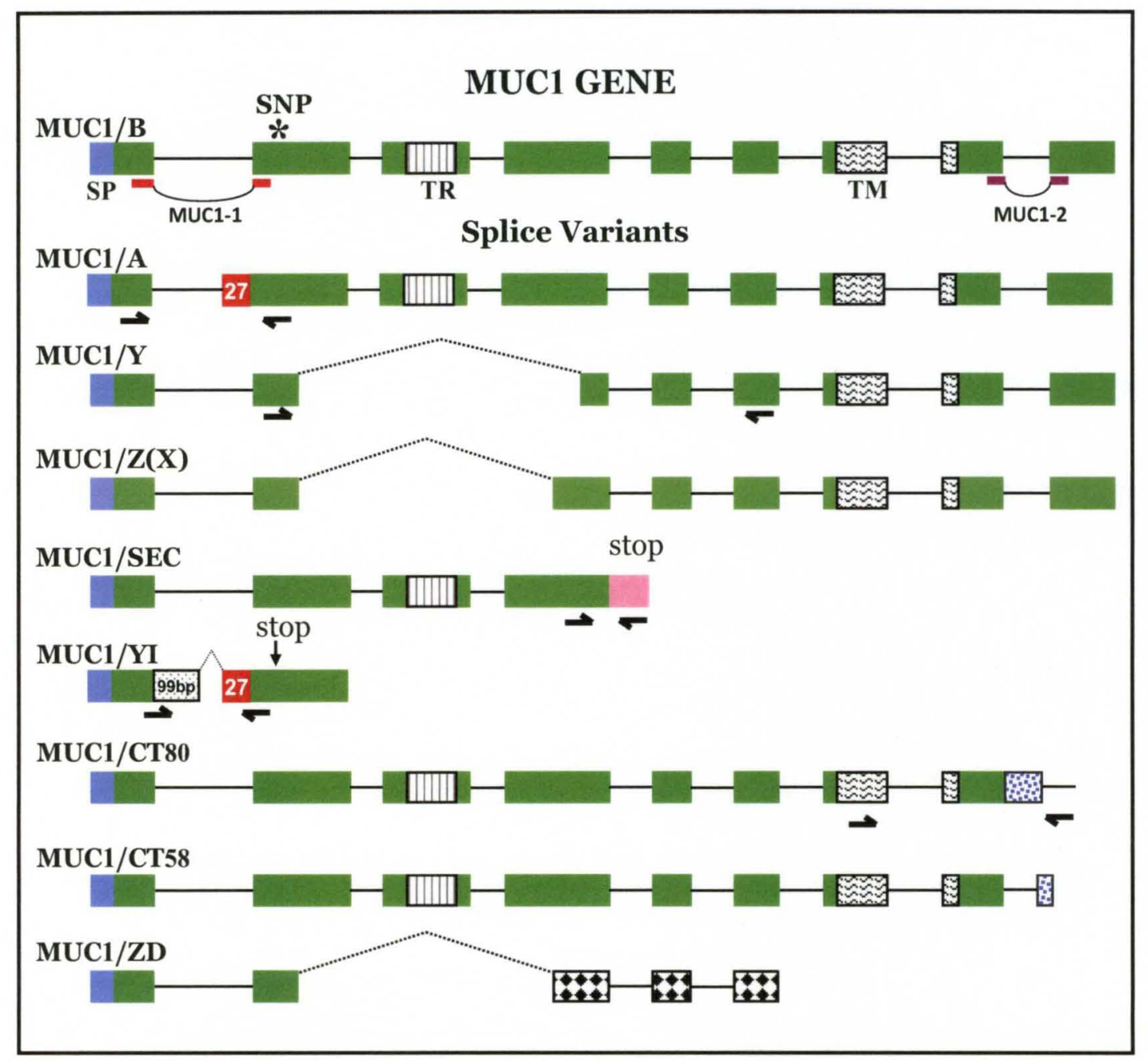

Figure 5. MUC1 splice variants. The exon-intron pattern is from the Ensembl website (http://www.ensembl.org). Variants are from the following references: MUC1/B $(53 ; 82)$ and MUC1/A (82;83); MUC1Y (86); MUC1/Z(X) (93;94); MUC1/SEC (83); MUC1/CT80 and MUC1/CT58 (95); and MUC1/ZD (84). MUC1/YI has not been described previously; it contains $99 \mathrm{bp}$ from the $5^{\prime}$ end of the first intron and $27 \mathrm{bp}$ from the 3' end of that intron. SP, signal peptide; SNP rs4072037 at position 8 of exon 2; TR, tandem repeat; and TM, transmembrane domain. The TR is not drawn to scale due to its large and variable size. MUC1-1 and MUC1-2 refer to real-time RT-PCR primer-probe sets. The arrows below MUC1/A represent the primers used in RT-PCR to detect MUC1/A and MUC1/B (Fig. 9, panel I); the arrows below MUC1/Y for the primers to detect $\mathrm{MUC1} / \mathrm{Y}$ and $\mathrm{MUC1} / \mathrm{Z}(\mathrm{X})$ (Fig. 9, panel IV); the arrows below MUC1/SEC for the primers to detect that splice variant (Fig. 9, panel III); the arrows below MUC1/YI for the primers to detect that splice variant (Fig. 9, panel II); and the arrows below MUC1/CT80 for the primers to detect MUC1/CT80 and MUC1/CT58. 
variant transcripts include four full length transcripts: MUC1/B $(53 ; 82)$ and MUC1/A $(82 ; 83)$ differ by the inclusion of $27 \mathrm{bp}$ from intron 1 in $\mathrm{MUC1} / \mathrm{A}$; and MUC1/CT80 and MUC1/CT58 differ from MUC1/A and MUC1/B in the cytoplasmic tail region (95). The MUC1/SEC transcript has lost the transmembrane domain and therefore encodes a soluble protein product (83). The nomenclature for variant transcripts that lack the tandem repeat region is confusing because in addition to MUC1/Y (86) another species was simultaneously named MUC1/Z (93) and MUC1/X (94). Here we refer to that variant as MUC1/Z(X). While several of these variants have also been found in normal human tissues, none have been reported in human ocular surface tissues despite the potential impact that these altered proteins could have on normal ocular surface physiology and ocular surface disease. The first purpose of this report is to characterize MUC1 splice variants in normal human ocular surface tissues.

Dry eye syndrome or keratoconjunctivitis sicca (KCS) is due to tear deficiency or excessive tear evaporation that causes damage to the ocular surface and symptoms of ocular discomfort (96). The two major types of KCS are aqueous deficient and evaporative. Although dry eye disease is common, the causes are obscure. Factors implicated in KCS pathogenesis include lacrimal inflammation, interruption of neuronal stimulation for tear secretion, defects in Meibomian gland function, and defects in mucin expression $(16 ; 43)$. In the present report we compared conjunctival epithelium from aqueous deficient dry eye patients and normal control donors for the presence of MUC1 splice variants. The results suggest that the percentage of dry eye patients expressing the MUC1/A variant in the conjunctival epithelium is lower than in normal control donors. MUC1/A has been shown to be associated with alleles containing an increased number of 
tandem repeats $(80 ; 81)$. Therefore, we hypothesize that one factor in susceptibility to dry eye disease may be reduced levels of MUCl having larger numbers of tandem repeat and consequently reduced protection of the ocular surface.

\section{Material and Methods}

Tissues and RNA: The inclusion of human subjects was in accordance with the Declaration of Helsinki and was approved by the local Institutional Review Board and the Human Subjects Protection and Privacy Office of the University of Louisville. Informed Consent and Research Authorization were obtained prior to collection of samples from enrolled subjects. Donor corneas and conjunctivae were obtained from the Kentucky Lions Eye bank. Conjunctival tissue included conjunctiva from the superior and inferior bulbar regions and from the nasal fornix. Corneas were trimmed free of all scleral tissue. Both corneas and conjunctivae were homogenized in ice cold RNA lysis buffer (Qiagen) and eluted through QIAshredder microcolumns. Total RNA was isolated using RNeasy ${ }^{\mathrm{TM}}$ microcolumns.

Lacrimal glands were obtained from either the National Disease Research Interchange (Philadelphia, PA) or from cadavers donated to the University of Louisville Fresh Tissue Laboratory. Glands were dissected and recovered extra-orbitally, stored in RNA Later (Qiagen), and processed for RNA isolation as described above.

Brush cytology was performed using sterile dacron polyester swabs (Puritan Medical Products). The temporal or nasal bulbar conjunctiva was scraped by gentle rotation of the brush. The swab was then immersed ten times in $1.0 \mathrm{ml}$ of RLT lysis 
buffer that was then mixed, frozen on dry ice, and stored at $-80^{\circ} \mathrm{C}$. Samples were thawed at $37^{\circ} \mathrm{C}$ for $10 \mathrm{~min}$, Vortexed for $30 \mathrm{sec}$, purified through QIA shredder columns, and then total RNA was obtained on RNeasy columns. Tears were collected in capillary tubes.

Dry eye subjects $(\mathrm{N}=9)$ were diagnosed as having moderate to severe aqueous deficient dry eye with tear film instability. Dry eye was documented by reduced Schirmer test $(<7 \mathrm{~mm} / 5 \mathrm{~min})$, reduced tearfilm breakup time $(<10 \mathrm{sec})$, and ocular surface staining (cornea with fluorescein, conjunctiva with lissamine green). There was no inherent mucosal disease (ocular cicatricial pemphigoid, scarring from StevensJohnson syndrome, trachomatous scarring) (97). The normal subjects $(\mathrm{N}=15)$ were without symptoms of dry eye and demonstrated on clinical examination normal tear volume and stability with no ocular surface staining, normal tear break up time, and normal Schirmer test values. No subjects had undergone LASIK surgery.

The quality and quantity of total RNA was evaluated using the Agilent 2100 Bioanalyzer (Agilent).

Quantitative mRNA analysis by real-time RT-PCR: Gene expression levels were determined after reverse transcription by real-time PCR using an Applied Biosystems PRISM 7000 or 7300 Sequence Detection System. Total RNA was treated with DNase, and then cDNA was synthesized using random hexamers and the SuperScript II firststrand synthesis kit (Invitrogen). The following primer-probe sets for real-time RT-PCR (Taqman) analysis were obtained as Assays on Demand reagents (Applied Biosystems

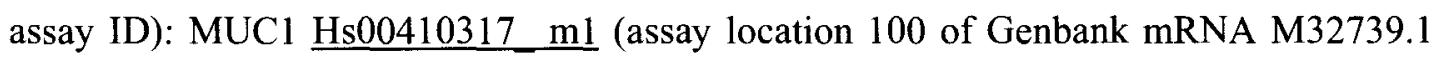


spanning the exon 1-exon 2 boundary, see Fig. 5) referred to here as the MUC1-1 set and Hs00159357_ml (assay location 896 of mRNA AY327596.1 spanning the exon 8-exon 9 boundary) referred to here as the MUC1-2 set; and 18S rRNA Hs99999901_sl.

Isoform expression values were compared to those obtained for the endogenous control 18S rRNA, which we used rather than GAPDH or $\beta$-actin because of the variability of those two latter endogenous controls between tissues and among individuals $(98 ; 99) . \mathrm{Ct}$ is defined as the threshold cycle at which the fluorescence produced by the cleavage of the Taqman fluorogenic probe rises above a background level. Delta $\mathrm{Ct}$ values ( $\mathrm{Ct}$ experimental minus $\mathrm{Ct} 18 \mathrm{~S}$ rRNA) were converted to a fold difference between experimental and $18 \mathrm{~S}$ rRNA, and presented as [1/(fold difference $)] \times 10,000$ so that stronger expression is represented by a higher value as previously described (100). Each real-time RT-PCR assay was run in duplicate or triplicate; in all cases the range of duplicate values was $<5 \%$ of the mean and the standard deviation of triplicate values was $<3.5 \%$ of the mean.

Conventional PCR and sequencing of PCR products: Primers used for conventional PCR were: primers $\mathrm{P} 1$ and $\mathrm{P} 2$ from (101) for detection of $\mathrm{MUC1} / \mathrm{A}$ and $\mathrm{MUC1} / \mathrm{B}$; primers $\mathrm{P} 2$ and $\mathrm{P} 7$ from (95) for the detection of MUC1/SEC; and primers P6 and P1 from (93) for the detection of MUC1/Y and MUC1/Z(X); and for detection of MUC1/YI FWD 5'TCACAGTGCTTACAGGTGAGG-3' and REV 5'-ACAACTGTTGCGGGTTTAGG-3'. Products were analyzed on a DNA 500 chip of the Agilent 2100 Bioanalyzer. PCR products of MUC1/A and MUC1/B amplification also were digested with AlwNI (New England Biolabs) and analyzed on a DNA 500 chip. For sequencing the PCR products 
were ligated into pGEM-T (Promega), and the plasmids were transformed into E. coli DH5 $\alpha$ (Invitrogen). DNA sequencing was performed in the EpScor sequencing facility, University of Louisville.

Western blotting: Details have been described previously (102). Briefly, tears and protein extracts from human submandibular (HSG) cells (103) and the MCF-7 human breast cancer cell line (104) were electrophoresed on a 3-8\% NuPAGE Tris-Acetate gel (Invitrogen, Carlsbad, CA) and transferred to PVDF membranes (Millipore, Marlborough, MA). Western Blot analysis was performed using the DF3 monoclonal antibody specific for the tandem repeat region of MUC1 (105) followed by horseradish peroxidase-coupled sheep anti-mouse Ig. The bands were developed using the SuperSignal West Pico detection system (Pierce, Rockford, IL) and visualized using the Kodak Image Station 440CF. The chemiluminescent bands and molecular weight bands were superimposed electronically in the final Western images.

\section{Results}

\section{MUC1 real-time RT-PCR}

As part of our study of the expression of the polypeptide GalNAc transferase glycosyltransferases and their mucin substrates (106), we determined the expression of the transmembrane mucin MUC1 in human ocular surface tissues. Quantitative real-time RT-PCR utilized a Taqman set (referred to here as the MUC1-1 set) that spanned the boundary between exons 1 and 2 (Fig. 5). Expression in four lacrimal glands was very 
weak whereas two cornea samples were strong and two were very weak (Fig. 6). Among four conjunctivae, three were very strong while the fourth was 200 -fold weaker.

To determine the cause for such large differences of MUCl expression between donors, we next tested using a second Taqman set (MUC1-2 set) that targeted the exon 8exon 9 boundary (Fig. 5) and found less than a five fold difference between the same four conjunctival samples (Fig. 6). This finding indicated that MUC1 was actually strongly expressed in all four conjunctival samples but that MUC1 had not been detected by the MUC1-1 set in the fourth sample. Electrophoretic analysis of the MUC1-1 reaction product from the fourth sample revealed that there was in fact a 90 bp product instead of the predicted $63 \mathrm{bp}$ product. Repeated analyses, cloning, and DNA sequencing revealed that this product contained $27 \mathrm{bp}$ from the $3^{\prime}$ end of the first intron; this variant sequence has been described previously as the splice variant MUC1/A (see Fig. 5) $(82 ; 83)$. This product was not detectable by the Taqman system because although the sequences to which the primers annealed remained intact, the sequence to which the Taqman probe annealed, namely the exon-exon boundary itself, had been disrupted by the addition of the intronic sequence. We had uncovered by chance a conjunctival donor who had minimal MUC1/B splicing (Fig. 5) at the exon 1-exon 2 boundary and instead almost exclusively had the MUC1/A splice site variant.

The MUC1/A splice variant encodes MUC1 protein having an additional 9 amino acids on the amino terminal side of the tandem repeat region and also is predicted to have an altered amino terminus because of a change of signal peptidase cleavage $(82 ; 83)$. This additional sequence could alter intracellular trafficking and/or subsequent MUC1 processing and, therefore, be relevant to MUC1 function and ocular surface physiology. 


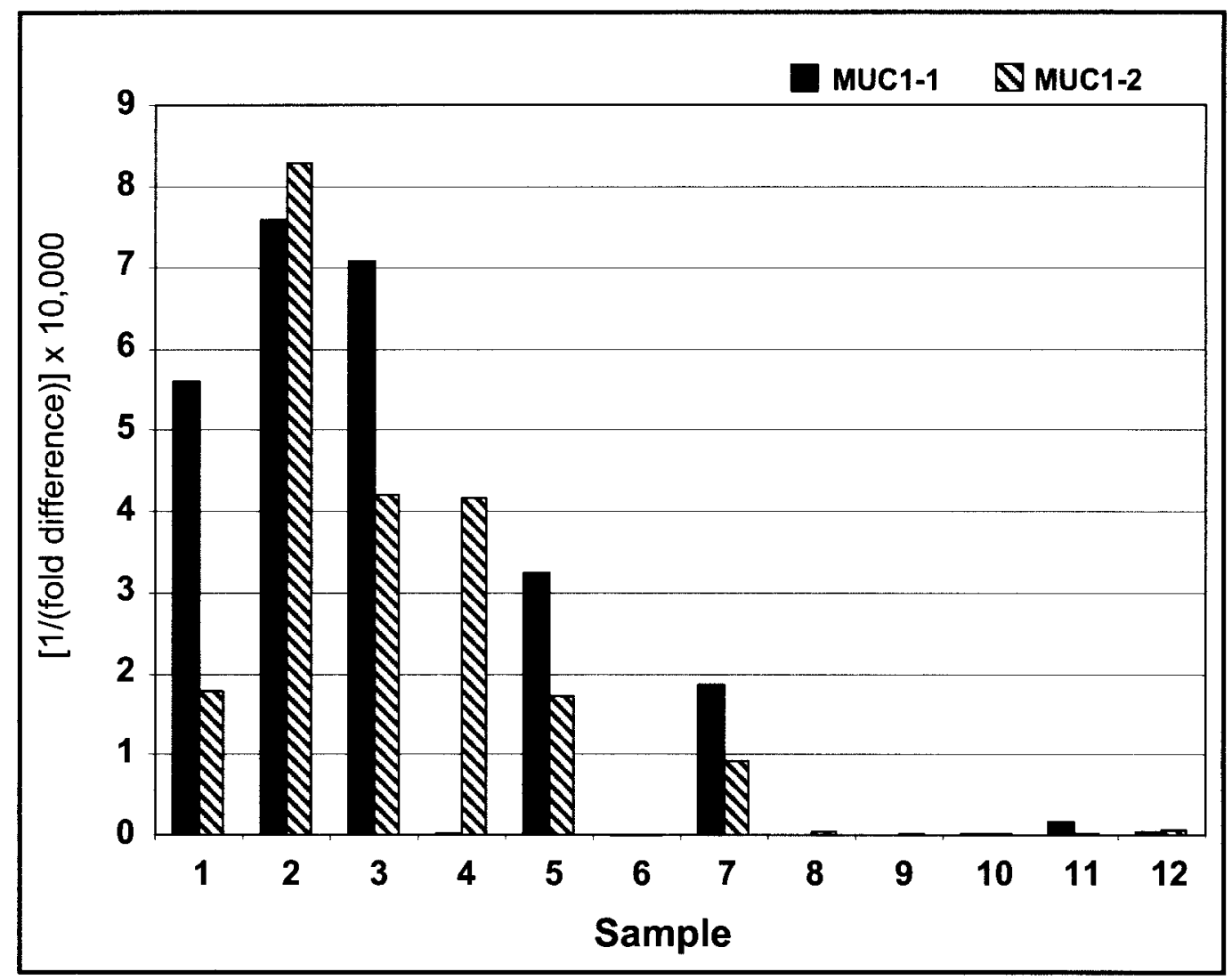

Figure. 6. Expression of MUC1 in human ocular surface tissues as determined by real-time RT-PCR. Taqman real-time RT-PCR results are expressed as $[1 /$ (fold difference)] x 10,000; fold difference is the difference between the experimental value and 18S rRNA (see Material and Methods). Values are the mean of duplicate Taqman data points. Samples: 1-4 conjunctiva; 5-8 cornea; 9-12 lacrimal gland. Lanes (age, gender): 1, 74M; 2, 56M; 3, 51M; 4, 72M; 5, 30M; 6, 67M; 7, 47F; 8, 55F; 9, 64F; 10 , $55 \mathrm{M} ; 11,86 \mathrm{~F}$; and $12,92 \mathrm{M}$. The MUC $1-1$ set targets the exon 1 -exon 2 boundary while the MUC 1-2 set targets the exon 8 -exon 9 boundary (Fig. 5). 
MUC1 splice variants have been described primarily in tumor tissue, only to a very limited extent in normal tissues $(95 ; 107)$, and not at all in ocular surface tissues. For these reasons we pursued the expression of MUC1/A and other MUC1 splice variants in ocular tissues by conventional RT-PCR.

\section{RT-PCR of MUC1 Splice Variants in Whole Ocular Surface Tissues}

RT-PCR analysis of splice variants MUC1/A and MUC1/B revealed that the first two conjunctival samples expressed both variants, the third expressed only $\mathrm{MUCl} / \mathrm{B}$, and the fourth expressed only MUC1/A (Fig. 7, panel I). This latter finding was consistent with the real-time RT-PCR results described above. Among the cornea samples, one expressed both $\mathrm{MUC1} / \mathrm{A}$ and MUC1/B, one expressed only MUC1/B and one expressed only MUC1/A. A final corneal sample did not express detectable MUC1/A or MUC1/B (Fig. 7, panel I, lane 6). However, expression of the ppGaNTases in this sample was comparable to that in other corneal samples (data not shown) indicating that the quality of the sample mRNA was satisfactory. Therefore, we have no explanation for the very low or negative expression of $\mathrm{MUCl}$ in this sample. Analysis of a single sample from lacrimal gland showed that it expressed only MUC1/A (Fig. 7, panel I, lane 9).

MUC1/SEC, a soluble variant missing the transmembrane domain (83) (Fig. 5), was present in all conjunctival and cornea samples but was not detectable in the lacrimal gland sample (Fig. 7). These results indicate that if MUC1/SEC protein is synthesized from these transcripts in conjunctivae and cornea then the protein will be present in tears. This report is the first to indicate this possibility. 
Both $\mathrm{MUC1} / \mathrm{Z}(\mathrm{X})$ and $\mathrm{MUC} 1 / \mathrm{Y}$ are variants lacking the tandem repeat region (Fig. 5). MUCl/Z(X) expression was detected in three conjunctival samples and two cornea samples while $\mathrm{MUCl} / \mathrm{Y}$ was detected in all four conjunctiva and one cornea sample. Neither $\mathrm{MUC1} / \mathrm{Y}$ or $\mathrm{MUC1} / \mathrm{Z}(\mathrm{X})$ was detected in the lacrimal gland sample.

To date we have not detected MUC1/CT80 or MUC1/CT58 (95) in any ocular surface tissues. However, during the course of sequencing the PCR products of the MUC1/A and MUC1/B amplification, we found a new MUC1 splice variant that we have termed MUC1/YI (Fig. 5). This variant retains $99 \mathrm{bp}$ from the $5^{\prime}$ end of the first intron and $27 \mathrm{bp}$ from the $3^{\prime}$ end of that intron, and results in a premature stop codon. The MUC1/YI splice site sequence matches the consensus sequence for alternative splicing (Table 1) (108). This transcript is predicted to produce a 27 amino acid peptide after signal peptidase cleavage (Fig. 8) that has no significant homology to any database sequence. We detected the MUC1/YI variant in two of the conjunctival samples, two of the cornea samples, and in the lacrimal gland sample (Fig. 7).

\section{RT-PCR Screening of Conjunctival Swab Samples from Dry Eye Subjects and Normal Controls for MUC1 Splice Variants}

Because of the possibility that MUCl splice variants could influence ocular surface physiology and disease, we screened for MUC1 splice variants in brush cytology samples of conjunctival epithelium obtained from an initial group of eleven subjects. Four out of six samples from dry eye subjects expressed only the MUC1/B form while in the remaining two dry eye sample one expressed a trace of MUC1/A and MUC1/B and the other expressed both MUC1/A and MUC1/B (Fig. 9, panel I). In striking contrast 


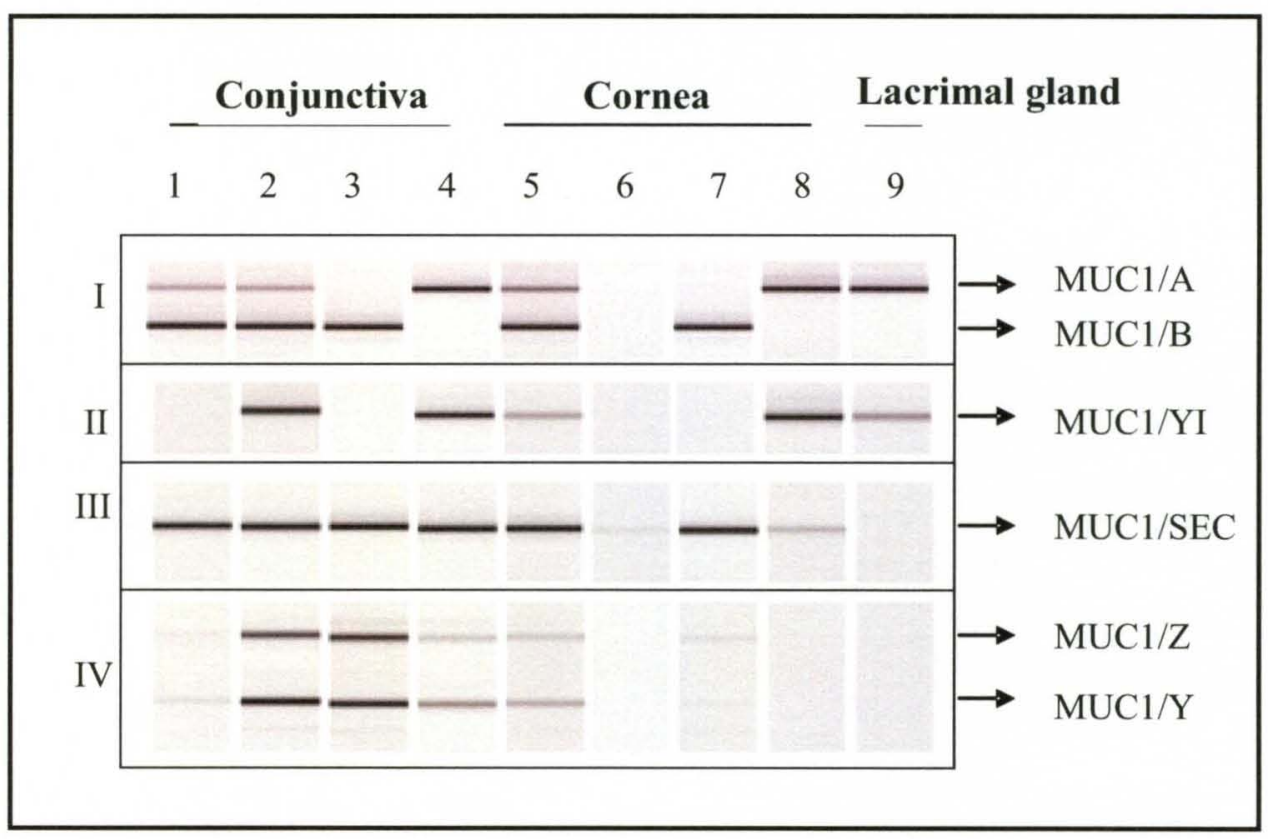

Figure 7. RT-PCR of MUC1 splice variants in whole ocular surface tissues. Panel I, MUC1/A and MUC1/B splice variants; panel II, MUC1/YI; panel III, MUC1/SEC; and panel IV, MUC1/Z(X) and MUC1/Y. Samples: 1-4 conjunctiva; 5-8 cornea; and 9 lacrimal gland; lanes 1-9 are in the same order as in Fig. 6. 


\section{Table 1}

Splice sites consensus sequences ${ }^{\mathrm{a}}$

\begin{tabular}{llc}
\hline $\begin{array}{l}\text { Splice } \\
\text { variant }\end{array}$ & Donor Sequence Acceptor Sequence \\
\hline $\begin{array}{l}\text { MUC1/B } \\
\text {...TGCTTACAG/gtgaggg...CCtaaacCcgcaacag/TTGTTA.... } \\
\text { MUC1/A }\end{array}$...TGCTTACAG/gtgaggg...ctttaacttcttacag/CTACCA.... \\
MUC1/YI ...GAAGTTAAG/gtaagaa...ctttaacttcttacag/CTACCA.... \\
\hline
\end{tabular}

${ }^{a}$ The splice site consensus sequence is (A or C)AG/GT(A or G)AGT at the splice site (shown as a back slash); each consensus trinucleotide region is underlined and the bases that match the consensus are shown in bold. There is also a polypyrimidine rich area 4 bases before the 3'end of the intron (splice acceptor) shown in italics. The new splice variant (MUC1/YI) matches the consensus sequence. 
$M T P G T Q S P F F L L L L L T V L T$ G E GUH EV G S G LP C L G G L R G L S V G F A P W Q Met A P Stop S Stop A T TA P KPA TV V T G S G H A S

Figure 8. Amino acid sequence of the peptide predicted to be encoded by the splice variant MUC1/YI. The italicized sequence is from exon 1, the bold and underlined sequence from the first intron, and the remaining sequence from exon 2 . The two vertical lines denote the predicted site of signal peptidase cleavage. 


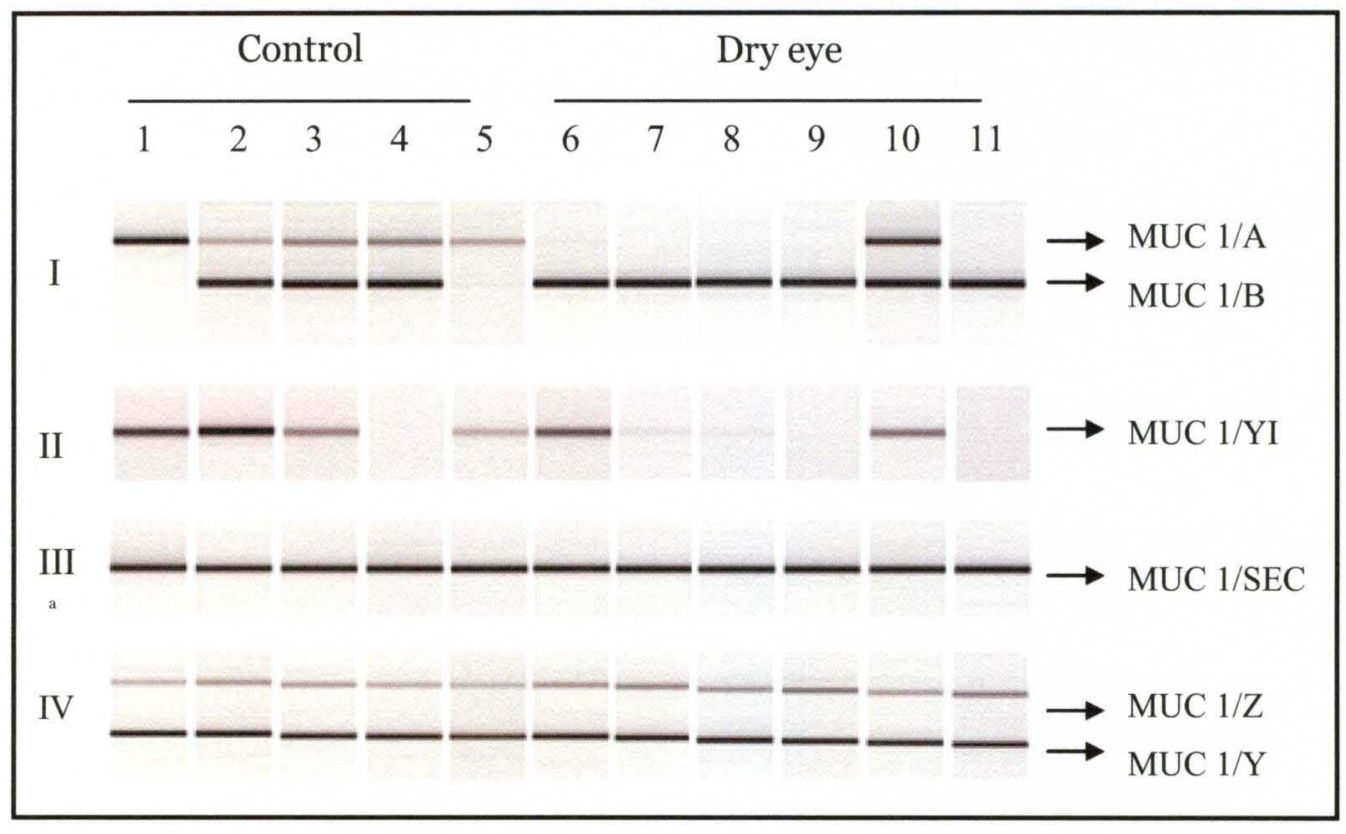

Figure 9. RT-PCR to detect MUC1 splice variants in conjunctival epithelial swab samples. Donors: normal controls (lanes 1-5) and dry eye patients (lanes 6-11). Panel: I, MUC1/A and MUC1/B; II, MUC1/YI; III, MUC1/SEC; and IV, MUC1/Z(X) and $\mathrm{MUC1} 1 \mathrm{Y}$. Band sizes (in bp): MUC1/A 222; MUC1/B $195 ; \mathrm{MUC1} / \mathrm{YI} \mathrm{145;}$ MUC1/SEC 184; MUC1/Y 276; and MUC1/Z(X) 329. See Material and Methods for primers used. Lanes (age, gender): 1, $57 \mathrm{~F} ; 2,29 \mathrm{~F} ; 3,61 \mathrm{M} ; 4,61 \mathrm{M} ; 5,72 \mathrm{~F} ; 6,63 \mathrm{~F} ; 7$, $85 \mathrm{~F} ; 8,48 \mathrm{~F} ; 9,70 \mathrm{~F} ; 10,74 \mathrm{~F}$; and 11, $57 \mathrm{~F}$. Electropherogram from the Agilent Bioanalyzer DNA 500 chip. 
samples from two out of five normal control subjects expressed only the MUC1/A form while the other three normal samples expressed both MUC1/A and MUC1/B. None of the control samples expressed only the MUC1/B variant. The PCR products were confirmed by sequencing. A summary of all analyses to date including additional donors is shown in Table 2. The results are compared to the distribution of the associated SNP rs4072037 (described in section below). The data indicate that the frequency of splice variants among the normal donor samples is approaching the frequency expected from the population at large based on the SNP data. In contrast the dry eye samples are continuing to be enriched in the $\mathrm{MUCl} / \mathrm{B}$ splice variant while MUC1/A homozygotes and heterozygotes are reduced.

Unlike these differences between the dry eye and normal control samples in expression of MUC1/A and MUC1/B described above, all eleven samples expressed MUC1/SEC, MUC1/Z(X) and MUC1/Y (Fig. 9, panels III and IV) while the MUC1/YI variant was detectable in four of five normal control samples and three of six samples from dry eye subjects (Fig. 9, panel II). In summary, these results indicate a clear difference in the expression of the MUC1/A and MUC1/B splice variants between dry eye patients and normal controls within this initial group of subjects.

\section{Screening Dry Eye and Normal Control Conjunctival Swab Samples for SNP Status} as a Measure of Tandem Repeat Size Class

Hilkens' group previously showed that the SNP at position 8 of exon 2 in the MUC1 gene controls alternative splicing at the boundary between exons 1 and $2(80)$; specifically, the G SNP allele results in the MUC1/A splice product while the A SNP 
Table 2

Comparison of frequencies of MUC1 SNP rs4072037 and MUC1 splice variants $^{\mathrm{a}}$

\begin{tabular}{|c|c|c|c|c|}
\hline \multirow[b]{2}{*}{$\begin{array}{l}\text { SNP } \\
\text { genotype }\end{array}$} & \multirow[b]{2}{*}{$\begin{array}{l}\text { SNP frequency } \\
(\%)\end{array}$} & \multirow[b]{2}{*}{$\begin{array}{l}\text { Splice site } \\
\text { variant }\end{array}$} & \multicolumn{2}{|c|}{ Splice variant frequency } \\
\hline & & & $\begin{array}{l}\text { Normal donors } \\
(\%)\end{array}$ & $\begin{array}{l}\text { Dry eye } \\
\text { donors }\end{array}$ \\
\hline $\mathrm{G} / \mathrm{G}$ & 18 & MUC1/A only & $4 / 15(27)$ & $1 / 9(11)$ \\
\hline $\mathrm{A} / \mathrm{G}$ & 49 & $\mathrm{AB}$ & $6 / 15(40)$ & $3 / 9(33)$ \\
\hline $\mathrm{A} / \mathrm{A}$ & 33 & MUC1/B only & $5 / 15(33)$ & $5 / 9(55)$ \\
\hline
\end{tabular}

${ }^{\text {a }}$ SNP frequencies for SNP rs4072037 are from Ensembl website and were determined on 30 mother-father-child trios from the CEPH collection (Utah residents with ancestry from northern and western Europe). Splice variants MUC1/A and MUC1/B were determined by RT-PCR as described in Materials and Methods and shown in Fig. 9, panel I. Normal donor group consisted of 6 males, 9 females, average age 55 years; dry eye donor group consisted of 9 females, average 65.3 years. 


\begin{tabular}{|c|c|c|c|c|}
\hline Splice site status & SNP & VNTR size class & AlwNI & $\begin{array}{c}\text { Susceptibility } \\
\text { to dry eye (proposed) }\end{array}$ \\
\hline MUC1/A & G & Large (60-90) & resistant & Lower \\
\hline $\mathrm{MUCl} / \mathrm{B}$ & A & Small (30-45) & sensitive & Greater \\
\hline
\end{tabular}

Figure 10. Relationships among MUC1/A and MUC1/B splice site status, SNP rs4072037 status, MUC1 tandem repeat number, AlwNI sensitivity, and proposed susceptibility to dry eye. The relationships between splice site status, SNP rs4072037 status, and VNTR size class have been established in the literature $(80 ; 81)$. The ranges of tandem repeat numbers for the two size classes are shown in parentheses. 
allele yields the MUC1/B variant (Fig. 10). To determine if that relationship holds for our population, we determined the status of the SNP in exon 2 using the restriction enzyme AlwNI. The G SNP allele is resistant while the A allele is sensitive to AlwNI digestion (summary in Fig. 10). We used as starting material for AlwNI digestion the products of PCR used for MUC1/A and MUC1/B analysis (shown in Fig. 9, panel I). In the two samples having only a MUC1/A band and not a MUC1/B band (Fig. 9, panel I, lanes 1 and 5), the MUC1/A band was resistant to AlwNI digestion (Fig. 11, lanes 1 and 5). In the four samples having only a MUC1/B band and not a MUC1/A band (Fig. 9, panel I, lanes $7,8,9$, and 11 ), the $\mathrm{MUC1} / \mathrm{B}$ band was sensitive, resulting in two fragments of 89 and $110 \mathrm{bp}$ as predicted from the location of the cleavage site (Fig. 11, lanes 7, 8, 9, and 11). In the samples with both MUC1/A and MUC1/B bands, the MUC1/A band was resistant while the MUC1/B band was cleaved (Fig. 11, lanes 2, 3, 4, 6 , and 10).

Overall, we conclude that conjunctival epithelial swab samples containing the $G$ allele of the SNP also express the MUC1/A splice site variant (compare Figs. 9 and 11, lanes 1 and 5) while samples containing the A allele of the SNP express the MUC1/B splice site variant (compare Figs. 9 and 11, lanes 7, 8, 9, and 11). Samples containing both splice site choices also contain both SNP alleles (Figs. 9 and 10, lanes 2-4, 6, and 10). Therefore, we have verified in conjunctival epithelium the relationship between SNP status and splice site choice established by Hilkens' group (80). 


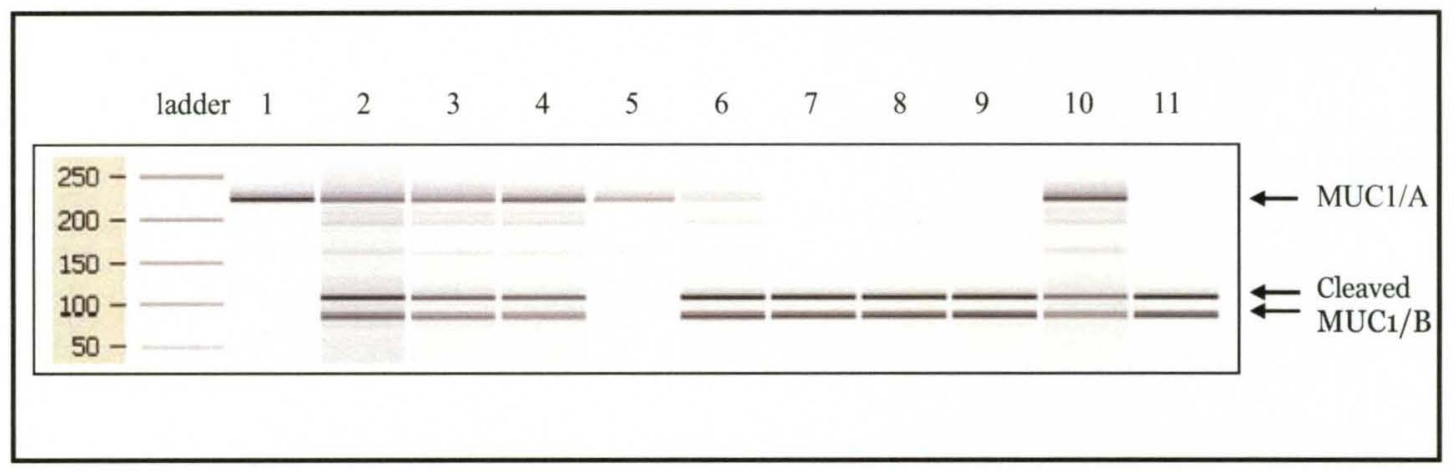

Figure 11. AlwNI digests of PCR products from conjunctival epithelial swab samples. PCR products from amplification with primers used for MUC1/A and /B (as in Fig. 5, panel I) were digested with AlwNI. Samples in same order as Fig. 5: lanes 1-5, normal controls; lanes 6-11, dry eye. MUC1/A $222 \mathrm{bp}$. MUC1/B products of digestion at 89 and $110 \mathrm{bp}$. 


\section{MUC1 Sizes in Tears}

Hilkens' and Swallow's groups have established that there is an association of three genetic elements of MUC1; namely, the SNP at position 8 of exon 2, the size class of tandem repeats (either large or small), and a CT dinucleotide repeat in intron $6(80 ; 81)$

(Fig. 10). Based on these relationships, the presence of the MUC1/A splice variant should indicate the presence of MUC1 protein with a VNTR region of the long size class whereas $\mathrm{MUC1} / \mathrm{B}$ should predict short VNTR. To provide initial verification of that relationship in conjunctival epithelium, we western blotted tears from normal subjects with the anti-MUC1 MoAb DF3 specific for the tandem repeat (105). Extracts of the human submandibular gland (HSG) cell line (103) (Fig. 12, lanes 2 and 8) and the human breast cancer cell line MCF-7 (104) (Fig. 12, lane 9) both displayed two reactive species. Previously Kufe's group described these two DF3 reactive species in extracts from MCF7 cells and concluded that these were the result of two protein cores that differed by 120,000 daltons and that were encoded by two transcripts of 4.5 and 7.0 kilobases (105). Although it was not known at the time, it is now clear that the two DF3 reactive species were one large and one small MUC1 VNTR size class member. Similarly, the two bands from HSG cells represent members of the small and large MUC1 tandem repeat size classes. Likewise tears from subject 3 , whose conjunctival epithelium expressed both MUC1/A and MUC1/B splice variants (Fig. 9, panel I, lane 3), produced two major bands, one of the long VNTR class and one from the short (Fig. 12, lane 4). The differences in migration of the tear bands compared to HSG bands may be due to either small differences of tandem repeat number or differences in glycosylation. Tears from subject 1, whose conjunctival epithelium expressed only MUC1/A (Fig. 9, panel I, lane 


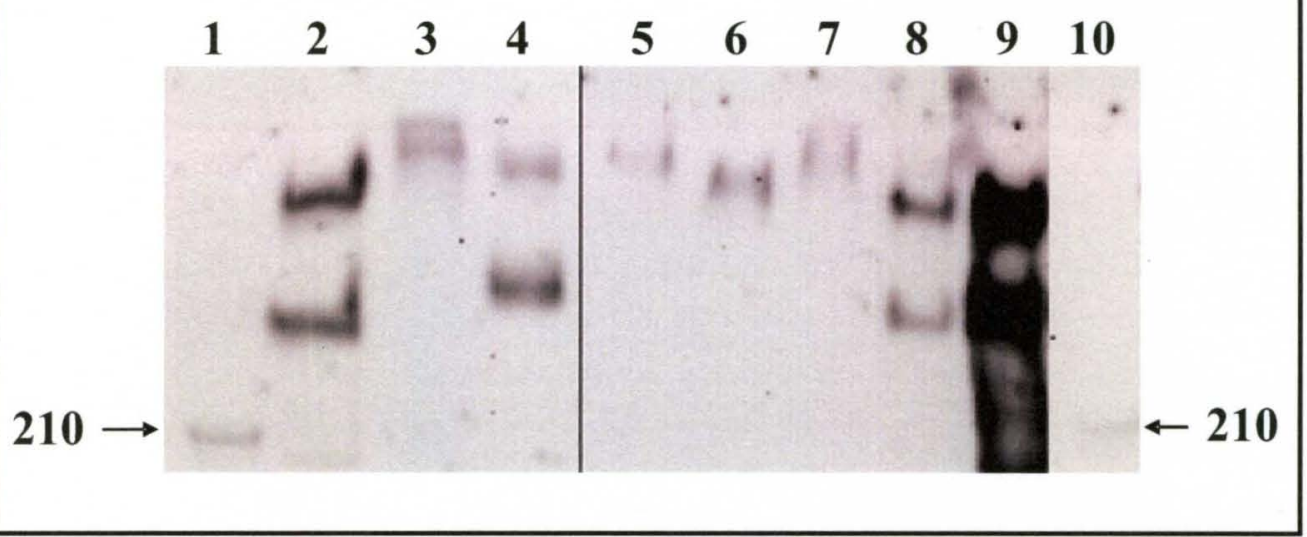

Figure 12. Western blot of tears with DF3 anti-MUC1. Electrophoresis was performed with a NuPAGE 3-8\% Tris acetate gel. After western blotting, bands were visualized using the Kodak Image Station 440CF. Lanes: 1 and 10, molecular weight markers with the only visible marker being the $210 \mathrm{kD}$ standard; lanes 2 and 8 , human submandibular gland epithelial cells (HSG) cells extract (103); lane 9, human breast cancer cell line MCF-7, used here as a positive control to indicate the locations of large and small MUC1 VNTR size classes; lanes 3 and 5, tears collected from normal donor 1 (analyzed also in Figs. 9 and 11, lane 1); lane 4, tears from normal donor 3 (analyzed also in Figs. 9 and 11, lane 3); and lanes 6 and 7, tears from two other normal MUC1/A positive, MUC1/B negative donors. Lanes 1-4 and 5-10 are from two different experiments. 
1), produced a doublet of bands (Fig. 12, lanes 3 and 5) that migrated more slowly than either the bands from subject 3, HSG cells, or MCF-7 cells. Similarly, tears from two other donors that expressed only MUC1/A (data not shown) produced DF3 reactive bands that migrated more slowly than the upper band of HSG and MCF-7 cells (Fig. 12, lanes 6 and 7). Thus, these results agree with the prediction that a individuals having conjunctival epithelium that expresses only the MUC1/A splice variant will produce only MUC1 protein with long VNTR while individuals like subject 3 that express both MUC1/A and MUC1/B splice variants in their conjunctival epithelium will produce MUC1 protein with both long and short VNTR.

\section{Discussion}

\section{MUC1 Variants in Ocular Tissues}

The mucins are among the many ocular surface components required to maintain a healthy ocular surface environment. The major mucins of ocular surface tissues fall into two classes: the soluble, gel-forming mucin MUC5AC expressed exclusively by conjunctival goblet cells and membrane associated mucins expressed mainly by nongoblet epithelial cells. In addition MUC2 expression in conjunctiva has been identified at the RNA level but as yet not at the protein level. Combining all reported human tissue mucins (reviewed in $(42 ; 46)$ ), corneas express MUC1, 4, 16, and 20; conjunctiva express MUC1, 2, 4, 5AC, 7, 13, 15, 16, 17 (109), and 20; and lacrimal glands express MUC1, 4, $5 B, 7$, and $20(110)$. 
Previous reports on the presence of mucins in ocular surface tissues did not address the question of whether mucin splice variants might be present. In the present report we demonstrate the expression at the mRNA level in human ocular surface tissues of the MUC1 splice variants MUC1/A, MUC1/B, MUC1/SEC, MUC1/Z(X), and $\mathrm{MUC1} / \mathrm{Y}$ that have all been identified previously in tumor tissue. In addition we describe a new variant $\mathrm{MUC1} / \mathrm{YI}$.

The presence of these MUC1 variants at the ocular surface could have several important effects on ocular surface physiology and disease. As mentioned in Results, the MUC1/A splice variant has two changes that could effect MUC1 processing, namely the addition of nine amino acids upstream of the tandem repeat and an altered signal peptidase cleavage site $(82 ; 83)$. Whereas transmembrane forms of MUC1 mediate cell signaling pathways (52), MUC1/SEC is missing the transmembrane domain. Therefore, MUC1/SEC would lack such signaling capability while retaining the extracellular functions of the carbohydrate-rich tandem repeat domain. The converse is true of the $\mathrm{MUCl} / \mathrm{Z}(\mathrm{X})$ and $\mathrm{MUC1} / \mathrm{Y}$ splice variants which retain signaling possibilities via the transmembrane and cytoplasmic domains but lack the tandem repeat region and its associated attributes of water retention, lubrication, and barrier function.

Currently there is considerable interest in the role of complexes between mucins and other secreted mucosal proteins in mucosal tissue disease. For example in human colon cancer cells, galectin-3 binds to MUC2 (111). A similar complex has been described among three MUC1 splice variants (112); the transmembrane bound MUC1/Y variant was shown to bind both MUC1/SEC and the soluble, extracellular domain of 
MUC1/B after its cleavage from the cell surface. Whether such a MUC1 self-complex exists at the ocular surface awaits future experimentation.

The MUC1/YI splice variant is predicted to produce a 27 amino acid peptide after signal peptidase cleavage (Fig. 8). However, many variant transcripts with premature stop codons result in mRNA degradation by the process of nonsense mediated decay (113). Therefore, future experiments are required to determine if MUC1/YI peptide is actually synthesized in ocular surface epithelial cells.

\section{MUC1/A Splice Variant, Tandem Repeat Number, and Dry Eye Disease}

Our data indicate that among an initial group of nine aqueous deficient dry eye subjects only one expressed the MUC1/A variant in the conjunctival epithelium while three expressed both MUC1/A and MUC1/B and five expressed only MUC1/B (Table 2). In contrast four of fifteen normal control donors expressed only MUC1/A, six expressed both MUC1/A and MUC1/B, and five expressed only MUC1/B. Although the difference in splice variants between normal and dry eye groups is not statistically significant, the normal group percentages are approaching the frequency expected based on the SNP data whereas the percentage of MUC1/A positive samples is reduced in the dry eye group. Sample collection is continuing to determine the statistical significance of these patterns.

Based on the above results and the relationship of $\mathrm{MUCl}$ elements established by Hilkens' and Swallow's groups $(80 ; 81)$ shown in Fig. 10, we propose the following hypothesis: there is a reduced frequency of the MUC1/A splice variant in ocular surface tissues in aqueous deficient dry eye disease and also there is a corresponding drop in the number of MUC1 alleles with longer numbers of tandem repeats (VNTR) in dry eye. 
This extension of the hypothesis to tandem repeat length is appealing because it offers an explanation for dry eye based on the notion of a reduced number of MUCl carbohydrate chains being less protective of the ocular surface. The mucin-like domain of MUC1 has been predicted to extend $200-500 \mathrm{~nm}$ above the cell membrane and far above the remainder of the glycocalyx $(46 ; 114)$. Longer VNTR having on average $60-90$ tandem repeats could clearly provide greater mucin functions of hydration, lubrication, and protection than shorter alleles having 30-45 tandem repeats. Also, we should note the possibility that apart from its association with VNTR length the MUC1/A variant itself could have an impact on ocular physiology because of the differences of amino acid sequence from $\mathrm{MUC1/B}$.

We have provided initial data that supports our hypothesis by showing that donors expressing only MUC1/A also had only large MUC1 VNTR by western blotting (Fig. 12, lanes 3, 5-7). However, formal testing of this hypothesis will require analysis of more patient samples to determine: (1) if there is a statistically significant reduction in the MUC1/A splice variant in samples of conjunctival epithelium from dry eye patients as compared to age and gender matched controls; and (2) if the MUC1 alleles of dry eye patients contain shorter VNTR than controls as determined by Southern blotting of genomic DNA and western blotting of tears.

The involvement of MUC1 in protection of epithelial surfaces has been reviewed $(47 ; 57 ; 115)$. For example one strain of MUC1 null mice were more susceptible to chronic infection and inflammation of the ocular surface and lower female reproductive tract than normal controls $(66 ; 116)$. 
Several reports have described a relationship between mucin tandem repeat number and particular diseases and are listed here as precedents for our hypothesis. Kyo et al. reported an association of rare tandem repeat alleles of the intestinal mucin MUC3 with ulcerative colitis (117). Vinall et al. found an association of gastritis due to $\mathrm{H}$. pylori infection with MUC1 shorter alleles (118). The salivary mucin MUC7 has two common alleles that have either 5 or 6 tandem repeats. Kirkbride et al. have reported that MUC7 with 5 tandem repeats is rarer in atopic asthmatics than atopic non-asthmatics (119). Swallow's group has found that MUC1 allele length may effect susceptibility to conditions that precede gastric carcinoma (120). They also found longer alleles of MUC2 in atopic non-asthmatics compared with normal controls or atopic asthmatics (121). The hypothesis of the latter study was essentially the same as that of our current report; namely, that a longer mucin VNTR region will decrease access to the cell surface of bacteria and other environmental agents as a result of the size, glycosylation, and consistency of the mucin. One point to note here is that the differences in tandem repeat number in several of those cases is less than what occurs between MUC1 having high or low size groups of tandem repeats; e.g., in the case of MUC3 in ulcerative colitis (117), the difference is only between 5 and 6 repeats of MUC3. In contrast in the case of MUC1 the difference between the large and small size groups is essentially two fold.

In summary if our hypothesis proves to be correct, it might be possible to predict the susceptibility of a person to dry eye disease by testing for the MUC1/A to MUC1/B ratio by brush cytology. Also, in the future it may be possible to restore MUC1/A levels to normal through either gene therapy or selective topical tear supplementation. 


\section{CHAPTER IV- MUC1 AND ESTROGEN RECEPTOR $\alpha$ GENE POLYMORPHISMS IN DRY EYE PATIENTS}

The text of this chapter was published in Exp. Eye Research; 88(3):334-8 (2009)

\section{Introduction}

The mucin MUC1 is one of several mucins that function at the ocular surface to protect that surface against pathogen invasion, to facilitate lubrication, and to retain water (42;46). MUC1 is present on corneal and conjunctival epithelial cells (122) and in the tears (90). The cytoplasmic domain of MUC1 serves as a platform for effectors of several cell signaling pathways (123). The large extracellular domain of MUC1 contains a variable number of tandem repeat (VNTR) region with each repeat containing five potential sites for O-glycosylation. $\mathrm{MUCl}$ alleles are divided into size classes that contain small (30-45) and large (60-90) numbers of tandem repeats. Among the many splice variants of MUC1, two full length variants, MUC1/B and MUC1/A, differ by the inclusion of $27 \mathrm{bp}$ from intron 1 in MUC1/A.

There are three major types of dry eye syndrome or keratoconjunctivitis sicca (KCS) (96). Evaporative dry eye is associated with abnormal tear composition resulting in rapid evaporation predominantly due to meibomian gland dysfunction. Aqueous deficient dry eye, as the name implies, is associated with inadequate tear production and is subdivided into Sjögren's and non-Sjögren's types. Although the epidemiology of dry eye has been well studied (67), reports of genetic patterns that might influence 
susceptibility to dry eye are few. We reported that the frequency of non-Sjögren's aqueous deficient dry eye patients expressing only the MUC1/A splice variant of the mucin MUC1 may be lower than in a normal control group (79). Swallow's group had previously found an association between $\mathrm{MUC1}$ splicing and the size class of the MUC1 VNTR region (81). Based on those findings, we hypothesized that VNTR length may be one factor determining susceptibility to dry eye disease. Another report suggesting a genetic factor in dry eye was provided by He et al who found a difference between Chinese dry eye and control groups in a polymorphism in estrogen receptor $\alpha(E R \alpha)$ (124). In the present study we determined the statistical significance and generality of these observations and tested if the MUC1 splice variant difference reflected a difference in the MUC1 VNTR size class. The results indicate a statistically significant difference between a normal control group and both non-Sjögren's aqueous deficient and evaporative dry eye groups in the MUC1 variant genotype frequency. However, the association between $\mathrm{MUCl}$ variant genotype frequency and VNTR size class was weak and did not support the hypothesis that VNTR length was a factor in determining susceptibility to dry eye. Finally, in the Caucasian populations tested there was no difference between normal control and either of the dry eye groups in ER $\alpha$ variant genotype frequency.

\section{Materials and Methods}

Tissues and DNA: The inclusion of human subjects was in accordance with the Declaration of Helsinki and was approved by the local Institutional Review Board and 
the Human Subjects Protection and Privacy Office of the University of Louisville. Informed Consent and Research Authorization were obtained prior to collection of samples from enrolled subjects. Non-Sjögren's aqueous deficient dry eye patients were identified as having both tear deficiency and ocular surface staining. Evaporative dry eye was diagnosed by reduced tear breakup time (TBUT $<7 \mathrm{sec}$ ) but normal tear production (Schirmer test $>7 \mathrm{~mm} / 5 \mathrm{~min}$ ) in the presence of meibomian gland obstruction. Ocular surface staining was measured by instillation of topical $2 \%$ fluorescein solution or $1 \%$ lissamine green solution. Fluorescein staining of the cornea and lissamine green staining of the conjunctiva was observed at the slitlamp examination in all of the aqueous deficient and evaporative dry eye subjects but none of the control group. All subjects were female Caucasians. All samples were obtained in Louisville, KY. Subject group ages were (mean +/- S.E.): normal controls 59 +/- 2.4 yr., non-Sjögren's aqueous deficient dry eye $58.2+/-2.4$, and evaporative dry eye $66.2+/-2.2$.

Buccal swabs were taken with OmniSwabs (Whatman). Genomic DNA was extracted from buccal swabs using the QIAamp DNA mini kit and from peripheral blood using the Blood \& Cell Culture DNA Midi kit (Qiagen). Total RNA was extracted from conjunctival brush swabs for splice variant analysis by PCR (79), and tear samples were used for western blotting.

SNP analysis: Single nucleotide polymorphism (SNP) assays (Applied Biosystems) were used to determine the frequency of the SNP (rs4072037) that controls the MUC1/A and MUC1/B splicing event and the SNP (rs2234693) in the ER $\alpha$ gene. 
Southern and western blotting: Southern blotting analysis of genomic DNA from the blood of 29 patients was performed by digesting with Hinfl and probing with a digoxigenin labeled MUC1 TR DNA probe kindly provided by Dr. M.A. Hollingsworth. Western blotting was performed on the tears from 16 patients as previously described (79). Briefly, protein samples from tears were electrophoresed on 3-8\% NUPAGE Trisacetate gels (Invitrogen) followed by incubation with the DF3 antibody specific for the MUC1 tandem repeat region (105). The bands were visualized using the Kodak Image Station 440CF.

\section{Results}

\section{Correlation Between MUC1 Splice Variant Pattern and SNP Genotype}

Ligtenberg et al. (80) established that the selection of splice variant MUC1/A or MUC1/B was determined by a SNP (rs4072037) in exon 2 of MUC1. We compared the presence of the MUC1/A and MUC1/B splice variants and the SNP genotype in our subject samples and found a perfect correlation (in 30/30 cases, data not shown). Therefore, we analyzed all additional cases by SNP analysis of genomic DNA rather than splice variant analysis of cDNA samples. The advantages of SNP analysis were: the increased number of volunteers who were willing to donate buccal swab samples as compared to conjunctival brush cytology swabs; and the simplicity and speed of sample processing and SNP assay of genomic DNA as compared to splice variant analysis of cDNA. 


\section{MUC1 SNP Genotype Frequencies Among Normal Controls and Dry Eye Groups}

We conducted a case control study to compare the genotype frequency of the SNP (rs4072037) in the MUC1 gene between normal control subjects and non-Sjögren's aqueous deficient dry eye subjects as well as evaporative dry eye subjects. All of these subjects were female Caucasians from the Louisville, Kentucky area. The SNP genotype frequency of the normal control group was statistically different from the non-Sjögren's aqueous deficient dry eye group $(\mathrm{P}=0.017)$ and also from the evaporative dry eye group $(\mathrm{P}=0.015$; Table 3$)$. The non-Sjögren's aqueous deficient dry eye group was markedly low in subjects of the G/G SNP genotype with only one individual being in that category (Table 3). This genotype corresponds to the MUC1/A only splice variant (Table 3 ) that we had found to be low in this category of dry eye in our initial report (79). Thus, we were able to establish the statistical significance of our observation that we had previously reported.

Given that meibomian gland obstruction is a factor involved in evaporative dry eye that is not found in non-Sjögren's aqueous deficient dry eye, it was surprising to find that the evaporative dry eye group was also significantly different than the control group in its MUC1 SNP genotype frequency (Table 3). However, when the two dry eye groups were compared with each other, they were not significantly different $(P=0.09)$. These findings suggest that these two types of dry eye may share a factor or mechanism of ocular surface damage related to MUC1 genotype. 
Table 3

MUC1 SNP genotype frequencies among normal controls and dry eye subjects $^{\text {a }}$

\begin{tabular}{|l|c|c|l|l|}
\hline $\begin{array}{l}\text { SNP } \\
\text { genotypea }\end{array}$ & $\begin{array}{l}\text { MUC1 splice } \\
\text { variant }\end{array}$ & $\begin{array}{l}\text { Normal } \\
\text { controls }\end{array}$ & $\begin{array}{l}\text { Non-Sjögren's } \\
\text { aqueous } \\
\text { deficient dry } \\
\text { eyeb }\end{array}$ & $\begin{array}{l}\text { Evaporative } \\
\text { dry eyeb }\end{array}$ \\
\hline G/G & A only & $7 / 29(24 \%)$ & $1 / 32(3 \%)$ & $3 / 21(14 \%)$ \\
A/G & AB & $18 / 29(62 \%)$ & $19 / 32(59 \%)$ & $7 / 21(33 \%)$ \\
A/A & B only & $4 / 29(14 \%)$ & $12 / 32(38 \%)$ & $11 / 21(52 \%)$ \\
\hline
\end{tabular}

${ }^{a}$ SNP rs4072037 in the MUC1 gene. All subjects were female Caucasians from the Louisville, Kentucky area.

${ }^{b}$ Statistics (Fisher exact probability test $2 \times 3$ ): normal controls versus non-Sjögren's aqueous deficient dry eye $\mathrm{P}=0.017$ and normal controls versus evaporative dry eye $\mathrm{P}=$ 0.015 . 


\section{Correlation Between MUC1 Splice Variant Pattern and VNTR Size Class}

Because of the rough correlation between the MUC1 SNP genotype status and VNTR size class established previously (81), we determined if the size class of the MUCl VNTR contributed to possible protection against damage from dry eye in subjects of the MUC1 SNP GG genotype. We analyzed tears by western blotting with the DF3 antibody specific for the VNTR region of MUC1. As we previously reported (79), extracts from the human submandibular gland (HSG) cell line produce two bands that can be used as markers for the large and small VNTR size classes (Fig. 13, lane 7). The GG SNP genotype should be associated with the large size class and the AA genotype with the small size class. In agreement with this prediction, both GG SNP genotype samples shown in Fig. 13 produced bands of the large VNTR size class and both GA genotype samples produced one large band and one small band (Fig. 13, lanes 1-4, respectively). However, one of the AA SNP genotype samples produced one large VNTR size class band and one small band (Fig. 13, lane 5) rather than the two small VNTR bands predicted for that genotype and as seen in the other AA sample (Fig. 13, lane 6). Overall, the size class of the MUC1 protein in tears corresponded to the MUC1 SNP genotype in only about $80 \%$ of the alleles tested (27/32 alleles).

To evaluate additional dry eye subjects, we conducted Southern blotting of genomic DNA from blood because of the limited tear volume in many aqueous deficient dry eye subjects. For each MUC1 SNP genotype, there were samples in which the VNTR size class agreed with the SNP genotype (GG genotype corresponding with only the large size class of VNTR, AA genotype having only the small size class, and GA genotype having both size classes as in Fig. 14, lanes 3, 5, 7, and 9) and samples in which 


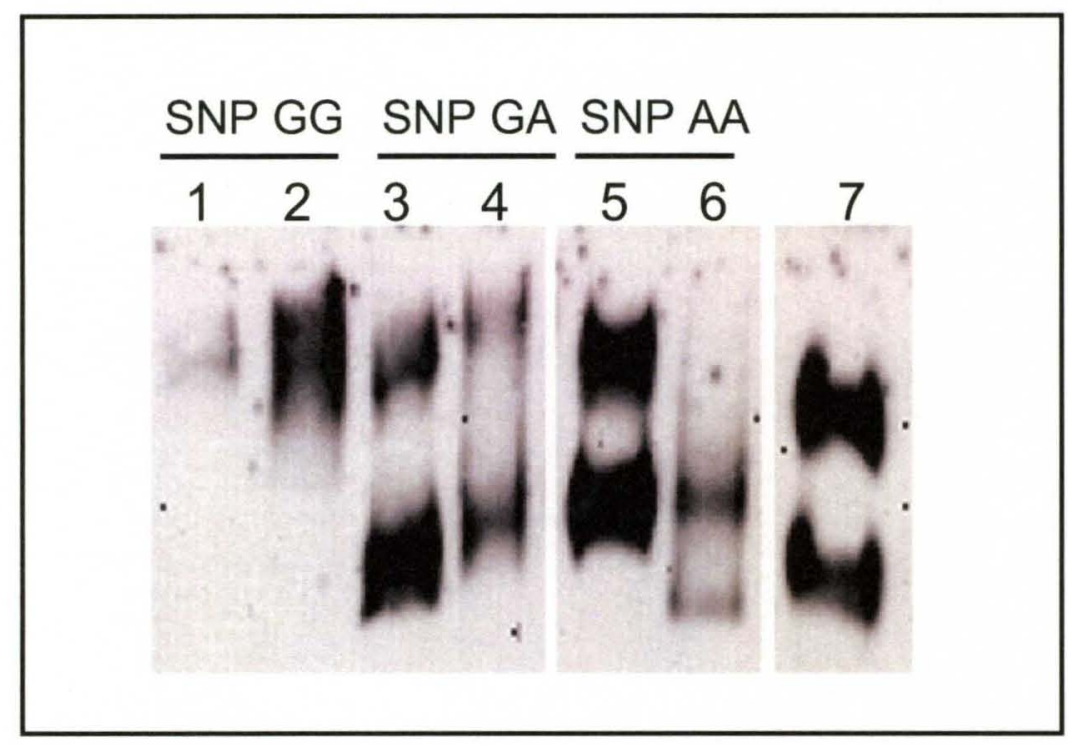

Figure 13. Western blot analysis of tears with DF3 anti-MUC1. Tears $(5 \mu \mathrm{l})$ from normal control donors were western blotted with anti-MUC1 antibody DF3. Lanes 1 and 2, SNP GG genotype; lanes 3 and 4, SNP GA genotype; lanes 5 and 6, SNP AA genotype; and lane 9, extract from the human submandibular gland (HSG) cell line cells (positive control for SNP GA heterozygote to show migration of large and small VNTR). 


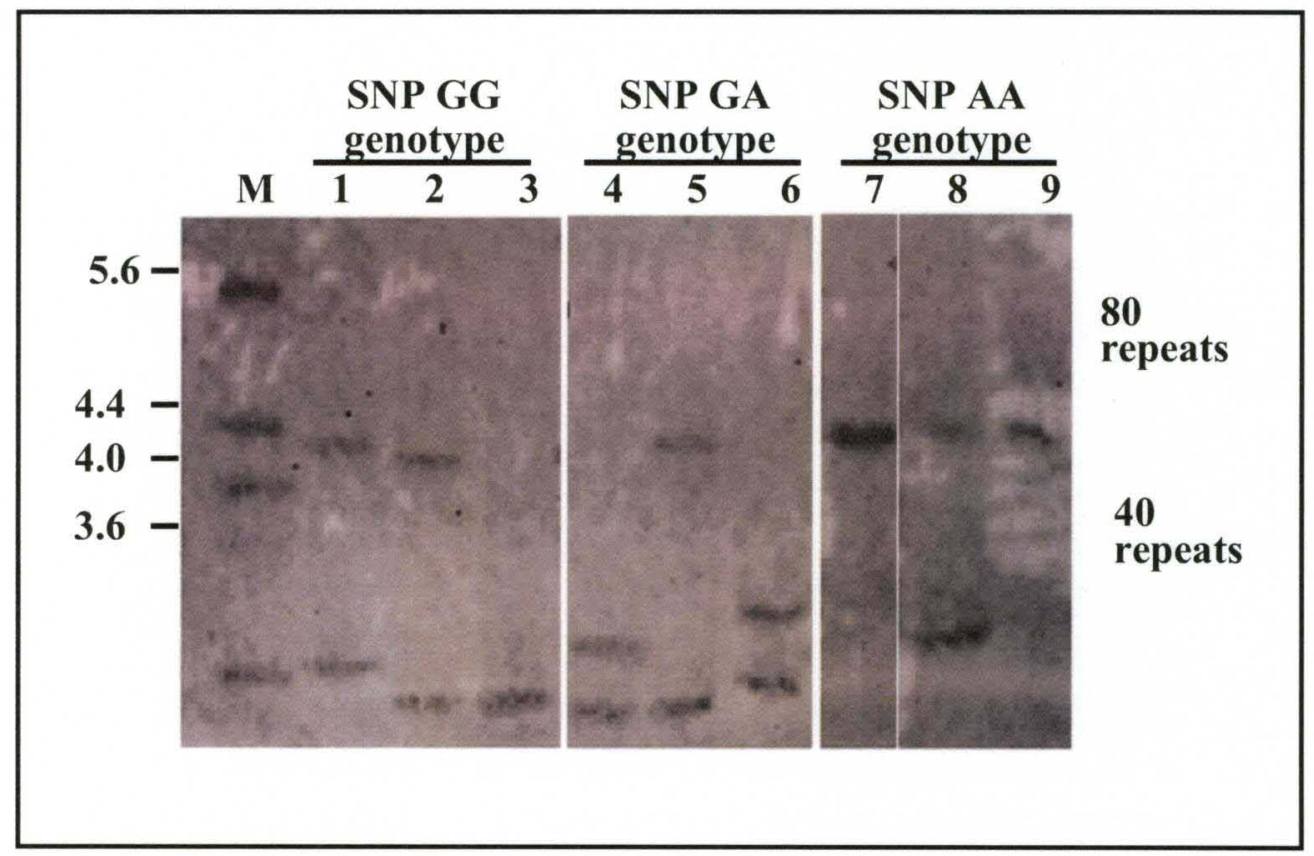

Figure 14. Comparison of MUC1 SNP genotype and VNTR allele size as determined by Southern blotting. Genomic DNA was isolated from nine subjects of the MUC1 SNP genotypes indicated at the top. Southern blotting distinguished VNTR allele lengths in the large size class (region of 80 repeats) and small size class (region of 40 repeats). MUC1 allele lengths agreed with the SNP genotypes in 46 of the total of 58 alleles analyzed (79\% agreement). M, markers with lengths given in $\mathrm{kb}$. 
the VNTR size class disagreed with the SNP genotype (lanes 1, 2, 4, 6, and 8). Similar to the western results, the SNP genotype correlated with the VNTR in only 46 of $58(79 \%)$ of the alleles analyzed. Therefore, these results suggested that VNTR size class was probably not associated with susceptibility to dry eye.

\section{ER $\alpha$ SNP Genotype Frequencies Among Normal Controls and Dry Eye Groups}

He et al. (124) used the PvuII restriction enzyme to analyze a polymorphism in intron 1 of the $\mathrm{ER} \alpha$ gene and found a significant difference in the genotype frequency between normal controls and patients with dry eye among Chinese subjects (Table 4). We determined if this polymorphism frequency difference between dry eye subjects and normal controls occurred in Caucasians. We utilized a simpler and more rapid SNP assay to determine the genotype frequency of that polymorphism (Table 4). Neither the nonSjögren's aqueous deficient dry eye group nor the evaporative dry eye group was different from the normal control group. Therefore, these results did not support the possibility that this ER $\alpha$ polymorphism could be used in Caucasians to distinguish normal controls from dry eye subjects.

\section{Discussion}

\section{ERa SNP Genotype Frequencies Among Caucasians}

He et al. reported a significant difference between Chinese normal control and dry eye groups in genotype frequency of a polymorphism in the ER $\alpha$ gene (124). Based on reported reduced values for tear break up time and Schirmer strip migration, these 
Table 4

ER $\alpha$ SNP genotype frequencies among normal controls and dry eye subjects ${ }^{\mathrm{a}}$

\begin{tabular}{|l|l|l|l|l|l|l|}
\hline $\begin{array}{l}\text { PvuII } \\
\text { pheno- } \\
\text { types }\end{array}$ & $\begin{array}{l}\text { PvuII } \\
\text { freq. } \\
\text { normal } \\
\text { controls } \\
\%^{\mathrm{a}}\end{array}$ & $\begin{array}{l}\text { PvuII } \\
\text { freq. } \\
\text { dry eye } \\
\%^{\mathrm{a}}\end{array}$ & $\begin{array}{l}\text { SNP } \\
\text { geno- } \\
\text { type }\end{array}$ & $\begin{array}{l}\text { Normal } \\
\text { controls }\end{array}$ & $\begin{array}{l}\text { Non-Sjögren's } \\
\text { aqueous } \\
\text { deficient dry } \\
\text { eye }^{\mathrm{b}, \mathrm{c}}\end{array}$ & $\begin{array}{l}\text { Evap- } \\
\text { orative } \\
\text { dry eye }\end{array}$ \\
\hline $\mathrm{PP}$ & 11 & 20 & $\mathrm{C} / \mathrm{C}$ & $5 / 21(24 \%)$ & $7 / 24(29 \%)^{\mathrm{c}}$ & $5 / 22(23 \%)^{\mathrm{c}}$ \\
\hline Pp & 64 & 43 & $\mathrm{C} / \mathrm{T}$ & $9 / 21(43 \%)$ & $9 / 24(38 \%)$ & $13 / 22(59 \%)$ \\
\hline pp & 25 & 37 & T/T & $7 / 21(33 \%)$ & $8 / 24(33 \%)$ & $4 / 22(18 \%)$ \\
\hline
\end{tabular}

${ }^{\text {a }}$ Pvull restriction enzyme phenotypes and frequencies for Chinese subjects from $\mathrm{He}$ et al. (124)

${ }^{b}$ SNP rs 2234693 in the ER $\alpha$ gene. Caucasian subjects from the same groups in Table 1.

${ }^{c}$ Statistics (Fisher exact probability test $2 \times 3$ ): normal controls versus non-Sjögren's aqueous deficient dry eye $\mathrm{P}=0.93$ and normal controls versus evaporative dry eye $\mathrm{P}=$ 0.48 . 
patients may have been of the non-Sjögren's aqueous deficient dry eye type. However, because there was no indication whether meibomian gland disease was specifically excluded, we cannot rule out the possibility that these patients might have been of the evaporative dry eye type or a combination of both types. In contrast to the genotype frequency differences in the Chinese population, we could not detect any difference in genotype frequency between normal controls and either the non-Sjögren's aqueous deficient dry eye group or the evaporative dry eye group when we analyzed this polymorphism in Caucasian subjects (Table 4). Thus, we have no evidence that this ER $\alpha$ polymorphism plays a role in susceptibility to dry eye in Caucasians. However, this ER $\alpha$ SNP analysis does provide a control for our MUC1 SNP results in that the ER $\alpha$ SNP data indicate that we did not inadvertently sample from different populations when we collected our normal controls and dry eye subjects from Kentucky.

\section{MUC1 SNP Genotype Frequencies Among Caucasians}

Our results indicate that the G/G genotype of the MUC1 SNP rs4072037 has a much lower frequency in non-Sjögren's aqueous deficient dry eye subjects with ocular surface staining as compared to normal controls (Table 3). This result confirms our initial observation (79) and suggests that this genotype may offer protection against the development of this type of dry eye disease. It is important to point out here that we classified these patients not only as having non-Sjögren's aqueous deficient dry eye but also as having ocular surface staining. Therefore, the MUC1 genotype may be related to protection of the ocular surface from damage rather than being related to the etiology of this type of aqueous-deficient dry eye disease (see Section below). The same rationale 
may apply to evaporative dry eye. Meibomian gland disease is known to be a component in the etiology of evaporative dry eye. It was surprising to find that two different types of dry eye disease both have MUC1 SNP genotype frequencies that differed significantly from the normal control group (Table 3). A possible explanation could be that both disease subtypes share mechanisms leading to damage to the ocular surface rather than sharing mechanisms responsible for the primary etiology of each disease subtype.

Dry eye disease is now considered to be an inflammatory disorder that affects the ocular surface (125). Inflammation of the lacrimal gland, the meibomian gland, and the ocular surface has been shown to play a critical role in the pathogenesis of dry eye $(27 ; 34)$. Increased levels of inflammatory mediators including pro-inflammatory cytokines, human leukocyte antigen (HLA-DR) and intercellular adhesion molecule (ICAM)-1, have been demonstrated in the tears and in the conjunctival epithelium of dry eye patients $(19 ; 126)$. The drop in estrogen and androgen levels during menopause is associated with increased cytokine production and inflammatory disease $(127 ; 128)$. MUC1 has been shown to modulate inflammation although the details of the role of $\mathrm{MUCl}$ are presently unclear. MUCl ablation experiments in mice showed an increase in inflammatory response indicating an anti-inflammatory role of MUC1 (65). Moreover, MUC1 expressed on resting T lymphocytes can inhibit the activation of T cells (68). In addition, it was recently reported that MUC1 can inhibit the activation of Toll-like receptors (129). In contrast to those three reports of MUC1 as an inflammatory inhibitor, MUCl was recently shown to activate the NF- $\mathrm{KB}$ pathway in both normal epithelial cells and cancer cell lines (69), thus suggesting a possible pro-inflammatory role of MUC1. 
Future studies will be required to clarify the precise role of $\mathrm{MUCl}$ in the development of damage to the ocular surface in dry eye syndrome.

\section{Possible Relationships of MUC1 Variants in Dry Eye Disease}

Ocular surface damage as evidenced by staining of the cornea and conjunctiva by fluorescein and lissamine green stains is a frequent consequence of dry eye disease (96). Staining of the surface epithelial cell by lissamine green and rose bengal dyes has been explained by loss of the protection of those cells by alteration of the glycocalyx that covers those cells (36). Fluorescein staining of the corneal epithelium is attributed to damage to the epithelial cell membranes (44). It is possible that variations in the MUC1 glycoprotein determine susceptibility to ocular surface damage through either diminished protection of the surface or inflammation modulated damage to the surface cells.

The most likely explanation for the observed differences of rs 4072037 allele frequencies between dry eye patients and controls is the unique splice acceptor site for exon 2 for MUC1/B (A allele) located 27 bp upstream of the one used by MUC1/A (G allele). As a result, MUC1/A protein as compared to $\mathrm{MUC1} / \mathrm{B}$ contains nine additional amino acids on the amino terminal side of the tandem repeat region. This additional sequence is predicted to change the signal peptidase cleavage site thereby altering the amino terminus of the mature protein $(82 ; 83)$. These two sequence changes could alter intracellular trafficking and/or subsequent MUCl processing and, therefore, be relevant to MUC1 function and ocular physiology. The general structure of MUC1 as a large transmembrane protein allows it to sense the external environment and to communicate that signal inside the cell via signal transduction mediated by the cytoplasmic domain. 
Consequently, the change in the N-terminus of the extracellular domain corresponding to MUC1B could potentially alter the interaction of $\mathrm{MUCl}$ with extracellular components thereby increasing the ability of the cell to respond to stimuli.

In addition to the possible involvement of MUC1 in modulating inflammation described above, there are at least three other ways that MUC1 variants could be related to susceptibility to dry eye ocular surface damage. First, the SNP could be associated with a previously undescribed sequence difference in the exons encoding the cytoplasmic domain. However, using PCR we amplified and sequenced the cytoplasmic domains of MUC1 from two MUC1/A only and two MUC1/B only cases and found that the sequences were identical (data not shown). Therefore, this possibility was ruled out.

Second, Swallow's group established that the MUC1 polymorphism studied in this report correlates with the size class of the VNTR tandem repeat region (either large or small), and a CT dinucleotide repeat in intron $6(81)$; i.e., the SNP genotype G produces MUC1/A and is associated with large tandem repeat alleles while the SNP genotype A that produces $\mathrm{MUCl} / \mathrm{B}$ is associated with small alleles. Based on this relationship, we initially hypothesized that the different MUC1 splice variant pattern in non-Sjögren's aqueous deficient dry eye patients could reflect a difference in the tandem repeat size (79); i.e., dry eye patients deficient in expression of the MUC1/A variant would have a lower number of tandem repeats, and therefore, reduced O-glycosylation of $\mathrm{MUC1}$ and less protection of the ocular surface. However, western and Southern blotting (Figs. 13 and 14) revealed that the correlation between the MUC1 SNP genotype and tandem repeat size class held in only about $80 \%$ of the cases. This less than perfect correlation agreed with the results of Swallow's group (81). Based on these results, it appears 
unlikely that MUCl tandem repeat size is responsible for susceptibility to dry eye disease.

Third, if the MUC1 SNP was inherited as part of a haplotype, then another genetic element within that haplotype could be the functional entity involved in susceptibility to dry eye rather than MUC1 itself. In fact there are three other SNPs with significant $\left(r^{2}>\right.$ 0.8) inheritance with the MUC1 SNP (see Haploview in the HapMap project). Two of these SNPs (rs2049805 and rs2990245) are in the intergenic region between the metaxin 1 and the glucerebrosidase (GBA) genes; one SNP (rs2066981) is intronic in the thromospondin 3 precursor (THBS3) gene; and one SNP rs364897 is in the $\beta$ glucocerebrosidase (GBA) gene. The latter SNP appeared to be the most promising candidate because it was the only non-synonymous SNP, coding for a Ser/Asn change, and also because GBA has been associated with epithelial hydration and maintenance of the epithelial permeability barrier (130). The minor allele frequency of this SNP in the Caucasian population reported by the HapMap was 0.42 . However, we could not detect any samples positive for the minor allele using a Taqman SNP assay (data not shown) on the same samples from our patient populations used for the other SNP assays described here. We concluded that this SNP does not exist in the Caucasian population at least at the frequency stated by HapMap. Therefore, if another element in the haplotype with MUC1 is the functional entity in dry eye, it remains to be identified. 


\section{CHAPTER V- MUC1/A AND MUC1/B SPLICE VARIANTS DIFFERENTIALLY REGULATE INFLAMMATORY CYTOKINE EXPRESSION}

\section{Introduction}

As discussed in Chapters I-IV, MUCl variants are hypothesized to play a key role in the development and progression of dry eye disease. The MUC1/A splice variant differs from the MUC1/B form by having an additional 9 aa within the MUC1-N domain (Figure 3). As stated in Chapter II, this additional sequence is predicted to change the signal peptidase cleavage site, thereby altering the localization signal within the amino terminus $(82 ; 83)$, and potentially changing its intracellular trafficking and/or subsequent processing. Although much is known about how the MUC1 CT regulates signal transduction (131), the contribution of MUC1-N in the cell signaling properties of MUC1 is poorly understood. A change in the MUC1-N domain may alter the interaction of MUC1 with extracellular components, thereby changing cellular to responses to external stimuli. Alternatively, the change in signal peptide sequence may alter intracellular location and thus intracellular signaling events. The impact of the 9 additional aa in the MUC1-N in MUC1/A versus $\mathrm{MUC1/B}$ on the intracellular localization and signaling functions of MUC1 has not been examined.

The goal of the studies described in this chapter was to elucidate the roles of the MUC1/A and MUC1/B splice variants in regulating cellular inflammatory responses to tumor necrosis factor alpha (TNF $\alpha)$. The importance of examining MUC1 splice variants from the standpoint of inflammatory responses is two fold: first, MUC1 has been 
demonstrated to play an important role in regulating inflammatory responses via modulation of the NF-кB pathway both in vitro and in vivo $(65 ; 67 ; 69)$. Second, dry eye disease is considered to be a chronic inflammatory disorder that affects the ocular surface (125). Thus, determining the roles of $\mathrm{MUC1} / \mathrm{A}$ and $\mathrm{MUC1} / \mathrm{B}$ splice variants in the regulation of inflammation will provide insight into the pathogenesis of dry eye disease. In this report, we demonstrate that $\mathrm{MUC1} / \mathrm{B}$ and $\mathrm{MUC1} / \mathrm{A}$ splice variants differ in their ability to modulate certain TNF $\alpha$-induced inflammatory responses.

\section{Materials and Methods}

Cell Culture: COS-7 cells were purchased from American Type Culture Collection. COS-7 cells were maintained in Dulbecco's Modified Eagle's Medium (DMEM, Invitrogen) supplemented with 10\% fetal bovine serum (FBS, Atlanta Biologicals).

Plasmids and MUC1/A cloning: The $\mathrm{MUCl} / \mathrm{B}$ and MUC1 $\triangle \mathrm{EX}$ in pCMV-DNA3 (pCDNA3) constructs were a kind gift from Dr. J.A. Schroeder at the Arizona Cancer Center, University of Arizona. The MUC1/B cDNA was originally cloned by M.A. Hollingsworth at the University of Nebraska Medical Center as described in (132). The MUC1/B cDNA was subcloned into HindIII/EcoRI sites of Litmus38i vector (NEB) using standard techniques. MUC1/B in Litmus38i was digested using $X m n \mathrm{I}$ and $B s m \mathrm{I}$ restriction enzymes (NEB). The additional $27 \mathrm{bp}$ present in the MUC1/A variant was cloned into XmnI and BsmI sites of MUC1/B using In-Fusion cloning (Clontech). Briefly, a 262 bp fragment containing the $27 \mathrm{bp}$ corresponding to the MUC1/A splice 
variant $(44 ; 79)$ was generated by PCR using cDNA from a MUC1/A homozygous donor and the following primers: 5'-CCT GCC TGA ATC TGT TCT GC-3' (forward) and 5'CTG GAG AGT ACG CTG CTG GT-3' (reverse). These primers are flanking the XmnI and BsmI sites in exons 1 and 2 of the MUCl gene, respectively. The amplification protocol consisted of an initial denaturation of $94^{\circ} \mathrm{C}$ for $1 \mathrm{~min}, 35$ cycles of denaturation at $94{ }^{\circ} \mathrm{C}$ for $30 \mathrm{~s}$, annealing at $60^{\circ} \mathrm{C}$ for $30 \mathrm{~s}$, and extension at $72{ }^{\circ} \mathrm{C}$ for $30 \mathrm{~s}$. The PCR product was ligated into $\mathrm{pCR}^{\circledR}$-Blunt II-TOPO ${ }^{\circledR}$ vector (Invitrogen). In-Fusion PCR was performed to generate a 252 bp product using $\mathrm{pCR}^{\circledR}$-Blunt II-TOPO ${ }^{\circledR}$ vector as a template and the following primers: 5'- CAG CGC CTG CCT GAA TCT GTT CTG CCC CCT CCC CA-3' (forward) and 5'-TCA TCC TTG TAA TCA GCA TTC TTC TCA GTA GAG CT-3' (reverse). In-Fusion Dry down reaction (Clontech) was used to ligate MUC1/A into the MUC1/B Litmus vector. The reaction mixture was transformed into One Shot Mach1-T1 competent E.coli (Invitrogen). Plasmid DNA from clones was sequenced to confirm correct ligation and the integrity of the full length MUC1/A sequence in pCDNA3.

Transfection of COS-7 cells: Cells were seeded in six-well plates at a density of $1 \times 10^{5}$ cells/well. Cells were transfected with $1 \mu \mathrm{g}$ of MUC1/A, MUC1/B, MUC1 $\Delta \mathrm{EX}$ or pCDNA3 (empty vector, EV) using FuGENE 6 reagent (Roche).

FACS: Transfected COS-7 cells were harvested at 24,48 and $72 \mathrm{~h}$ and stained using M2 anti-FLAG antibody (M2, Sigma) diluted in PBS containing $5 \%$ FBS and sodium azide. 
Stained cells were analyzed using a FACS calibur (Becton Dickinson). Cell Quest Software 1.2.2 was used for acquisition and analysis of each cell sample $(n=10,000)$.

WCE and western blotting: WCE were prepared by incubating the cells for $30 \mathrm{~min}$ in lysis buffer (20 mM Tris pH 7.5, $150 \mathrm{mM} \mathrm{NaCl}, 1 \%$ NP40 and 5mM EDTA pH 8.0) containing protease inhibitors (Roche). Protein concentrations were determined by a Bradford assay (BioRad). Proteins were separated on $14 \%$ Tris-Glycine gels (Invitrogen) and transferred to PVDF membranes (Millipore). The membranes were blocked $5 \%$ nonfat milk in PBS-T (0.1\% Tween20) and immunoblotted with the indicated antibodies. Armenian hamster against MUC1-CD (CT2, Thermo Scientific), $\beta$-actin (Sigma), TGF $\beta$ (Cell Signaling), DF3 against MUC1-N (Signet). HyGlo chemiluminescent HRP antibody detection reagent (Denville Scientific) was used to detect protein bands. The membranes were visualized on Kodak Biomax ML film (VWR). Resulting immunoblots were scanned using a Microtek ScanMaker i800 scanner (Carson). Un-Scan-It 6.1 for Windows (Silk Scientific) was used to quantitate the integrated optical densities (IOD) for each band and analyze the relative amounts of immunoreactive protein, based on pixel density as previously described (133).

Immunofluorescence: Cells were seeded onto glass coverslips and allowed to grow overnight to approximately $50 \%$ confluency. Cells were transfected with $\mathrm{MUC1} / \mathrm{A}$, MUC1/B, MUC1 $\triangle \mathrm{EX}$ or pCDNA3 (empty vector) as above. Cells were washed once with PBS and chilled on ice for 10 min. The cells were then incubated in cold $5 \%$ MEM with M2 anti-FLAG antibody (Sigma) at a dilution of 1:1000 for $1 \mathrm{~h}$ at $4{ }^{\circ} \mathrm{C}$. After 
incubation with the primary antibody the cells were washed three times with ice-cold $5 \%$ MEM followed by incubation with goat anti-mouse DyLight 488 conjugated (Invitrogen) and wheat germ agglutinin (WGA) Alexa Fluor 633 conjugated (Invitrogen), both diluted 1:200 in cold $5 \%$ MEM. After incubation in secondary antibody, the cells were washed three times with cold PBS and fixed on ice for $15 \mathrm{~min}$ in $4 \%$ para-folmaldehyde. The cells were then washed once in PBS and mounted with ProLong Anti-fade (Invitrogen). Images were captured using an Olympus FV1000 confocal microscope. Imaging was performed with appropriate single-color controls with individual channels recorded sequentially.

RNA isolation, RT-PCR, and quantitative real-time RT-PCR (QRT-PCR): Total RNA was extracted using RNeasy microcolumns (QIAGEN) according to the manufacturer's protocols. Reverse transcription was performed by using random hexamers and the HighCapacity cDNA Archive Kit (Applied Biosystems). QRT-PCR was performed with the ABI PRISM 7900 SDS 2.1 (Applied Biosystems) by relative quantification with standard thermal cycler conditions. TaqMan primers and probes for IL-1 $\beta$, IL-8, TGF $\beta$, PDCD4 and control gene 18S rRNA were purchased as Assays-on-Demand Gene Expression Products (Applied Biosystems). Expression of each target gene was determined in triplicate and normalized to $18 \mathrm{~S}$ rRNA. Analysis and fold differences were determined using the comparative $\mathrm{C}_{\mathrm{T}}$ method. Unless otherwise indicated fold change was calculated from the $\Delta \Delta C_{\mathrm{T}}$ values with the formula $2^{-\Delta \Delta C_{\mathrm{T}}}$. Experiments were repeated 3-4 times and values averaged. 
MTT Assays: COS-7 cells seeded onto $96-w e l l$ plates at a density of 2000 cells/well and allowed to grow overnight. Cells were transfected in quadruplicate with $0.05 \mu \mathrm{g}$ plasmid DNA: EV, MUC1/A, or MUC1/B using FuGENE HD (Roche). Cell proliferation was determined using the CellTiter $96{ }^{\circledR} \mathrm{AQ}^{\text {ueous }}$ One solution Cell proliferation Assay (Promega) following the manufacturer's protocol. The absorbance was recorded at $490 \mathrm{~nm}$ using a SpectraMax M2 microplate reader (Molecular Devices).

ELISA: COS-7 cells were transfected with EV, MUC1/A, MUC1/B or MUC1 $\triangle E X$ expression vectors in six-well plates. After $48 \mathrm{~h}$ incubation, cells were treated with 10 $\mathrm{ng} / \mathrm{ml} \mathrm{TNF} \alpha$ (Prepotech) for $24 \mathrm{~h}$ and media was collected. The media was concentrated using Amicon ultra 10K centrifugation columns (Millipore). IL-8 quantification was performed using a kit from BD Biosciences and following manufacturer's protocol.

NF-kB Luciferase reporter assay: COS-7 cells were seeded in 24-well plates at a density of $2.5 \times 10^{4}$ cells/well and transfected as described above. Each well received $250 \mathrm{ng}$ of a NF- $\mathrm{kB}$ luciferase reporter (Promega), $5 \mathrm{ng}$ of a Renilla luciferase reporter (pRL-tk) from Promega and $500 \mathrm{ng}$ plasmid DNA for $\mathrm{EV}, \mathrm{MUC1} / \mathrm{A}, \mathrm{MUC1} / \mathrm{B}$ or $\mathrm{MUC1} \triangle \mathrm{EX}$. Forty-eight $\mathrm{h}$ after transfection, triplicate wells were left untreated or treated with 1 or 10 $\mathrm{ng} / \mathrm{ml} \mathrm{TNF} \alpha$. The cells were harvested 4 and $24 \mathrm{~h}$ after treatment using Promega's Passive Lysis buffer. Luciferase and Renilla luciferase activities were determined using Promega's Dual Luciferase assay in a Plate Chameleon luminometer (BioScan, Washington, DC). Firefly luciferase was normalized by Renilla luciferase to correct for transfection efficiency. Fold induction was determined by dividing the averaged 
normalized values from each treatment by the untreated value for each transfection condition.

miRNA isolation and QRT-PCR: COS-7 cells were seeded in six-well plates at a density of $1 \times 10^{5}$ cells/well and transfected as described above. After $48 \mathrm{~h}$ incubation, cells were treated with $10 \mathrm{ng} / \mathrm{ml} \mathrm{TNF} \alpha$ (Prepotech) for $24 \mathrm{~h}$. miRNA-enriched total RNA was extracted from cells using the miRCURYmiRNA isolation kit (Exiqon). The quality and quantity of the isolated RNA was analyzed using a NanoDrop spectrophotometer and Agilent Bioanalyzer. cDNA was synthesized using the miRCURY LNA ${ }^{\mathrm{TM}}$ first strand cDNA synthesis kit (Exiqon) and QPCR performed using the miRCURY LNA ${ }^{\mathrm{TM}}$ SYBR Green master mix (Exiqon) using the miRNA primer set for miR-21 (Exiqon). 5S RNA was used for normalization of miRNA expression. Analysis and fold change was determined using the comparative threshold cycle $(\mathrm{Ct})$ method. The change in miRNA expression was calculated as fold-change, i.e., relative to untreated (control).

MUC1 ectodomain release: Conditioned media was collected from transfected COS-7 grown in six-well plates and treated with various concentrations of TNF $\alpha$ for 24 h. $500 \mu l$ of media was concentrated to $15 \mu \mathrm{l}$ using Amicon ultra $10 \mathrm{~K}$ columns (Millipore). $13 \mu 1$ of conditioned media was separated on $3-8 \%$ Tris-acetate gels (Invitrogen) and immunoblotted with DF3 Mab (Signet) to MUC1-N. 
Statistical analyses: Results are expressed as mean \pm S.E.M of 3-5 independent experiments in which each treatment was done in triplicate. Student's $t$ test was performed when indicated. $p<0.05$ was considered significant.

\section{Results}

\section{Expression of MUC1/A and MUC1/B Splice Variants in COS-7 cells}

To determine the functional consequence of the extra 9 aa present at the MUC1-N domain of MUC1/A, the additional $27 \mathrm{bp}$ from the exon 1-2 junction and SNP in exon 2 was successfully inserted into the MUC1/B vector (134) (Fig. 15A). The FLAG tag was preserved in the MUC1/A construct for ease of screening. The MUC1 $\mathrm{EX}$ expression vector was used to determine the contribution of the MUC1-N domain in the regulation of inflammatory cytokine production. As shown in Fig. $15 A \mathrm{MUCl} \triangle \mathrm{EX}$ lacks most of the MUC1-N.

Although previous investigators showed that MUC1/B was correctly localized to the plasma membrane (PM) (134), this is the first evaluation of the cellular localization and function of the MUC1/A splice variant. To compare the cellular distribution of MUC1/A and MUC1/B, COS-7 cells (MUC1-null) were transiently transfected with each

construct. The transfection efficiency and MUC1/A and MUC1/B protein expression levels were determined by flow cytometry using the FLAG antibody (Fig. 15B) and western blot using an antibody specific for the MUC1-CD (Fig. 15C). Cell surface MUC1/A and MUC1/B expression was detected in $~ 20-35 \%$ of the cells $24-72 \mathrm{~h}$ after 


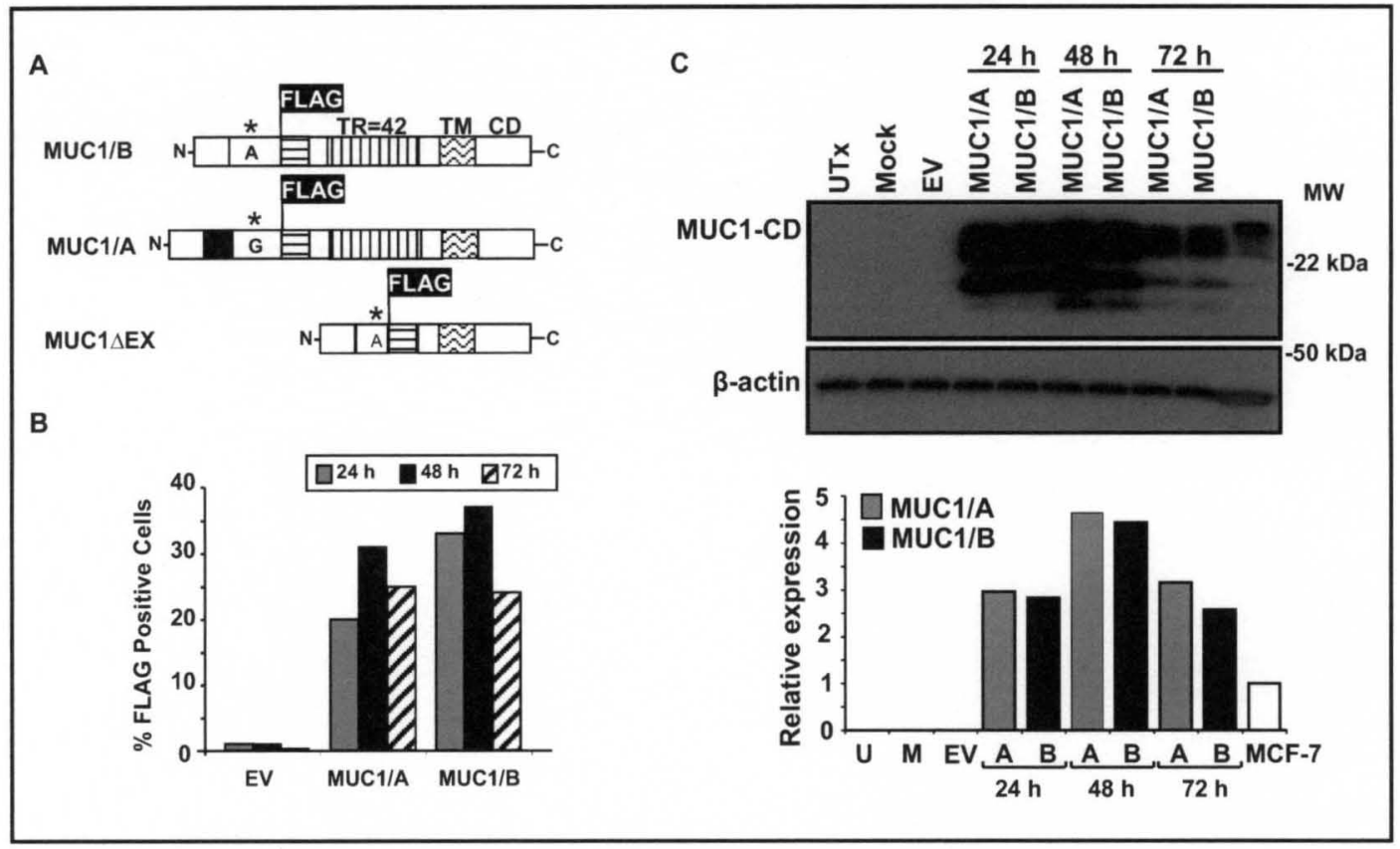

Figure 15. Expression of MUC1/A and MUC1/B in COS-7 cells. (A) Schematic diagram of $\mathrm{MUC1} / \mathrm{A}, \mathrm{MUC1} / \mathrm{B}$ and $\mathrm{MUC1} 1 \mathrm{EX}$ constructs used for transfection of COS7 cells. The insertion of the FLAG tag within the N-terminal domain (NTD) is indicated. There are 42 tandem repeats (TR) in both MUC1/A and MUC1/B whereas MUC1 $\triangle \mathrm{EX}$ lacks the tandem repeat. The transmembrane (TM) and C-terminal domains (CD) are indicated. * indicates the SNP and nucleotide change between MUC1/B and MUC1/A. The black box indicates the additional $27 \mathrm{bp}$ in MUC1/A. (B) Flow cytometry analysis of FLAG expression in COS-7 cells 24, 48 and $72 \mathrm{~h}$ post-transfection using M2 anti-FLAG antibody and PE-conjugated secondary antibody. Values are from one representative FACS analysis. (C) Western analysis of MUC1 protein expression in WCE from COS-7 cells either untransfected (UTx), transfected with the empty vector (EV), a mock control (no DNA), or expression vectors for MUC1/A or MUC1/B for 24, 48 and $72 \mathrm{~h} .6 \mu \mathrm{g}$ of WCE from MCF-7 cells was loaded into the far right lane as a positive control for MUC1. The blot was probed with CT2 anti-MUC1 antibody (Labvision) and $\beta$-actin (Sigma) which was used as a loading control. The bar graph shows the quantitation of MUC1/A and MUC1/B relative to $\beta$-actin expression relative to MCF-7 that was set to one for comparison. 
transfection (Fig. 15B). These results indicate that MUC1/A and MUC1/B localized to the PM, as seen for native MUCl/B in epithelial cells (135). Western blots of whole cell extracts showed that the levels of $\mathrm{MUCl} / \mathrm{A}$ and $\mathrm{MUC1}$ /B protein expression in COS-7 cells 24,48 and $72 \mathrm{~h}$ post-transfection were similar (Fig. 15C), confirming the FACS data. The expression of endogenous MUC1 in MCF-7 human breast cells, which have high MUC1 expression (136), is shown for comparison. The highest expression of MUC1/A and MUC1/B was achieved $48 \mathrm{~h}$ after transfection. Thus, this time of transfection was used for further experiments to characterize MUC1/A and MUC1/B function. Overexpression of MUC1/A and MUC-1B had no effect on COS-7 viability (Fig. 16).

To further evaluate PM localization of MUC1/A and MUC1/B, immunohistochemistry was performed on nonpermeabilized COS-7 cells using an antiFLAG antibody and Alexa-Flour-conjugated wheat germ agglutinin (WGA) as a PM marker. The PM localization of the MUC1 $\triangle \mathrm{EX}$ protein was evaluated in parallel. The MUC1 $1 \mathrm{EX}$ expression vector contains the transmembrane domain (Fig. 15A) and is therefore expected to localize to the PM; however no one has evaluated the cellular localization of MUC1 $\triangle \mathrm{EX}$. As shown in Figure 17, MUC1/A, MUC1/B and MUC1 $1 \mathrm{EX}$, all localize to the PM of COS-7 cells as indicated by the overlap in signal (yellow) with WGA. No difference was observed between MUC1/A, MUC1/B and MUC1 $\triangle \mathrm{EX}$ protein localization. The empty vector (EV, negative control) control panel demonstrates the specificity of the FLAG antibody. 


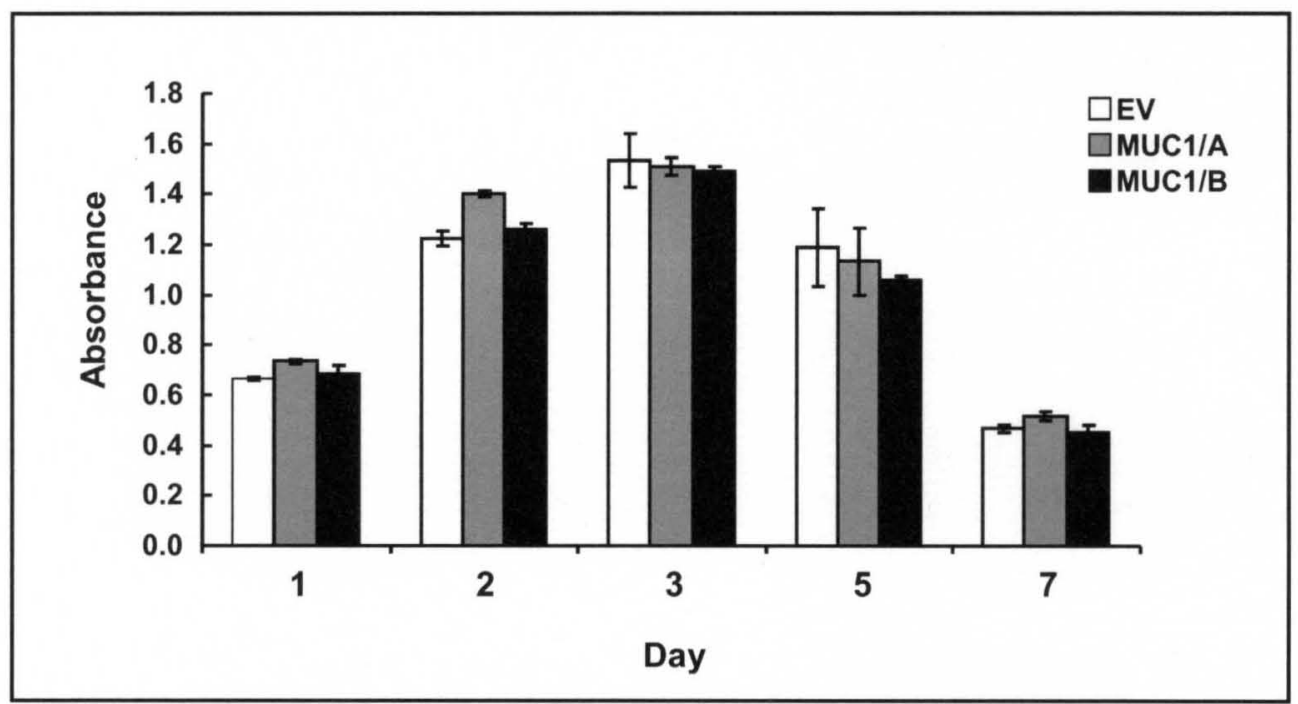

Figure 16. Expression of MUC1/A and MUC1/B in COS-7 cells does not affect cell viability. COS-7 cells were transfected with the empty vector (EV), MUC1/A, or MUC1/B. After 1, 2, 3, 5, and 7 days, cell viability was measured by MTT assay. Values are the average of quadruplicate determinations within one experiment \pm SEM. This experiment is representative of two experiments that showed similar results. 


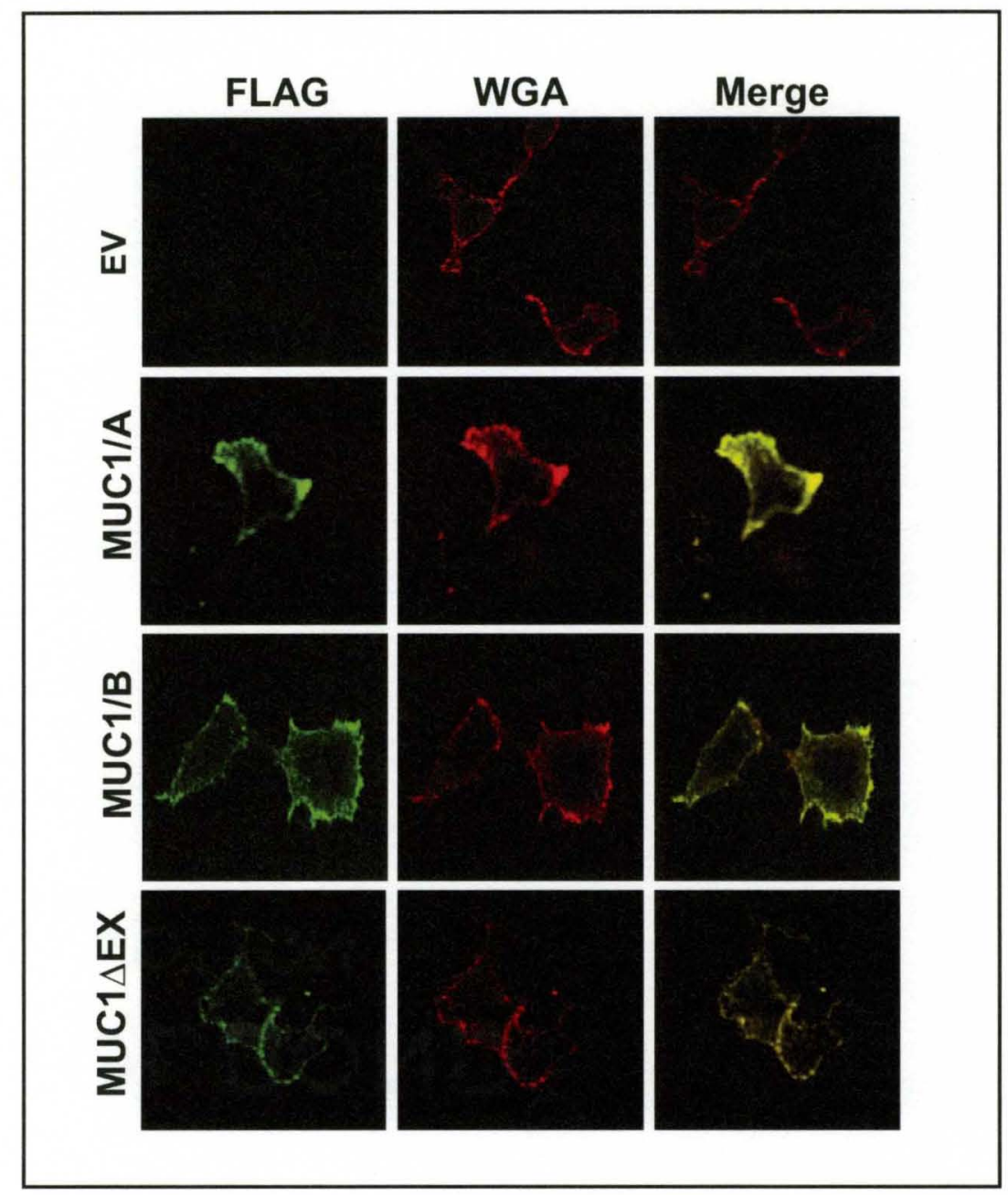

Figure 17. Surface expression of MUC1/A and MUC1/B in COS-7 cells. COS-7 cells were transfected with the empty vector ( $\mathrm{EV}$, negative control), $\mathrm{MUC1} / \mathrm{A}, \mathrm{MUC1} / \mathrm{B}$, or MUC1 $1 \mathrm{EX}$ as described in Materials and methods. Forty-eight hours after transfection, the cells were stained with the M2 anti-FLAG antibody (green) and Wheat Germ Agglutinin (WGA, red) as a plasma membrane marker. Images were captured using an Olympus FV1000 confocal microscope. The colocalization of FLAG and WGA is indicated in yellow in the merged image. 


\section{Regulation of the Inflammatory Response by MUC1/A and MUC1/B}

Previous research indicates that $\mathrm{MUC1} / \mathrm{B}$ has both anti-inflammatory and proinflammatory properties $(67 ; 69 ; 137)$. To determine if MUC1/A and MUC1/B differentially modulate inflammatory responses, COS-7 cells were transfected with EV, as a negative control, MUC1/A, MUC1/B or MUC1 $\triangle \mathrm{EX}$ for $48 \mathrm{~h}$. Cells were treated with $10 \mathrm{ng} / \mathrm{ml} \mathrm{TNF} \alpha$ for 4 and $24 \mathrm{~h}$ to initiate the inflammatory response $(138 ; 139)$. QRT-PCR was used to determine the mRNA levels of pro-inflammatory cytokines known to be induced by TNF $\alpha$ : IL-1 $\beta$ (140) and IL-8 (141). Because IL- 8 and TNF $\alpha$ are increased in the tears of patients with dry eye disease $(142 ; 143)$, IL-8 regulation by MUC1 splice variants is relevant to this study. COS-7 cells transfected with EV and then treated with TNF $\alpha$ exhibited a 12- and 40-fold increase in IL-1 $\beta$ and IL-8 mRNA at $4 \mathrm{~h}$, respectively (Fig. 18A). There was a statistically significant decrease in $4 \mathrm{~h} \mathrm{TNF} \alpha-$ induced IL-1 $\beta$ and IL-8 expression in COS-7 cells expressing either MUC1/B or MUC1 $1 \mathrm{EX}$ compared to the EV control. In contrast, MUC1/A-expressing cells did not attenuate the induced expression of IL- $1 \beta$ after 4 hrs of TNF $\alpha$. At the $4 \mathrm{~h}$ time point, the TNF $\alpha$-induced expression of IL-8 was also inhibited in MUC1/A expressing cells compared to EV. After $24 \mathrm{~h}$ of TNF $\alpha, \mathrm{COS}-7$ cells expressing MUC1/A exhibited an increase in IL-1 $\beta$ and IL-8 compared to EV-transfected cells. Interestingly, MUC1/B or MUC1 $\triangle \mathrm{EX}$ no longer inhibited the induction of IL-1 $\beta$ and IL-8 mRNA after $24 \mathrm{~h}$ TNF $\alpha$ treatment.

To confirm the differential regulation of IL-8 expression by MUC1/A and MUC1/B, the amount of IL-8 protein released into the media of transfected COS-7 cells was examined $24 \mathrm{~h}$ after TNF $\alpha$ treatment (Fig. 18B). Cells transfected with MUC1/A 


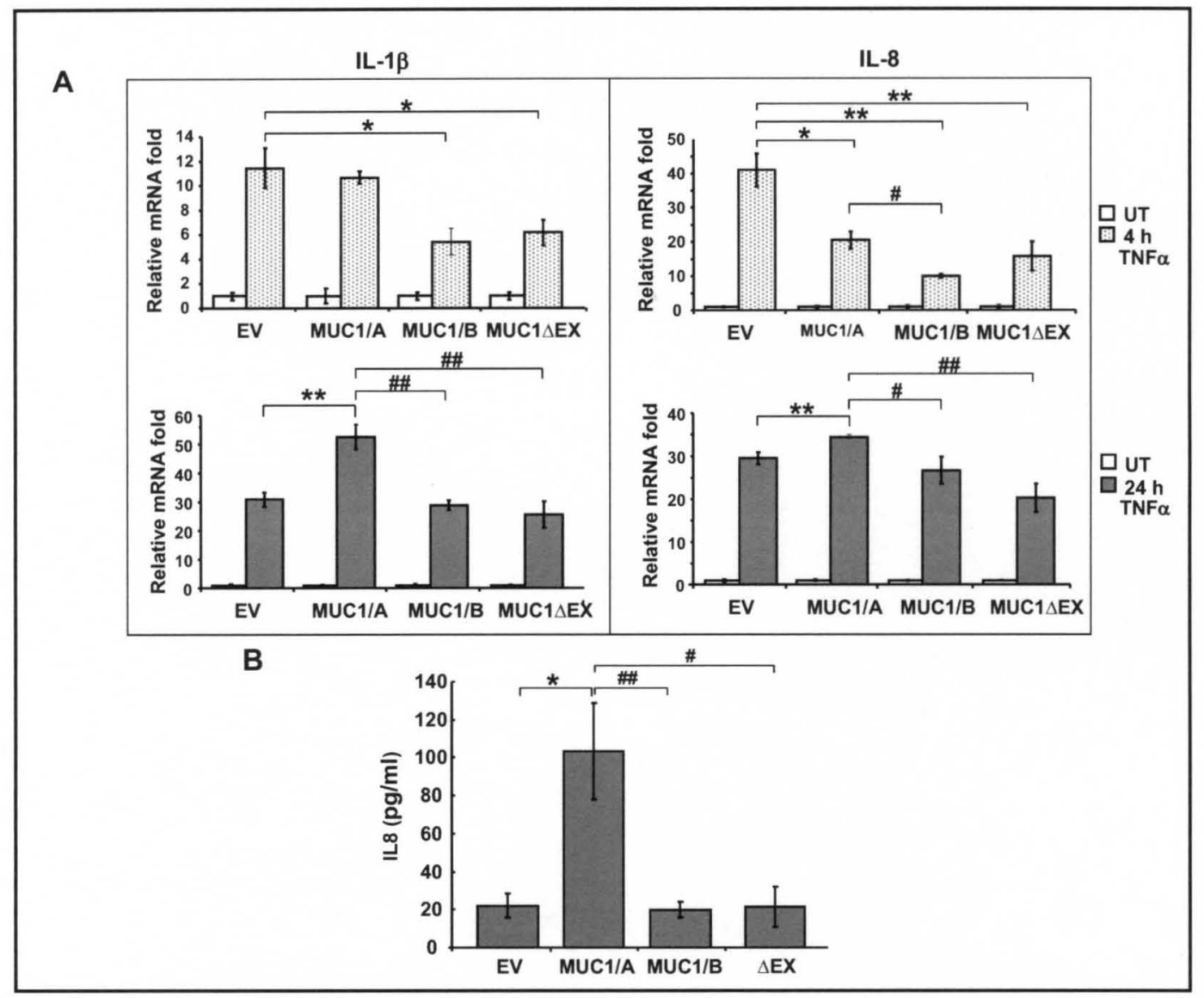

Figure 18. MUC1/A and MUC1/B differentially regulate IL-1 $\beta$ and IL-8 expression. COS-7 cells were transfected with empty vector (EV), MUC1/A, MUC1/B, or MUC1 $\triangle E X$ for $48 \mathrm{~h}$. Cells were left untreated (UT) or treated with $10 \mathrm{ng} / \mathrm{ml} \mathrm{TNF} \alpha$ for 4 and $24 \mathrm{~h}$. (A) QRT-PCR analysis of IL-1 $\beta$ or IL-8 mRNA was performed. TNF $\alpha$ induced expression in EV-transfected cells at $4 \mathrm{~h}$ was set to one for comparison. There was $~ 12$-fold induction of IL-1 $\beta$ and 40 -fold induction of IL-8 with TNF $\alpha$ treatment relative to basal. (B) COS-7 cells were treated for $24 \mathrm{~h}$ with $10 \mathrm{ng} / \mathrm{ml} \mathrm{TNF} \alpha$. IL-8 protein levels were measured in the cultured media by ELISA. Values in panels A and B are the mean \pm SEM of $3-5$ experiments. *, $\mathrm{p}<0.05$ compared to EV. ${ }^{* *}, \mathrm{p}<0.001$ compared to EV. \#, $\mathrm{p}<0.05$ compared to $\mathrm{MUC1} / \mathrm{A}$. \#\#, $\mathrm{p}<0.001$ compared to $\mathrm{MUC1} / \mathrm{A}$. 
released 5-fold more IL-8 protein compared to cells transfected with the EV control. No change in IL-8 protein secretion was observed in cells expressing $\mathrm{MUC1} / \mathrm{B}$ or MUC1 $\triangle E X$ compared to EV. These data agree with the $24 \mathrm{~h}$ mRNA data for IL- 8 shown in Fig. $18 \mathrm{~A}$.

\section{MUC1/A Increases Basal TGF $\beta$ mRNA and Protein Expression}

MUC1 exerts anti-inflammatory activity in response to Pseudomonas aeruginosa in vivo and in vitro $(65 ; 137 ; 144)$. Because TGF $\beta$ is a potent anti-inflammatory cytokine (145), we examined whether MUC1/A and MUC1/B regulate TGF $\beta$ expression. Interestingly, MUC1/A overexpression in COS-7 cells significantly increased basal TGF $\beta$ mRNA levels (Fig. 19A). In contrast, no change in basal TGF $\beta$ mRNA was detected in MUC1/B or MUC1 $\triangle \mathrm{EX}$ overexpressing cells. TNF $\alpha$ increased TGF $\beta$ mRNA

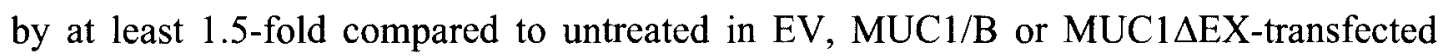
cells, but not in MUC1/A-transfected cells. TNF $\alpha$-induced levels of TGF $\beta$ mRNA were comparable in EV, MUC1/B or MUC1 $\triangle \mathrm{EX}$ transfected cells. Western blot analysis of the TGF $\beta$ precursor protein revealed an increase in basal TGF $\beta$ protein in the MUC1/Atranfected COS-7 cells compared to $\mathrm{EV}-, \mathrm{MUCl} / \mathrm{B}$ - and $\mathrm{MUC1} \Delta \mathrm{EX}$ - transfected cells (Fig. 19B). These data demonstrate that changes in the structure of the MUC1 extracellular domain (MUC1-N) alter downstream signaling resulting in differential regulation of basal and TNF- $\alpha$ induced TGF $\beta$ expression. 


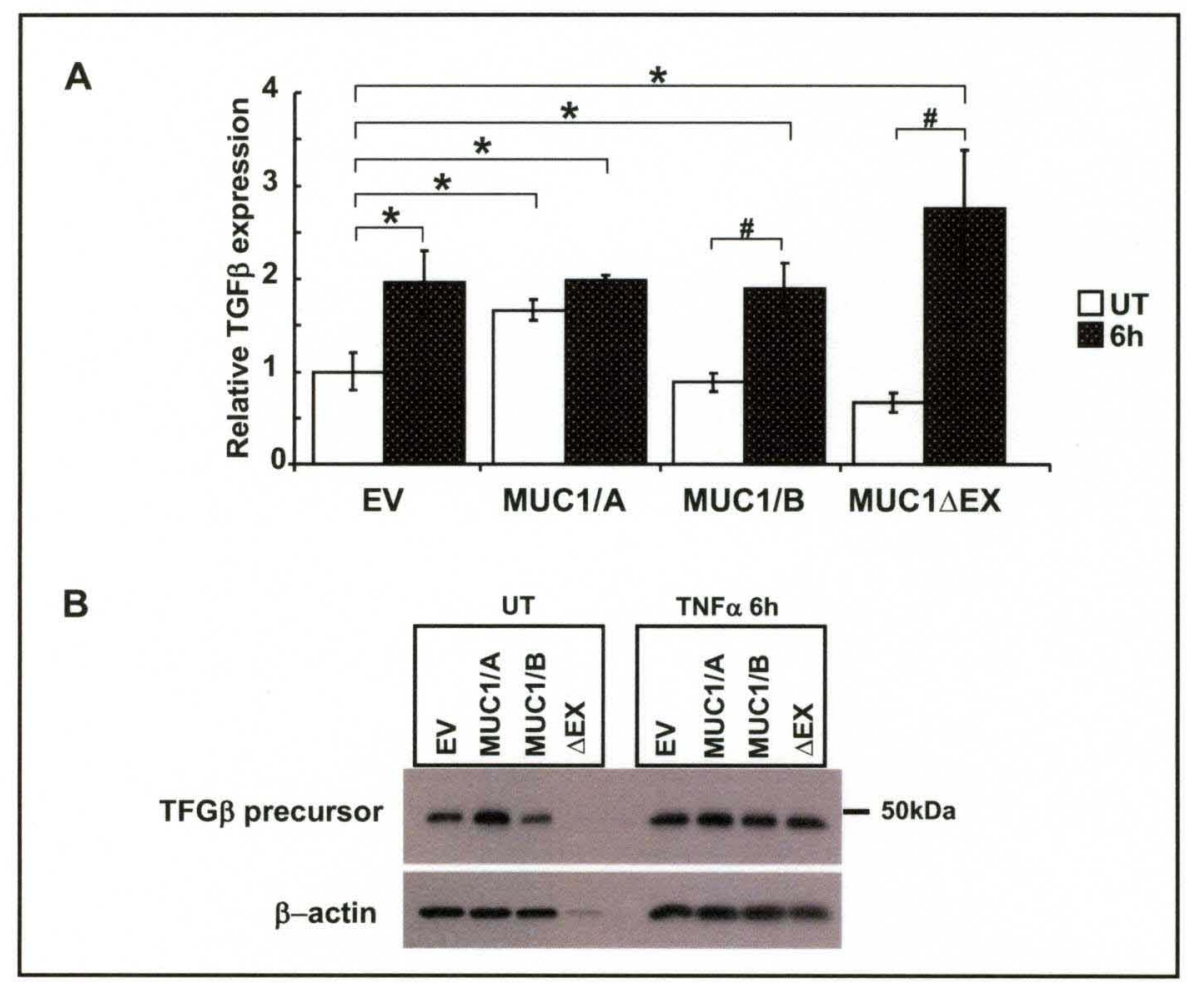

Figure 19. MUC1/A stimulates TGF $\beta$ expression. COS-7 cells were transfected with $\mathrm{EV}$ control, $\mathrm{MUC1} / \mathrm{A}, \mathrm{MUC1} / \mathrm{B}$, or MUC1 $\triangle \mathrm{EX}$ for $48 \mathrm{~h}$ prior to treatment with $10 \mathrm{ng} / \mathrm{ml}$ $\mathrm{TNF} \alpha$ for $6 \mathrm{~h}, \mathrm{UT}=$ untreated. (A) QRT-PCR analysis of TGF $\beta$ mRNA was performed. TGF $\beta$ expression in EV-transfected/UT cells was set to one for comparison. Values are the mean \pm SEM of 3 experiments. ${ }^{*}, \mathrm{p}<0.05$ compared to EV-UT. \#, $\mathrm{p}<0.05$ compared to $\mathrm{MUC1} / \mathrm{B}$ or MUC1 $\triangle \mathrm{EX}$ UT. (B) Western blot analysis of TGF $\beta$ precursor expression in WCE $(6 \mu \mathrm{g})$. The blot was probed with TGF $\beta$ antibody (Cell Signaling) and then stripped and reprobed for $\beta$-actin as a loading control. This blot is representative of two blots that showed the same results. 


\section{Regulation of NF-kB-Luciferase Reporter by MUC1/A and MUC1/B}

TNF $\alpha$ activation of NF- $\kappa B$ induces IL- $1 \beta$ and IL- 8 transcription. To determine if MUC1/A and MUC1/B affect NF- $\mathrm{B}$ activation, a NF- $\mathrm{B}$ luciferase reporter assay was performed in COS-7 cells transfected with $\mathrm{EV}, \mathrm{MUC1} / \mathrm{A}, \mathrm{MUC1} / \mathrm{B}$ or MUC1 $\mathrm{EX}$ (Fig 20). As expected, TNF $\alpha$ increased NF- $\mathrm{KB}$ luciferase reporter activity in a concentrationdependent manner in cells treated for 4 or $24 \mathrm{~h}$ with TNF $\alpha$. MUC1/B overexpressing cells showed reduced TNF $\alpha$-induced reporter activity when treated with $1 \mathrm{ng} / \mathrm{ml}$ TNF $\alpha$ for $4 \mathrm{~h}$ compared to the EV control. With $10 \mathrm{ng} / \mathrm{ml} \mathrm{TNF} \alpha$, both MUC1/A and MUC1/B overexpressing cells showed inhibition of the NF- $\mathrm{KB}$ reporter activity compared to EV at $4 \mathrm{~h}$. Interestingly, MUC1 $\triangle \mathrm{EX}$ overexpression did not inhibit the NF-kB luciferase response, suggesting that the extracellular domain is required to inhibit the NF- $\mathrm{B}$ response. When COS-7 cells were incubated with 1 or $10 \mathrm{ng} / \mathrm{ml}$ TNF $\alpha$ for $24 \mathrm{~h}$, similar responses to the $4 \mathrm{~h}$ were observed. MUC1/B significantly inhibited 1 and $10 \mathrm{ng} / \mathrm{ml}$ TNF $\alpha$ - activated NF- $\kappa B$ luciferase activity, whereas MUC1/A increased the NF- $\mathrm{B}$ luciferase activity at $1 \mathrm{ng} / \mathrm{ml}$ but had no effect at $10 \mathrm{ng} / \mathrm{ml}$. These results are in agreement with the IL-1 $\beta$ and IL- 8 mRNA expression results showing an inhibition of IL- $1 \beta$ and IL- 8 by MUCl/B at $4 \mathrm{~h}$.

\section{Regulation of microRNA miR-21 by MUC1/A and MUC1/B}

A recent report showing that IL-1 $\beta$ and TNF $\alpha$ induced miR-21 expression via NF- $\mathrm{KB}$ activation in pancreatic cancer cells (146) prompted us to examine if MUC1/A or MUC1/B would affect TNF $\alpha$-induced miR-21 expression. miR-21 is an oncomir and has also been shown to be upregulated by ERK activation in cardiac fibroblasts 


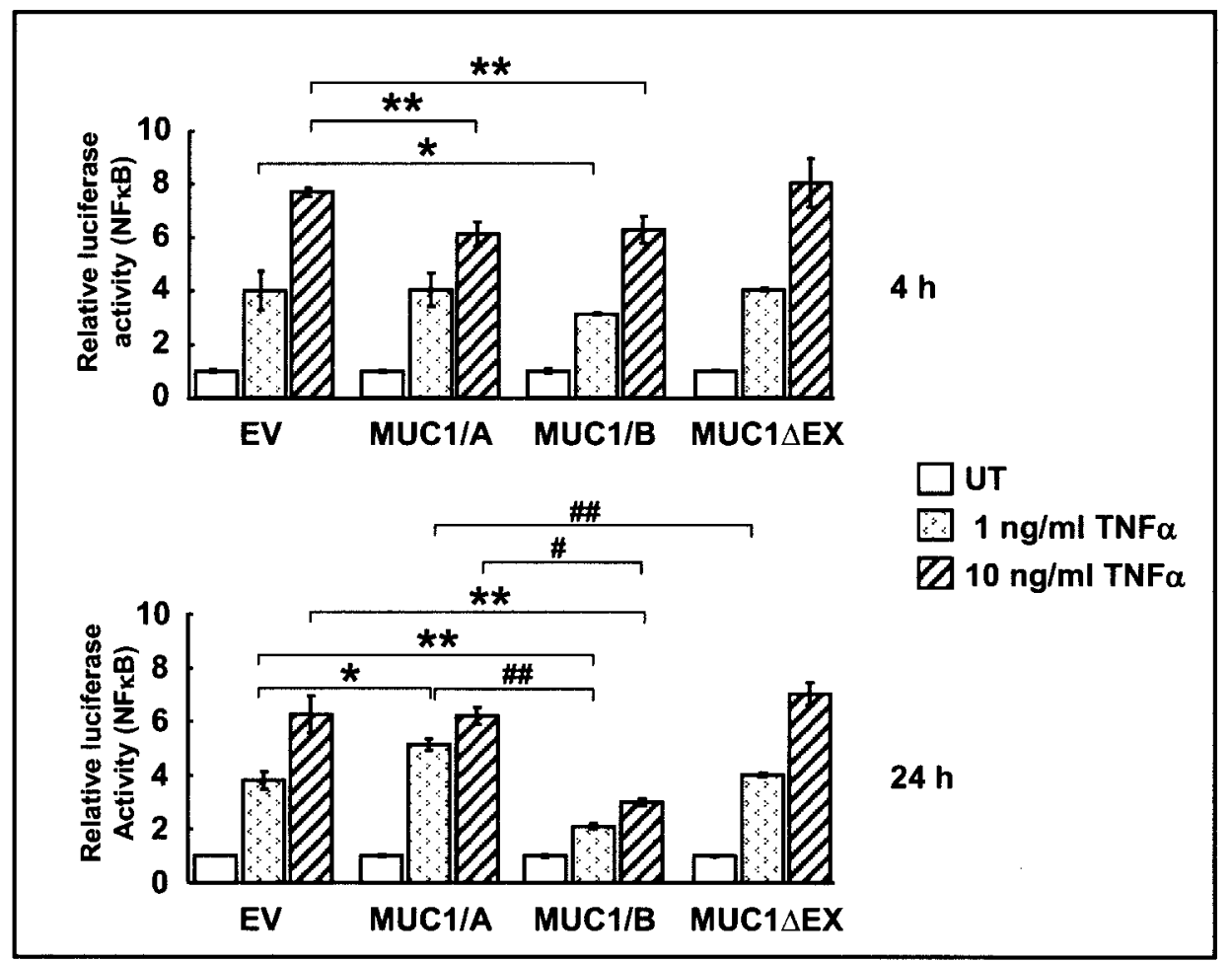

Figure 20. Effect of MUC1/A and MUC1/B overexpression in TNF $\alpha$-induced NFkB activation. COS-7 cells were transfected with $250 \mathrm{ng}$ of a NF-kB luciferase reporter (Promega), $5 \mathrm{ng}$ of a Renilla luciferase reporter (pRL-tk) from Promega and $500 \mathrm{ng}$ plasmid DNA for EV, MUC1/A or MUC1/B. Forty-eight hours after transfection, wells were left untreated (UT) or treated with 1 or $10 \mathrm{ng} / \mathrm{ml}$ TNF $\alpha$. The cells were harvested at 4 and $24 \mathrm{~h}$ after treatment. Luciferase and Renilla luciferase activities were determined. Values were calculated as described in Material and Methods and are the mean \pm SEM of 3 experiments. *, $\mathrm{p}<0.05$ compared to EV. ${ }^{* *}, \mathrm{p}<0.001$ compared to EV. \#, $\mathrm{p}<0.05$ compared to MUC1/A. \#\#, $\mathrm{p}<0.001$ compared to MUC1/A. 
(147). Because our data show that MUC1/B inhibits TNF $\alpha$-induced IL-1 $\beta$ expression at $4 \mathrm{~h}$, we hypothesized that MUC1/B will abrogate the induction of miR-21 by TNF $\alpha$. The results agreed with the predicted outcome: MUC1/B inhibited TNF $\alpha$-induced miR-21 expression at $24 \mathrm{~h}$ (Fig. 21A). Surprisingly, MUC1/A also inhibited the TNF $\alpha$-induced miR-21 up-regulation, but to a lesser extent than MUC1/B.

We next examined if the regulation of miR-21 by MUC1/A and MUC1/B leads to changes in genes that are downstream of miR-21. Established gene targets of miR-21 regulation include programmed cell death 4 (PDCD4) (148). Based on the inhibition of miR-21 in cells expressing MUC1/A and MUC1/B, we hypothesized that PDCD4 inhibition will be blocked in these cells. Figure $21 B$ shows that MUC1/A and MUC1/B reduced basal $P D C D 4$ expression and blocked the suppression of $P D C D 4$ detected in TNFa-treated cells. The reduction in PDCD4 is commensurate with the increase in miR21 seen in TNF $\alpha$-treated-EV-transfected cells (Fig. 21 $A$ ). Together, these data indicate that both $\mathrm{MUC1} / \mathrm{A}$ and $\mathrm{MUC1} / \mathrm{B}$ inhibit $\mathrm{TNF} \alpha$-induced miR-21 expression and thus ameliorate the blockade of PDCD4 expression. PDCD4-/- mice show reduced inflammatory responses indicating that PDCD4 promotes inflammation (149). The ability of MUC1/A and MUC1/B to suppress basal PDCD4 expression may inhibit inflammation.

\section{MUC1 Ectodomain Release}

The MUC1-N, also called the ectodomain, is shed into the media from human corneal limbal epithelial cell line (HCLE) and human uterine epithelial cells (HES) under normal conditions as well as in response to specific stimuli including TNF $\alpha(139 ; 150)$. 


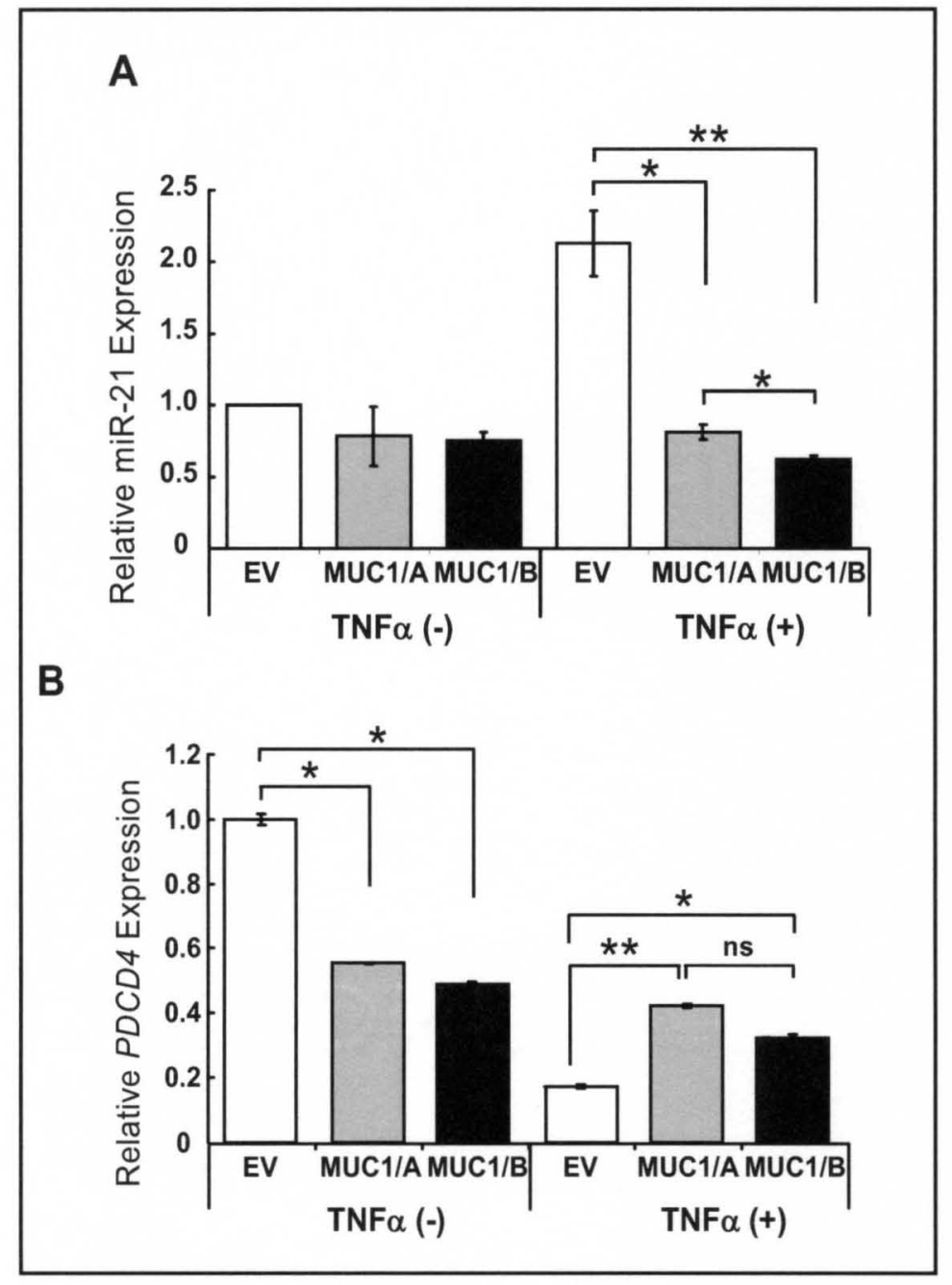

Figure 21. MUC1/A and MUC1/B inhibit TNF $\alpha$-induced miR-21 expression. COS7 cells transfected with EV, MUC1/A or MUC1/B were treated with $10 \mathrm{ng} / \mathrm{ml} \mathrm{TNF} \alpha$ for $24 \mathrm{~h}$. (A) QRT-PCR for mature miR-21 was quantified using 5S rRNA for normalization. (B) QRT-PCR for PDCD4 mRNA was normalized to $18 \mathrm{~S}$ rRNA. Values are the avg. +/SEM from triplicate determinations in one experiment. 
Since MUC1/A and MUC1/B differ in their ability to regulate the induction of inflammatory cytokines, MUC1/A and MUC1/B ectodomain release was examined to determine if these variants differ in ectodomain shedding. Figure 22 shows the amount of MUC1-N released into the media of transfected cells, either untreated or treated with 1 or $10 \mathrm{ng} / \mathrm{ml} \mathrm{TNF} \alpha$ for $24 \mathrm{~h}$. There was an increase in the amount of MUC1-N released into the media from cells expressing MUC1/B and treated with $10 \mathrm{ng} / \mathrm{ml} \mathrm{TNF} \alpha$. In contrast, MUC1/A expressing cells did not increase the MUC1-N release in response to TNF $\alpha$ treatment. There was no significant difference in the amounts of MUC1-N shed between cells transfected with $\mathrm{MUCl} / \mathrm{A}$ or $\mathrm{MUC1} / \mathrm{B}$; however, there was a trend for higher MUC1/A ectodomain release in cells untreated or treated with $1 \mathrm{ng} / \mathrm{ml} \mathrm{TNF} \alpha$.

\section{Discussion}

We recently reported that $\mathrm{MUC1} / \mathrm{A}$ and $\mathrm{MUC1} / \mathrm{B}$ splice variants show different patterns of expression in conjunctival tissue from non-Sjögren's and evaporative dry eye compared to normal controls (44). The lack of expression of MUC1/A in samples from patients with non-Sjögren's dry eye disease indicates a possible protective role of MUC1/A in preventing the symptoms accompanying dry eye disease. The biological significance of these MUC1 splice variants and how they contribute to dry eye susceptibility remain to be elucidated. This report demonstrates for the first time that MUC1/A and MUC1/B differ in their ability to regulate the TNF $\alpha$-induced inflammatory responses. Whereas MUC1/B was previously reported to have anti-inflammatory activity 


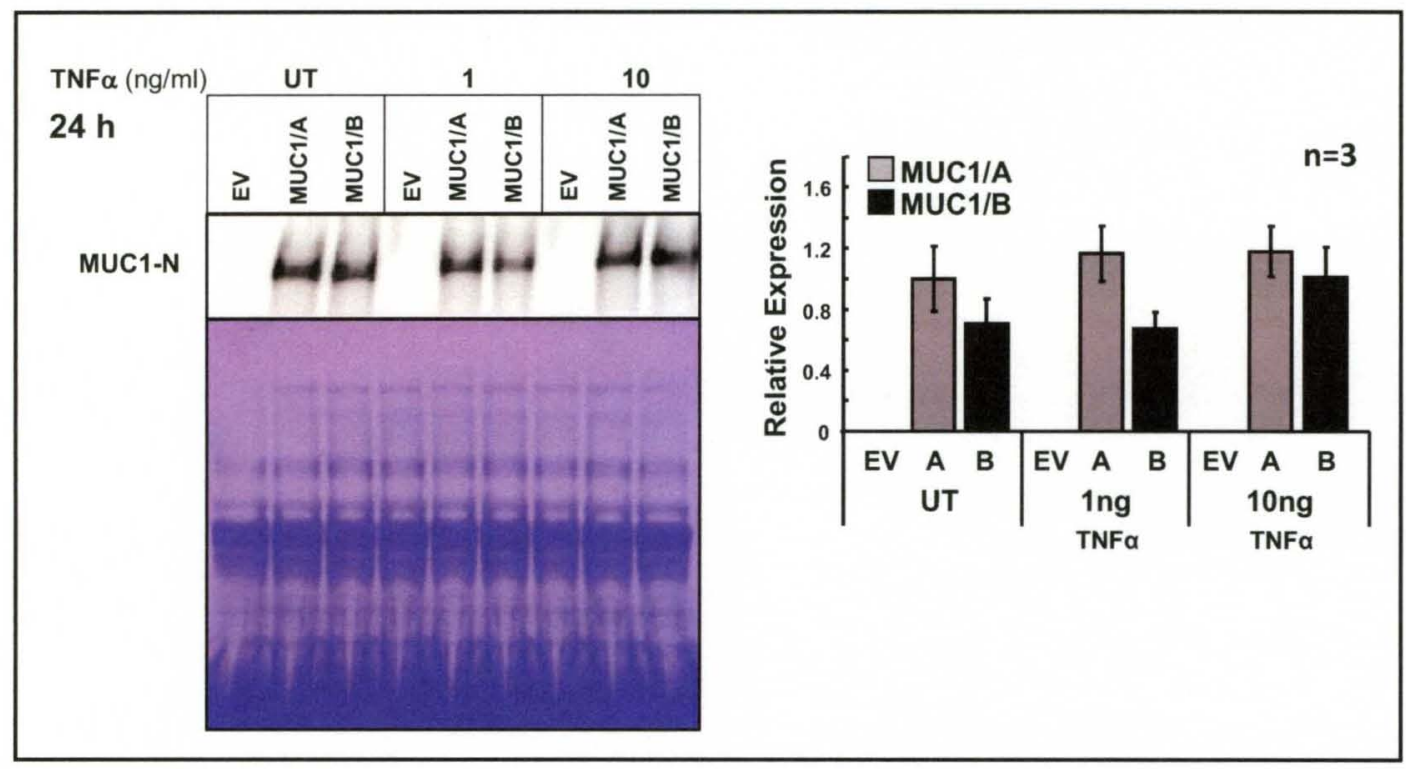

Figure 22. MUC1 ectodomain release in COS-7 cells transfected with MUC1/A or MUC1/B and treated with TNF $\alpha$. Conditioned media was collected COS-7 transfected with empty vector (EV), MUC1/A (A), or MUC1/B (B) grown in 6-well plates and treated with the indicated concentrations of TNF $\alpha$ for $24 \mathrm{~h}$. The media was concentrated and identical amounts were separated on 3-8 \% Tris-acetate gels. The immunoblots were probed with an antibody (DF3) to the extracellular domain of MUC1. To control for loading, an identical gel was stained with Coommassie blue. The graph represents the quantification of the MUC1-N bands normalized to the Coommassie net pixel intensity of the entire lane. Values are the average of 3 separate experiments \pm SEM. 
$(65 ; 144)$, this is the first report to demonstrate that the MUC1/A splice variant has a functional role in the regulation of cellular inflammation and that there are specific differences in the anti-inflammatory activities of these two splice variants. We observed that MUC1/B has greater efficacy in inhibiting the pro-inflammatory response induced by TNF $\alpha$ compared to MUC1/A. These data indicate that the insertion of 9 aa in the MUC1-N terminal domain forming MUC1/A alters the cell signaling properties of MUC1. Specifically, we demonstrated that, depending on the experimental conditions, MUC1/B inhibits the increase in IL-1 $\beta$ and IL-8 stimulated by TNF $\alpha$ whereas MUC1/A increases the expression of these two pro-inflammatory cytokines. Not all cellular responses are different between $\mathrm{MUC1} / \mathrm{A}$ and $\mathrm{MUC1} / \mathrm{B}$, e.g., both inhibit the induction of miR-21 by TNF $\alpha$ and inhibit basal PDCD4 expression. In addition, we demonstrate that MUC1/A, and not MUC1/B, increases basal TGF $\beta$ expression. To the best of our knowledge, this is the first report showing that MUC1 regulates TGF $\beta$ expression.

In patients with dry eye disease, the ocular surface is exposed to proinflammatory cytokines produced by infiltrating lymphocytes (151). Here, MUC1/B expression in COS-7 cells blocked the TNF $\alpha$-mediated increase in the transcription of pro-inflammatory cytokines IL-1 $\beta$ and IL-8. These findings are consistent with a report showing that MUC1 overexpression inhibits activation of Toll-like receptors in cultured cells indicating that MUC1 has anti-inflammatory properties (144). Interestingly, the inhibition of TNF $\alpha$-induced cytokine expression by MUC1/B was time-dependent, i.e., IL-8 up-regulation by TNF $\alpha$ was inhibited by MUC1/B in the first $4 \mathrm{~h}$ after TNF $\alpha$ treatment, but that inhibition by MUC1/B was ablated at $24 \mathrm{~h}$ (Fig. 18). In contrast, MUC1/A increased IL-1 $\beta$ and IL-8 mRNA after $24 \mathrm{~h}$ of TNF $\alpha$ treatment. In summary, 
these data indicate that MUC1/A has less anti-inflammatory activity than MUC1/B. These data do not explain the correlation between the lower frequency of MUC1/A expression and non-Sjogrens aqueous deficient and evaporative dry eye, but demonstrate that MUC1/A and MUC1/B mediate different cytokine responses to TNF $\alpha$. Interestingly, the TNF $\alpha$-stimulated cytokine response in MUC1 $\Delta \mathrm{EX}$-expressing cells was similar to MUC1/B- expressing cells. This result was somewhat unexpected because MUC1 $\Delta \mathrm{EX}$ lacks most of the extracellular domain which is the part of MUC1 that is different between MUC1/A and MUC1/B. Thus, the pro-inflammatory phenotype of MUC1/A indicates that the extra 9 aa in the $\mathrm{N}$-terminus affects its signaling properties.

The precise mechanisms accounting for the differential role of MUC1/A and MUC1/B in regulating TNF $\alpha$-induced IL-1 $\beta$ and IL-8 transcription remain to be fully elucidated. However, we postulate that differential regulation of the NF- $\kappa \mathrm{B}$ pathway by MUC1/A and MUC1/B plays a key role in the concomitant differences in cytokine expression. We demonstrated that MUC1/B, but not MUC1/A, inhibited TNF $\alpha$-induced NF- $\mathrm{kB}$ driven luciferase reporter activity with $24 \mathrm{~h}$ TNF $\alpha$ treatment. However, in agreement with our data showing that MUC1/A inhibited TNF $\alpha$-induced IL- 8 mRNA only at the $4 \mathrm{~h}$ time point, MUC1/A inhibited TNF $\alpha$ activation of the NF- $\mathrm{B}$ luciferase reporter activity only at $10 \mathrm{ng} / \mathrm{ml} \mathrm{TNF} \alpha$ at $4 \mathrm{~h}$. These findings indicate different timedependent effects of MUC1/A versus $\mathrm{MUC1} / \mathrm{B}$ in response to TNFa. Surprisingly, MUC1 $\triangle \mathrm{EX}$ did not inhibit TNF $\alpha$-induced activation of the NF- $\kappa \mathrm{B}$ driven luciferase reporter. These results were unexpected because the MUC1-CD is thought to mediate the intracellular activities of MUC1 (57) and also because $\triangle \mathrm{EX}$ blocked TNF $\alpha$-induced 
induction of IL-1 $\beta$ and IL-8. This intriguing finding further supports the idea that MUC1-N and MUC1-CD subunits work together to modulate signal transduction events.

The 9 aa insertion in the MUC1-N did not cause differences in PM localization between $\mathrm{MUC1} / \mathrm{A}$ and $\mathrm{MUC1} / \mathrm{B}$; however, there may be subtle differences in their localization that were not detected. It is also possible that MUC1/A and MUC1/B interact with a different repertoire of regulatory proteins in the PM and cytoplasm or other intracellular compartments that differentially mitigate the TNF $\alpha$-induced inflammatory response. Another possibility is that the MUC1-CD of MUC1/A and MUC1/B are differently phosphorylated which would be expected to differentially impact downstream signaling. Although the extra 9 aa in MUC1/A-N are not predicted to create or delete a phosphorylation site, it is possible that MUC1/A and MUC1/B interact with different protein kinases/phosphatases that alter intracellular signaling.

It is also important to note that COS-7 cells were used in this study because they are readily transfectable and MUC1 null. However, these monkey kidney cells are not a good model for the polarized epithelial cells that constitute the ocular surface. There is no cell polarity in COS-7 cells, thus the cellular distribution and PM localization of MUC1/A and MUC1/B may be different in other cells. Furthermore, COS-7 cells lack detectable levels of intracellular signaling targets, i.e., IКB $\alpha$ and IKK (Y. Imbert, unpublished observation) making additional studies of signaling pathways impossible in this cell line. Future studies should utilize cells more appropriate to dry eye such as corneal or conjunctival epithelial cell lines. Nevertheless, the results presented here with COS-7 cells clearly indicate functional differences between MUC1/A and MUC1/B. 
The increase TGF $\beta$ basal expression by MUC1/A has not been previously reported. TGF $\beta$ is a potent anti-inflammatory cytokine that plays an important role in maintaining the lacrimal gland homeostasis (38). TGF $\beta$ ablation in mice leads to the development of "crusty eyes" due to inflammation of the lacrimal gland (32). The ability of MUC1/A to induce TGF $\beta$ suggests that one mechanism by which MUC1/A confers protection to the ocular surface is by providing constitutive protection to the lacrimal gland through TGF $\beta$. Since the frequency of the MUC1/A only genotype was reduced in dry eye disease patients (Table 3), this important finding requires further investigation.

Our data indicate that both MUC1/A and MUC1/B inhibit TNF $\alpha$-induced miR-21 expression and thus ameliorate the blockade of PDCD4 expression. miRNAs are upstream regulators of gene expression and are responsible for controlling important physiological and pathological processes, including inflammation (reviewed in (152)). PDCD4 is a tumor-suppressor gene that inhibits protein translation and stimulates inflammation. TNFa-downregulation of $P D C D 4$ in pro-inflammatory environments was reported to decrease inflammation $(149 ; 153)$. To our knowledge, this is the first investigation of the effect of MUCl on miR-21 expression and activity. The ability of $\mathrm{MUC1} / \mathrm{A}$ and $\mathrm{MUC1} / \mathrm{B}$ to increase the levels of PDCD4 in response to TNF $\alpha$ provides another mechanism by which these splice variants can sustain inflammation.

In conclusion, our findings indicate that $\mathrm{MUCl} / \mathrm{A}$ and $\mathrm{MUC1} / \mathrm{B}$ have overlapping and distinct anti-inflammatory properties as reflected in cytokine activation and NF- $\mathrm{B}$ regulation, but similar activities in regulating miR-21 expression. The difference in the function of MUC1/A and MUC1/B detected in transfected COS-7 cells is the first step in understanding how their expression in conjunctival tissue is involved in dry eye disease. 


\section{CHAPTER VI- RESEARCH IMPLICATIONS}

Dry eye is a complex and multifactorial disease, whose underlying causes are unknown (5). Patients suffering from this chronic and debilitating disease can find relief from the symptoms with current palliative therapies; however, these therapies do not yet stop the progression of the disease. Evidence accumulated over the past few years has identified a number of factors that correlate with susceptibility to develop dry eye disease including aging, hormonal status, environmental stress, meibomian gland dysfunction, mucin status, and autoimmune attack to the secretory glands of the eye. Such correlations, however, do not provide a mechanism for the occurrence of dry eye disease. This dissertation focused on the role of MUCl splice variants as potential genetic factors that regulate the mechanisms behind the pathologies associated with dry eye disease. Advances in understanding the causative elements of dry eye disease will be beneficial to patients currently suffering from this disease.

One major finding of this dissertation is that MUC1/A expression is reduced in the non-Sjögren's and evaporative dry eye population (described in Chapter IV) (44). The lower frequency of MUC1/A in the dry eye population establishes MUC1/A and $\mathrm{MUC1/B}$ expression status as genetic susceptibility factors, and suggests a protective role of the MUC1/A splice variant against ocular damage that is associated with dry eye disease. Elucidating how MUC1/A and MUC1/B relate to the cellular and molecular elements involved in the occurrence of dry eye disease may lead to the discovery of new 
therapeutic targets. The experiments described in Chapter $\mathrm{V}$ build on results from Chapters III and VI and examined the role of $\mathrm{MUC1} / \mathrm{A}$ and $\mathrm{MUC1} / \mathrm{B}$ in regulating the cellular inflammatory response. The results from these studies demonstrated for the first time that MUC1/A and MUC1/B differently regulate inflammatory signals. Specifically, I present evidence that MUC1/A had mixed pro- and anti-inflammatory activities depending on the experimental conditions, whereas MUC1/B had a short-lasting antiinflammatory activity after exposure to short-term (4 h) TNF $\alpha$.

MUC1 is a membrane-anchored mucin expressed at the ocular surface and provides protection against extrinsic insults. Consistent with the importance of $\mathrm{MUCl}$ in maintaining the integrity of the ocular surface, studies have examined whether MUC1 levels were altered in the dry eye population compared to controls $(16 ; 154)$. In one study MUC1 protein and mRNA was found to be increased in Sjogrens's dry eye compared to non-Sjögren's and normal controls subjects (154). The same study also detected increased soluble MUC1 expression in tears of non-Sjögren's aqueous deficient dry eye compared to normal controls. However, these changes in MUC1 expression are likely a consequence or a compensatory response to the chronic inflammatory nature of the disease. In contrast, we identified the reduced frequency of the MUC1/A splice variant as a genetic susceptibility element contributing to the prevalence of non-Sjögren's and evaporative dry eye (44). These data indicate that non- Sjögren's and evaporative dry eye must share some common underlying mechanisms that involve MUC1.

The results presented in Chapter VI indicate that the size of the VNTR is not the element responsible for providing protection against dry eye. The Southern blot data (Fig. 14) demonstrated that, contrary to what I had initially hypothesized, MUC1/A 
alleles do not correlate $100 \%$ with large size VNTR and therefore, the protection that comes from expressing MUC1/A alleles is not simply from mechanical hindrance.

The work presented in Chapter $\mathrm{V}$ examined the role of $\mathrm{MUC1} / \mathrm{A}$ and $\mathrm{MUC1} / \mathrm{B}$ in the regulation of cellular inflammation. One important finding in this Chapter is that the expression of the MUC1/A splice variant correlates with an increase in basal levels of TGF $\beta$ (Fig. 19). TGF $\beta$ plays an anti-inflammatory role in the ocular surface; therefore, our data indicates that $\mathrm{MUCl} / \mathrm{A}$ confers protection to the ocular surface by increasing TGF $\beta$. It will be interesting to determine if $\mathrm{MUC1} / \mathrm{A}$ and $\mathrm{MUC} / 1 \mathrm{~B}$ genotype correlates with TGF $\beta$ expression levels in human subjects. Future research will be necessary to determine the mechanism by which MUC1/A increases TGF $\beta$ expression.

Another interesting discovery was that MUC1/A stimulated the TNF $\alpha$-mediated proinflammatory response at $24 \mathrm{~h}$ (Figs. 18 and 20). Although I had initially hypothesized that MUC1/A would have greater anti-inflammatory activity, based on the reduced MUC1/A only genotype in dry eye patients, these data remain consistent with the hypothesis that MUC1/A plays a protective role. Inflammation is a defense mechanism to protect tissues from external damage and therefore it could be advantageous to have enhanced expression of proinflammatory mediators for a short period of time.

The discovery that MUC1/A and MUC1/B have a differential role in the regulation of inflammation is also relevant to tumorigenesis. It is well established that inflammation is a critical component of tumor progression (for review (155)) and therefore, our findings are also relevant to the development and progression of cancer. The expression of MUC1 splice variants have been reported in breast, ovarian, cervical, and prostate tumors $(101 ; 156-158)$. The frequency of the MUC1/A genotype was 
reported to be significantly reduced in hereditary prostate cancer compared to the population (158). Likewise, MUCl/A expression has been reported to be reduced in ductal carcinoma in situ (159). The functional discrepancies between MUC1/A and $\mathrm{MUC1} / \mathrm{B}$ described here can therefore be used as models to explore the role of MUC1 splice variants in the development of cancer.

One strength of this research is that we identified $\mathrm{MUC1} / \mathrm{A}$ and $\mathrm{MUC1} / \mathrm{B}$ as genetic elements contributing to the prevalence of two categories of dry eye, and we have demonstrated different physiologic functions of these two splice variants in transfected COS-7 cells. Importantly, the ability to link specific genetic variations to differences in molecular functions that mediate pathogenic events causing the symptoms of dry eye disease will provide new targets for potential intervention therapies. One drawback from the studies conducted in Chapter V is that COS-7 cells were used because of their ease in uptake of plasmids, rather than corneal or conjunctival cells. It is possible that in a different cell context, these splice variants may exhibit different properties. Another limitation is that much of what we have learned in terms of how MUC1/A and MUC1/B regulate inflammatory responses is based on a model of acute TNF $\alpha$-stimulated inflammation. Therefore, how our results compare to a chronic inflammation setting such as in dry eye disease remains to be tested. Despite these limitations, this research has provided new knowledge about the importance of MUC1 splice variants in dry eye disease. Additionally, these studies have opened new avenues for further research. Finally, although the MUC1/A and MUC1/B status alone is not sufficient to cause or to predict the development of dry eye, a more direct role of $\mathrm{MUC1} / \mathrm{A}$ and $\mathrm{MUC1} / \mathrm{B}$ as regulators of important cellular processes such as inflammation has been demonstrated. 


\section{REFERENCES}

1. Sullivan, D. A., Sullivan, B. D., Evans, J. E., Schirra, F., Yamagami, H., Liu, M., Richards, S. M., Suzuki, T., Schaumberg, D. A., Sullivan, R. M., and Dana, M. R. (2002) Ann. N. Y. Acad. Sci. 966, 211-222

2. Maissa, C. and Guillon, M. (2010) Cont. Lens Anterior. Eye 33, 176-182

3. Tavares, F. P., Fernandes, R. S., Bernardes, T. F., Bonfioli, A. A., and Soares, E. J. (2010) Semin. Ophthalmol. 25, 84-93

4. Stern, M. E., Gao, J. P., Siemasko, K. F., Beuerman, R. W., and Pflugfelder, S. C. (2004) Exp. Eye Res. 78, 409-416

5. DEWS (2007) The Ocular Surface 5, 67-202

6. Calonge, M., Enriquez-de-Salamanca, A., Diebold, Y., Gonzalez-Garcia, M. J., Reinoso, R., Herreras, J. M., and Corell, A. (2010) Ocul. Immunol. Inflamm. 18, 190-199

7. Nelson, J. D. (1998) Adv. Exp. Med. Biol. 438, 1-9

8. Dartt, D. A. (2002) Prog. Retin. Eye Res. 21, 555-576

9. Pflugfelder, S. C. (1996) Adv. Dent. Res. 10,9-12

10. Nakamura, H., Kawakami, A., and Eguchi, K. (2006) Transl. Res. 148, 281-288

11. Goto, E., Endo, K., Suzuki, A., Fujikura, Y., Matsumoto, Y., and Tsubota, K. (2003) Invest Ophthalmol. Vis. Sci. 44, 533-539

12. Craig, J. P. and Tomlinson, A. (1997) Optom. Vis. Sci. 74, 8-13

13. Gilbard, J. P., Farris, R. L., and Santamaria, J. (1978) Arch Ophthalmol. 96, 677681

14. Goto, T., Zheng, X., Klyce, S. D., Kataoka, H., Uno, T., Karon, M., Tatematsu, Y., Bessyo, T., Tsubota, K., and Ohashi, Y. (2003) Am J Ophthalmol. 135, 607612

15. Yeh, S., Song, X. J., Farley, W., Li, D. Q., Stern, M. E., and Pflugfelder, S. C. (2003) Invest Ophthalmol. Vis. Sci. 44, 124-129 
16. Argueso, P., Balaram, M., Spurr-Michaud, S., Keutmann, H. T., Dana, M. R., and Gipson, I. K. (2002) Invest Ophthalmol. Vis. Sci. 43, 1004-1011

17. Zhao, H., Jumblatt, J. E., Wood, T. O., and Jumblatt, M. M. (2001) Cornea 20, 873-877

18. Foulks, G. N. (2008) Drugs Aging 25, 105-118

19. Luo, L., Li, D. Q., Doshi, A., Farley, W., Corrales, R. M., and Pflugfelder, S. C. (2004) Invest Ophthalmol. Vis. Sci. 45, 4293-4301

20. Luo, L., Li, D. Q., Corrales, R. M., and Pflugfelder, S. C. (2005) Eye Contact Lens 31, 186-193

21. Corrales, R. M., Stern, M. E., De Paiva, C. S., Welch, J., Li, D. Q., and Pflugfelder, S. C. (2006) Invest Ophthalmol. Vis. Sci. 47, 3293-3302

22. Li, D. Q., Chen, Z., Song, X. J., Luo, L., and Pflugfelder, S. C. (2004) Invest Ophthalmol. Vis. Sci. 45, 4302-4311

23. Luo, L., Li, D. Q., Doshi, A., Farley, W., Corrales, R. M., and Pflugfelder, S. C. (2004) Invest Ophthalmol. Vis. Sci. 45, 4293-4301

24. Li, D. Q., Luo, L., Chen, Z., Kim, H. S., Song, X. J., and Pflugfelder, S. C. (2006) Exp. Eye Res. 82, 588-596

25. Brignole, F., Pisella, P. J., Goldschild, M., De Saint, J. M., Goguel, A., and Baudouin, C. (2000) Invest Ophthalmol. Vis. Sci. 41, 1356-1363

26. Jones, D. T., Monroy, D., Ji, Z., Atherton, S. S., and Pflugfelder, S. C. (1994) Invest Ophthalmol. Vis. Sci. 35, 3493-3504

27. Stern, M. E., Gao, J., Schwalb, T. A., Ngo, M., Tieu, D. D., Chan, C. C., Reis, B. L., Whitcup, S. M., Thompson, D., and Smith, J. A. (2002) Invest Ophthalmol. Vis. Sci. 43, 2609-2614

28. Barabino, S. and Dana, M. R. (2004) Invest Ophthalmol. Vis. Sci. 45, 1641-1646

29. Schrader, S., Mircheff, A. K., and Geerling, G. (2008) Dev. Ophthalmol. 41, 298312

30. Takahashi, M., Ishimaru, N., Yanagi, K., Haneji, N., Saito, I., and Hayashi, Y. (1997) Clin. Exp. Immunol. 109, 555-561

31. Humphreys-Beher, M. G., Hu, Y., Nakagawa, Y., Wang, P. L., and Purushotham, K. R. (1994) Adv. Exp. Med. Biol 350, 631-636

32. Cartney-Francis, N. L., Mizel, D. E., Frazier-Jessen, M., Kulkarni, A. B., McCarthy, J. B., and Wahl, S. M. (1997) Am J Pathol. 151, 1281-1288 
33. Schaumberg, D. A., Buring, J. E., Sullivan, D. A., and Dana, M. R. (2001) JAMA 286, 2114-2119

34. Miljanovic, B., Trivedi, K. A., Dana, M. R., Gilbard, J. P., Buring, J. E., and Schaumberg, D. A. (2005) Am. J. Clin. Nutr. 82, 887-893

35. Sommer, A. (2003) Forum Nutr 33-35

36. (2002) Arch Ophthalmology 1689-1699

37. Krenzer, K. L., Dana, M. R., Ullman, M. D., Cermak, J. M., Tolls, D. B., Evans, J. E., and Sullivan, D. A. (2000) J. Clin. Endocrinol. Metab 85, 4874-4882

38. Rocha, E. M., Wickham, L. A., Huang, Z., Toda, I., Gao, J., da Silveira, L. A., and Sullivan, D. A. (1998) Adv. Exp. Med. Biol 438, 485-491

39. Sullivan, D. A., Wickham, L. A., Rocha, E. M., Krenzer, K. L., Sullivan, B. D., Steagall, R., Cermak, J. M., Dana, M. R., Ullman, M. D., Sato, E. H., Gao, J., Rocha, F. J., Ono, M., Silveira, L. A., Lambert, R. W., Kelleher, R. S., Tolls, D. B., and Toda, I. (1999) Ann. N. Y. Acad. Sci. 876, 312-324

40. Kufe, D., inghirami, G., Abe, M., Hayes, D., Justi-Wheeler, H., and Schlom, J. (1984) Hybridoma 3, 223-232

41. Hollingsworth, M. A. and Swanson, B. J. (2004) Nature Reviews Cancer 4, 45-60

42. Watanabe, H. (2002) Cornea 21, S17-S22

43. Danjo, Y., Watanabe, H., Tisdale, A. S., George, M., Tsumura, T., Abelson, M. B., and Gipson, I. K. (1998) Invest Ophthalmol. Vis. Sci. 39, 2602-2609

44. Imbert, Y., Foulks, G. N., Brennan, M. D., Jumblatt, M. M., John, G., Shah, H. A., Newton, C., Pouranfar, F., and Young, W. W., Jr. (2009) Exp. Eye Res. 88, 334-338

45. Higuchi, T., Orita, T., Nakanishi, S., Katsuya, K., Watanabe, H., Yamasaki, Y., Waga, I., Nanayama, T., Yamamoto, Y., Munger, W., Sun, H. W., Falk, R. J., Jennette, J. C., Alcorta, D. A., Li, H. P., Yamamoto, T., Saito, Y., and Nakamura, M. (2004) J. Biol. Chem. 279, 1968-1979

46. Gipson, I. K. (2004) Exp. Eye Res. 78, 379-388

47. Gendler, S. J. and Spicer, A. P. (1995) Annu. Rev. Physiol 57, 607-634

48. von Mensdorff-Pouilly, S., Kinarsky, L., Engelmann, K., Baldus, S. E., Verheijen, R. H., Hollingsworth, M. A., Pisarev, V., Sherman, S., and Hanisch, F. G. (2005) Glycobiology 15, 735-746 
49. Kohlgraf, K. G., Gawron, A. J., Higashi, M., Meza, J. L., Burdick, M. D., Kitajima, S., Kelly, D. L., Caffrey, T. C., and Hollingsworth, M. A. (2003) Cancer Res. 63, 5011-5020

50. Kadayakkara, D. K., Beatty, P. L., Turner, M. S., Janjic, J. M., Ahrens, E. T., and Finn, O. J. (2010) Pancreas 39, 510-515

51. Thornton, D. J., Rousseau, K., and McGuckin, M. A. (2008) Annu Rev Physiol 70, $459-486$

52. Wei, X., Xu, H., and Kufe, D. (2005) Cancer Cell 7, 167-178

53. Gendler, S. J., Lancaster, C. A., Taylor-Papadimitriou, J., Duhig, T., Peat, N., Burchell, J., Pemberton, L., Lalani, E. N., and Wilson, D. (1990) J. Biol. Chem. 265, 15286-15293

54. Pemberton, L., Taylor-Papadimitriou, J., and Gendler, S. J. (1992) Biochem Biophys Res. Commun. 185, 167-175

55. Voynow, J. A., Gendler, S. J., and Rose, M. C. (2006) Am. J. Respir. Cell Mol. Biol. 34, 661-665

56. Levitin, F., Stern, O., Weiss, M., Gil-Henn, C., Ziv, R., Prokocimer, Z., Smorodinsky, N. I., Rubinstein, D. B., and Wreschner, D. H. (2005) J. Biol. Chem. 280, 33374-33386

57. Gendler, S. J. (2001) J. Mammary. Gland. Biol. Neoplasia. 6, 339-353

58. Bafna, S., Kaur, S., and Batra, S. K. (2010) Oncogene 29, 2893-2904

59. Carson, D. D. (2008) Sci. Signal. 1, e35

60. Leng, Y., Cao, C., Ren, J., Huang, L., Chen, D., and Kufe, D. (2007) J. Biol. Chem.

61. Kinlough, C. L., McMahan, R. J., Poland, P. A., Bruns, J. B., Harkleroad, K. L., Stremple, R. J., Kashlan, O. B., Weixel, K. M., Weisz, O. A., and Hughey, R. P. (2006) J. Biol. Chem. 281, 12112-12122

62. Rahn, J. J., Shen, Q., Mah, B. K., and Hugh, J. C. (2004) J. Biol. Chem. 279, 29386-29390

63. Kam, J. L., Regimbald, L. H., Hilgers, J. H., Hoffman, P., Krantz, M. J., Longenecker, B. M., and Hugh, J. C. (1998) Cancer Res. 58, 5577-5581

64. Regimbald, L. H., Pilarski, L. M., Longenecker, B. M., Reddish, M. A., Zimmermann, G., and Hugh, J. C. (1996) Cancer Res. 56, 4244-4249 
65. Lu, W., Hisatsune, A., Koga, T., Kato, K., Kuwahara, I., Lillehoj, E. P., Chen, W., Cross, A. S., Gendler, S. J., Gewirtz, A. T., and Kim, K. C. (2006) J. Immunol. 176, 3890-3894

66. Kardon, R., Price, R. E., Julian, J., Lagow, E., Tseng, S. C., Gendler, S. J., and Carson, D. D. (1999) Invest Ophthalmol. Vis. Sci. 40, 1328-1335

67. Ueno, K., Koga, T., Kato, K., Golenbock, D. T., Gendler, S. J., Kai, H., and Kim, K. C. (2008) Am J Respir Cell Mol Biol 38, 263-268

68. Chang, J. F., Zhao, H. L., Phillips, J., and Greenburg, G. (2000) Cell Immunol. 201, 83-88

69. Ahmad, R., Raina, D., Trivedi, V., Ren, J., Rajabi, H., Kharbanda S, and Kufe, D. (2007) Nat Cell Biol. . 9, 1419-1427

70. Abe, M. and Kufe, D. (1993) Proc. Natl. Acad. Sci. U. S. A 90, 282-286

71. Zaretsky, J. Z., Sarid, R., Aylon, Y., Mittelman, L. A., Wreschner, D. H., and Keydar, I. (1999) FEBS Lett. 461, 189-195

72. Gaemers, I. C., Vos, H. L., Volders, H. H., van, d., V, and Hilkens, J. (2001) $J$ Biol Chem. 276, 6191-6199

73. Kovarik, A., Peat, N., Wilson, D., Gendler, S. J., and Taylor-Papadimitriou, J. (1993) J Biol Chem. 268, 9917-9926

74. Lagow, E. L. and Carson, D. D. (2002) J. Cell Biochem. 86, 759-772

75. Surveyor, G. A., Gendler, S. J., Pemberton, L., Das, S. K., Chakraborty, I., Julian, J., Pimental, R. A., Wegner, C. C., Dey, S. K., and Carson, D. D. (1995)

Endocrinology 136, 3639-3647

76. Braga, V. M., Pemberton, L. F., Duhig, T., and Gendler, S. J. (1992) Development $115,427-437$

77. Zhou, X., DeSouza, M. M., Julian, J., Gendler, S. J., and Carson, D. D. (1998) Mol Cell Endocrinol. 143, 65-78

78. Rajabi, H., Jin, C., Ahmad, R., McClary, C., Joshi, M. D., and Kufe, D. (2010) Genes Cancer 1, 62-68

79. Imbert, Y., Darling, D. S., Jumblatt, M. M., Foulks, G. N., Couzin, E. G., Steele, P. S., and Young, W. W., Jr. (2006) Exp. Eye Res. 83, 493-501

80. Ligtenberg, M. J., Gennissen, A. M., Vos, H. L., and Hilkens, J. (1991) Nucleic Acids Res. 19, 297-301 
81. Pratt, W. S., Islam, I., and Swallow, D. M. (1996) Ann. Hum. Genet. 60 ( Pt 1), 21-28

82. Ligtenberg, M. J., Vos, H. L., Gennissen, A. M., and Hilkens, J. (1990) J. Biol. Chem. 265, 5573-5578

83. Wreschner, D. H., Hareuveni, M., Tsarfaty, I., Smorodinsky, N., Horev, J., Zaretsky, J., Kotkes, P., Weiss, M., Lathe, R., Dion, A., and . (1990) Eur. J. Biochem. 189, 463-473

84. Levitin, F., Baruch, A., Weiss, M., Stiegman, K., Hartmann, M. L., Yoeli-Lerner, M., Ziv, R., Zrihan-Licht, S., Shina, S., Gat, A., Lifschitz, B., Simha, M., Stadler, Y., Cholostoy, A., Gil, B., Greaves, D., Keydar, I., Zaretsky, J., Smorodinsky, N., and Wreschner, D. H. (2005) J. Biol. Chem. 280, 10655-10663

85. Wreschner, D. H., Zrihan-Licht, S., Baruch, A., Sagiv, D., Hartman, M. L., Smorodinsky, N., and Keydar, I. (1994) Adv. Exp. Med. Biol. 353, 17-26

86. Zrihan-Licht, S., Vos, H. L., Baruch, A., Elroy-Stein, O., Sagiv, D., Keydar, I., Hilkens, J., and Wreschner, D. H. (1994) Eur. J. Biochem. 224, 787-795

87. Miljanovic, B., Dana, M. R., Sullivan, D. A., and Schaumberg, D. A. (2007) Invest Ophthalmol. Vis. Sci. ARVO Abstract,

88. Mantelli, F. and Argueso, P. (2008) Curr. Opin. Allergy Clin. Immunol. 8, 477483

89. Inatomi, T., Spurr-Michaud, S., Tisdale, A. S., Zhan, Q., Feldman, S. T., and Gipson, I. K. (1996) Invest Ophthalmol. Vis. Sci. 37, 1684-1692

90. Jumblatt, J. E., Cunningham, L. T., Li, Y., and Jumblatt, M. M. (2002) Cornea 21, 818-824

91. Lynch, K. W. (2004) Nat. Rev. Immunol. 4, 931-940

92. Kalnina, Z., Zayakin, P., Silina, K., and Line, A. (2005) Genes Chromosomes. Cancer 42, 342-357

93. Oosterkamp, H. M., Scheiner, L., Stefanova, M. C., Lloyd, K. O., and Finstad, C. L. (1997) Int. J. Cancer 72, 87-94

94. Baruch, A., Hartmann, M., Zrihan-Licht, S., Greenstein, S., Burstein, M., Keydar, I., Weiss, M., Smorodinsky, N., and Wreschner, D. H. (1997) Int. J. Cancer 71, 741-749

95. Hinojosa-Kurtzberg, A. M., Johansson, M. E., Madsen, C. S., Hansson, G. C., and Gendler, S. J. (2003) Am. J. Physiol Gastrointest. Liver Physiol 284, G853-G862 
96. Lemp, M. A. (1998) Adv. Exp. Med. Biol. 438, 791-803

97. Lemp, M. A. (1995) CLAO J 21, 221-232

98. Medhurst, A. D., Harrison, D. C., Read, S. J., Campbell, C. A., Robbins, M. J., and Pangalos, M. N. (2001) J. Neurosci. Res. 98, 9-20

99. Bustin, S. A. (2001) J. Molec. Endocrin. 25, 169-193

100. Young, W. W., Jr., Holcomb, D. R., Ten Hagen, K. G., and Tabak, L. A. (2003) Glycobiology 13, 549-557

101. Obermair, A., Schmid, B. C., Packer, L. M., Leodolter, S., Birner, P., Ward, B. G., Crandon, A. J., McGuckin, M. A., and Zeillinger, R. (2002) Int. J. Cancer 100, 166-171

102. Jaskiewicz, E., Zhu, G., Taatjes, D. J., Darling, D. S., Zwanzig, G. E., Jr., and Young, W. W., Jr. (1996) Glycoconjugate J. 13, 213-223

103. Royce, L. S., Kibbey, M. C., Mertz, P., Kleinman, H. K., and Baum, B. J. (1993) Diff. 52, 247-255

104. Brooks, S. C., Locke, E. R., and Soule, H. D. (1973) J. Biol. Chem. 248, 62516253

105. Abe, M. and Kufe, D. (1989) Cancer Res. 49, 2834-2839

106. Imbert, Y., Jumblatt, M. M., Foulks, G. N., Couzin, E. G., Steele, P. S., and Young, W. W., Jr. (2006) Cornea 10, 1193-1199

107. Hey, N. A., Meseguer, M., Simon, C., Smorodinsky, N. I., Wreschner, D. H., Ortiz, M. E., and Aplin, J. D. (2003) Reprod. Biol. Endocrinol. 1, 2

108. Zhang, X. H., Heller, K. A., Hefter, I., Leslie, C. S., and Chasin, L. A. (2003) Genome Res. 13, 2637-2650

109. Corrales, R. M., Calonge, M., Herreras, J. M., Saez, V., Mayo, A., and Chaves, F. J. (2003) Curr. Eye Res. 27, 323-328

110. Paulsen, F., Langer, G., Hoffmann, W., and Berry, M. (2004) Cell Tissue Res. 316, 167-177

111. Dudas, S. P., Yunker, C. K., Sternberg, L. R., Byrd, J. C., and Bresalier, R. S. (2002) Gastroenterology 123, 817-826

112. Baruch, A., Hartmann, M., Yoeli, M., Adereth, Y., Greenstein, S., Stadler, Y., Skornik, Y., Zaretsky, J., Smorodinsky, N. I., Keydar, I., and Wreschner, D. H. (1999) Cancer Res. 59, 1552-1561 
113. Moore, M. J. (2002) Science 298, 370-371

114. Hilkens, J., Ligtenberg, M. J., Vos, H. L., and Litvinov, S. V. (1992) Trends Biochem. Sci. 17, 359-363

115. Hanisch, F. G. and Muller, S. (2000) Glycobiology 10, 439-449

116. DeSouza, M. M., Surveyor, G. A., Price, R. E., Julian, J., Kardon, R., Zhou, X., Gendler, S., Hilkens, J., and Carson, D. D. (1999) J. Reprod. Immunol. 45, 127 158

117. Kyo, K., Parkes, M., Takei, Y., Nishimori, H., Vyas, P., Satsangi, J., Simmons, J., Nagawa, H., Baba, S., Jewell, D., Muto, T., Lathrop, G. M., and Nakamura, Y. (1999) Hum. Mol. Genet. 8, 307-311

118. Vinall, L. E., King, M., Novelli, M., Green, C. A., Daniels, G., Hilkens, J., Sarner, M., and Swallow, D. M. (2002) Gastroenterology 123, 41-49

119. Kirkbride, H. J., Bolscher, J. G., Nazmi, K., Vinall, L. E., Nash, M. W., Moss, F. M., Mitchell, D. M., and Swallow, D. M. (2001) Eur. J. Hum. Genet. 9, 347-354

120. Silva, F., Carvalho, F., Peixoto, A., Seixas, M., Almeida, R., Carneiro, F., Mesquita, P., Figueiredo, C., Nogueira, C., Swallow, D. M., Amorim, A., and David, L. (2001) Eur. J. Hum. Genet. 9, 548-552

121. Vinall, L. E., Fowler, J. C., Jones, A. L., Kirkbride, H. J., de, B. C., Laine, A., Porchet, N., Gum, J. R., Kim, Y. S., Moss, F. M., Mitchell, D. M., and Swallow, D. M. (2000) Am. J. Respir. Cell Mol. Biol. 23, 678-686

122. Inatomi, T., Spurr-Michaud, S., Tisdale, A. S., Zhan, Q., Feldman, S. T., and Gipson, I. K. (1996) Invest Ophthalmol. Vis. Sci. 37, 1684-1692

123. Ramirez RD, Sheridan S, Girard L, Sato M, Kim Y, Pollack J, Zou Y, Kurie JM, Dimaio JM, Milchgrub S, Smith AL, Souza RF, Gilbey L, Zhang X, Gandia K, Vaughan MB, Wright WE, Gazdar AF, Shay JW, and Minna JD (2004) Cancer Res. 64, 9027-9034

124. He, Y., Li, X., Bao, Y., Sun, J., and Liu, J. (2006) Yan. Ke. Xue. Bao. 22, 233-236

125. Pflugfelder, S. C. (2004) Am. J. Ophthalmol. 137, 337-342

126. Solomon, A., Dursun, D., Liu, Z., Xie, Y., Macri, A., and Pflugfelder, S. C. (2001) Invest Ophthalmol. Vis. Sci. 42, 2283-2292

127. Cvoro, A., Tzagarakis, F. C., Tatomer, D., Paruthiyil, S., Fox, M. S., and Leitman, D. C. (2006) Mol. Cell 21, 555-564 
128. Pfeilschifter, J., Koditz, R., Pfohl, M., and Schatz, H. (2002) Endocr. Rev. 23, 90 119

129. Cvoro, A., Tatomer, D., Tee, M., Zogovic, T., Harris, H. A., and Leitman, D. C. (2008) J Immunol. 180, 630-636

130. Holleran, W. M., Takagi, Y., Menon, G. K., Jackson, S. M., Lee, J. M., Feingold, K. R., and Elias, P. M. (1994) J. Lipid Res. 35, 905-912

131. Jonckheere, N. and Van, S., I (2010) Biochimie 92, 1-11

132. Burdick, M. D., Harris, A., Reid, C. J., Iwamura, T., and Hollingsworth, M. A. (1997) J. Biol. Chem. 272, 24198-24202

133. Dougherty, S. M., Mazhawidza, W., Bohn, A. R., Robinson, K. A., Mattingly, K. A., Blankenship, K. A., Huff, M. O., McGregor, W. G., and Klinge, C. M. (2006) Endocr. Relat Cancer 13, 113-134

134. Schroeder, J. A., Thompson, M. C., Gardner, M. M., and Gendler, S. J. (2001) J. Biol. Chem. 276, 13057-13064

135. Argueso, P., Guzman-Aranguez, A., Mantelli, F., Cao, Z., Ricciuto, J., and Panjwani, N. (2009) J Biol Chem. 284, 23037-23045

136. Wei, X. L., Xu, H., and Kufe, D. (2006) Molecular Cell 21, 295-305

137. Guang, W., Ding, H., Czinn, S. J., Kim, K. C., Blanchard, T. C., and Lillehoj, E. P. (2010) J Biol Chem.

138. Sonoda, S., Uchino, E., Nakao, K., and Sakamoto, T. (2006) Br. J Ophthalmol. 90, 120-122

139. Thathiah, A., Brayman, M., Dharmaraj, N., Julian, J. J., Lagow, E. L., and Carson, D. D. (2004) Endocrinology 145, 4192-4203

140. Schroder, K. and Tschopp, J. (2010) Cell 140, 821-832

141. Lane, B. R., Liu, J., Bock, P. J., Schols, D., Coffey, M. J., Strieter, R. M., Polverini, P. J., and Markovitz, D. M. (2002) J Virol. 76, 11570-11583

142. Nokami, J., Ohkura, M., Dan-oh, Y., and Sakamoto, Y. (1991) Tetrahedron Lett. 32, 2409-2412

143. Pflugfelder, S. C., Jones, D., Ji, Z., Afonso, A., and Monroy, D. (1999) Curr. Eye Res. 19, 201-211

144. Ueno, K., Koga, T., Kato, K., Golenbock, D. T., Gendler, S. J., Kai, H., and Kim, K. C. (2008) Am J Respir Cell Mol Biol 38, 263-268 
145. Hong, S., Lee, H. J., Kim, S. J., and Hahm, K. B. (2010) World J Gastroenterol. 16, 2080-2093

146. Roggli, E., Britan, A., Gattesco, S., Lin-Marq, N., Abderrahmani, A., Meda, P., and Regazzi, R. (2010) Diabetes 59, 978-986

147. Haghikia, A. and Hilfiker-Kleiner, D. (2009) Cardiovasc. Res. 82, 1-3

148. Wickramasinghe, N. S., Manavalan, T. T., Dougherty, S. M., Riggs, K. A., Li, Y., and Klinge, C. M. (2009) Nucleic Acids Res. 37, 2584-2595

149. Hilliard, A., Hilliard, B., Zheng, S. J., Sun, H., Miwa, T., Song, W., Goke, R., and Chen, Y. H. (2006) J Immunol. 177, 8095-8102

150. Albertsmeyer, A. C., Kakkassery, V., Spurr-Michaud, S., Beeks, O., and Gipson, I. K. (2010) Exp. Eye Res. 90, 444-451

151. Barabino, S. and Dana, M. R. (2007) Chem. Immunol. Allergy 92, 176-184

152. O'Day, E. and Lal, A. (2010) Breast Cancer Res. 12, 201

153. Yasuda, M., Nishizawa, T., Ohigashi, H., Tanaka, T., Hou, D. X., Colburn, N. H., and Murakami, A. (2009) Carcinogenesis 30, 1209-1216

154. Caffery, B., Heynen, M. L., Joyce, E., Jones, L., Ritter, R., III, and Senchyna, M. (2010) Mol Vis. 16, 1720-1727

155. Kundu, J. K. and Surh, Y. J. (2008) Mutat. Res. 659, 15-30

156. Obermair, A., Schmid, B. C., Stimpfl, M., Fasching, B., Preyer, O., Leodolter, S., Crandon, A. J., and Zeillinger, R. (2001) Gynecol. Oncol. 83, 343-347 


\section{APPENDIX I- RESULTS FROM INITIAL AIMS 2 AND 3}

Initial Aim 2: Determine if MUC1 interacts directly and functionally with ER $\alpha$ and/or

ER $\beta$ in human submandibular gland (HSG) and ocular surface epithelial cell lines.

Here I will describe the experiments done towards completion of this aim.

Experiment 1: Western Blot analysis was performed to determine MUC1, ER $\alpha$ and ER $\beta$ protein expression in HSG and TERT-immortalized human corneal epithelial cell line (hTCE-D, kindly provided by Dr. S.D. Dimitrijevich, University of North Texas). Fig. $23 A$ shows MUCl and ER $\alpha$ protein expression in hTCE-D, HSG, and MCF-7 cells (MCF-7 were used here as positive controls for MUC1 and ER $\alpha$ ). $\alpha$-tubulin was used as a loading control. The migration size of $\operatorname{ER} \alpha$ appears lower than the expected $67 \mathrm{kDa}$ for full length $\mathrm{ER} \alpha$, but we note that migration of the baculovirusexpressed rhER $\alpha$ and $\mathrm{ER} \alpha$ in the NE from MCF-7 cells shows comparable migration. Fig. 23B demonstrates that HSG and hTCE-D cells express ER $\beta$. These results indicate that HSG and hTCE-D cells and are suitable to express MUC1, ER $\alpha$ and ER $\beta$ and therefore are suitable for the studies proposed in this aim.

Experiment 2: Coimmunoprecipitation (coIP) experiments were performed using H23 and H1793 non small cell lung cancer cell (NSCLC) lines. Although these experiments were not performed in HSG or hTCE-D cells, they provide evidence of interaction between MUC1 and ER $\alpha$ and ER $\beta$. CoIP experiments revealed that MUC1 interacts constitutively with ER $\alpha$ and ER $\beta$ in H1793 and H23 lung adenocarcinoma cells 
(Fig. 24). The lower interaction of MUCl and $E R \alpha / \beta$ in $H 23$ cells is likely due to low levels of MUC1 in $\mathrm{H} 23$ cells compared to $\mathrm{H} 1793$ cells. 


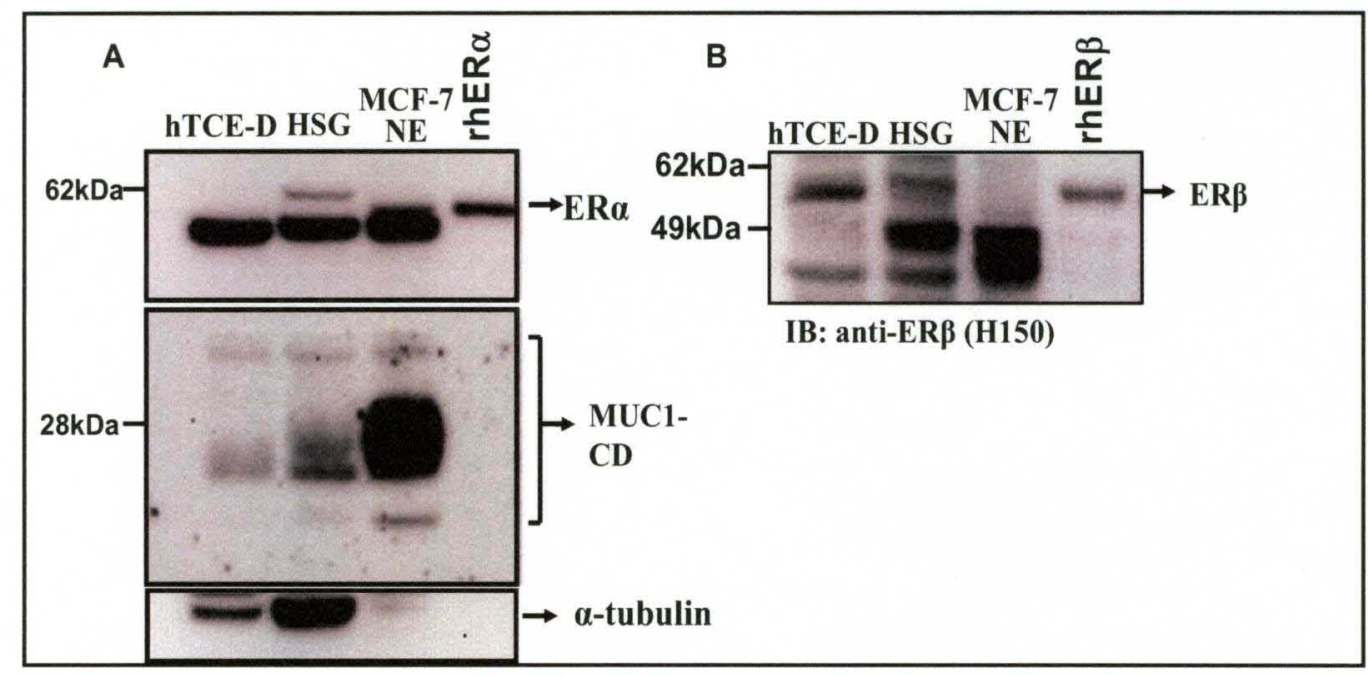

Figure 23. MUC1, ERo, and ERß are expressed in HSG and hTCE-D cells. Protein lysates from the indicated cells were subjected to immunoblotting with anti-MUC1, antiER $\alpha$, anti-ER $\beta$ and $\alpha$-tubulin antibodies. Lysates were loaded on a $4-12 \%$ Bis-Tris gel (Invitrogen). (A) Western blot probed with CT2 anti-MUC1 (NeoMarkers) and AER320 anti-ER $\alpha$ (NeoMarkers). (B) Western blot probed with H150 anti-ER $\beta$ (Santa Cruz). Baculoviral-expressed recombinant human $\mathrm{ER} \alpha$ and $\operatorname{ER} \beta$ (rhER $\beta 1$, long form) were used as positive controls. $\alpha$ - tubulin was used as a loading control. Immunoreactive bands were visualized using the Kodak Image Station 440CF. 


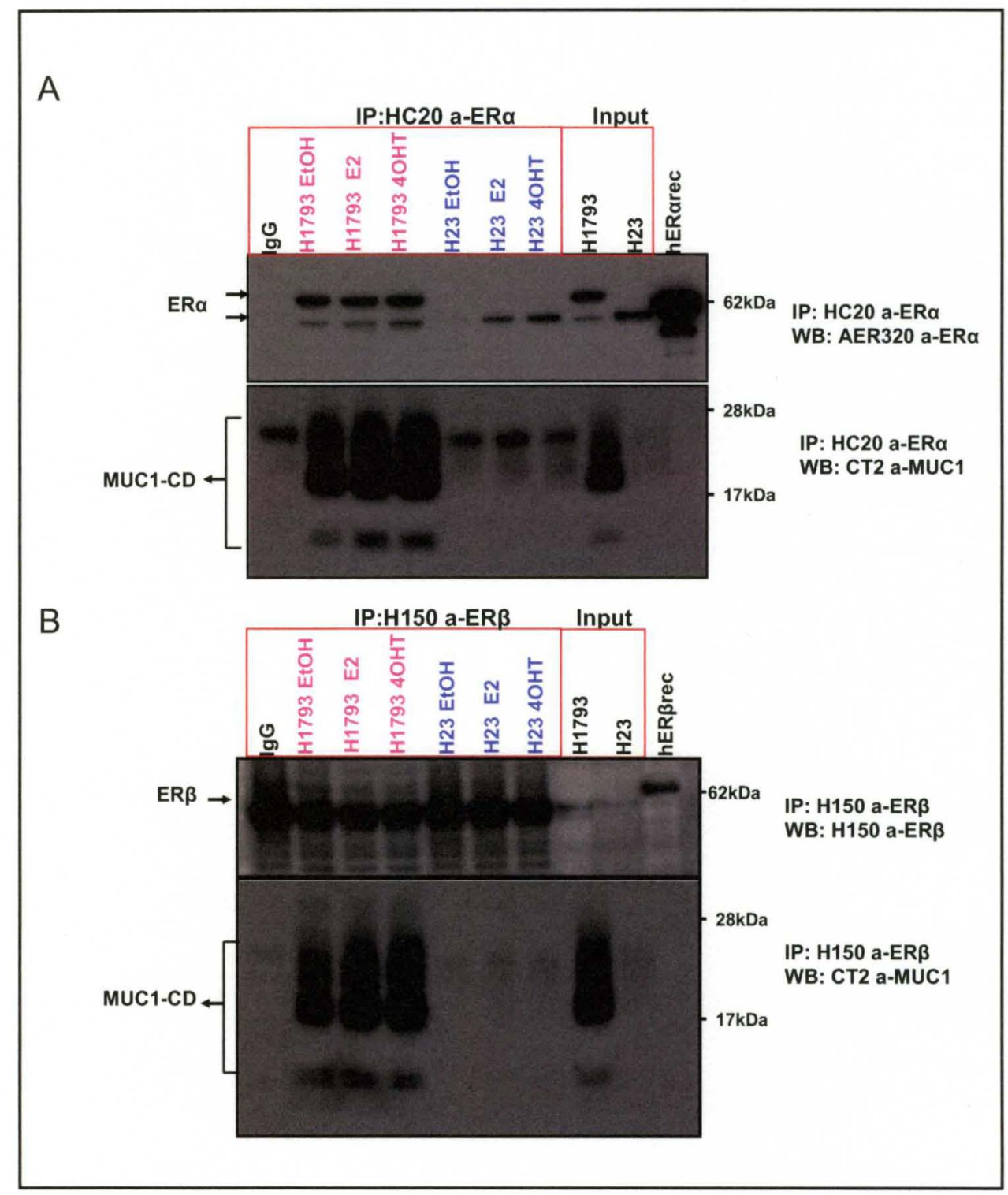

Figure 24. MUC1, ER $\boldsymbol{\alpha}$ and ER $\boldsymbol{\beta}$ interact in lung cancer cells. H23 and H1793 lung adenocarcinoma cells were grown in 5\% CSS-FBS-supplemented medium for $48 \mathrm{~h}$ prior to treatment. H23 was derived from a male patient and H1793 from a female patient (133). The cells were treated with ethanol vehicle control $(\mathrm{EtOH}), 10 \mathrm{nM}$ estradiol $\left(\mathrm{E}_{2}\right)$ or $100 \mathrm{nM}$ 4-hydroxytamoxifen (4-OHT) for $1 \mathrm{~h}$. Nuclear fractions were prepared using NE-PER Nuclear and Cytoplasmic Extraction Reagents (Pierce) according to the manufacturer's protocol. $400 \mu \mathrm{g}$ nuclear extracts (NE) were immunoprecipitated with (A) HC-20 anti-ER $\alpha$ (Santa Cruz) or (B) H-150 anti-ER $\beta$ (Santa Cruz). The proteins were separated on 14\% Tris-Glycine gel (Invitrogen) and transferred to PVDF membranes. The membranes were probed with CT2 anti-MUC1 (NeoMarkers) and (A) AER320 anti-ER $\alpha$ (NeoMarkers) or (B) H-150 anti-ER $\beta$ antibody (SantaCruz). Human recombinant $E R \alpha / \beta$ was used as a control for $E R \alpha / \beta$ reactivity. 
Initial Aim 3: Elucidate the anti-inflammatory role of MUC1, ER $\alpha$ and/or ER $\beta$ in human $\underline{\text { submandibular gland and human ocular surface. }}$

Experiment 1: QRT-PCR was performed to examine HSG response to TNF $\alpha$ treatment. HSG cells were treated with $10 \mathrm{ng} / \mathrm{ml} \mathrm{TNF} \alpha$ for $4 \mathrm{~h}$, mRNA levels for the indicated genes were determined. TNF $\alpha$ increased transcription of cyclooxygenase isoform 2 (COX-2), IL-1 $\beta$, IL-8 and ICAM-1 in HSG cells (Fig. 25).

Experiment 2: Previous reports have shown that MUC1 is upregulated by TNF $\alpha$ in a human uterine epithelial cell line (139), hence I examined the expression of MUC1 mRNA and protein in response to TNF $\alpha$ treatment in HSG cells. HSG cells were left untransfected or transfected with EV, MUC1/B, or MUC1 $1 \mathrm{EX}$ and treated with TNF $\alpha$. Figure 26 shows the mRNA and protein levels of MUC1. Here we demonstrate that MUCl is upregulated in response to TNF $\alpha$ treatment in HSG cells.

Experiment 3: To test the potential anti-inflammatory activity of $\mathrm{MUC1} / \mathrm{B}$ in HSG cells, cells were transiently transfected with either an empty vector or MUC1/B using the Amaxa nucleofector. After $48 \mathrm{~h}$, the cells were incubated with $10 \mathrm{ng} / \mathrm{ml} \mathrm{TNF} \alpha$ for 4 and $24 \mathrm{~h}$ to induce an inflammatory response. As indicated in Fig. 27A, I was able to overexpress MUC1/B in HSG cells. Fig $27 B$ shows mRNA levels of IL-8 in cells transfected either with an EV or with MUC1/B that were left untreated or incubated with $10 \mathrm{ng} / \mathrm{ml} \mathrm{TNF} \alpha$ for 4 and $24 \mathrm{~h}$. Treatment of HSG cells transfected with an EV with TNF $\alpha$ for 4 and $24 \mathrm{~h}$ induced IL-8 mRNA expression by 78 - and 200- fold, respectively. 
The increase in IL-8 mRNA expression is attenuated in HSG cells overexpressing MUC1/B. These data agree with the results shown in Chapter V (Fig. 18) and show that MUC1/B inhibits the TNF $\alpha$-induced inflammatory response in HSG cells as well as COS-7 cells. 


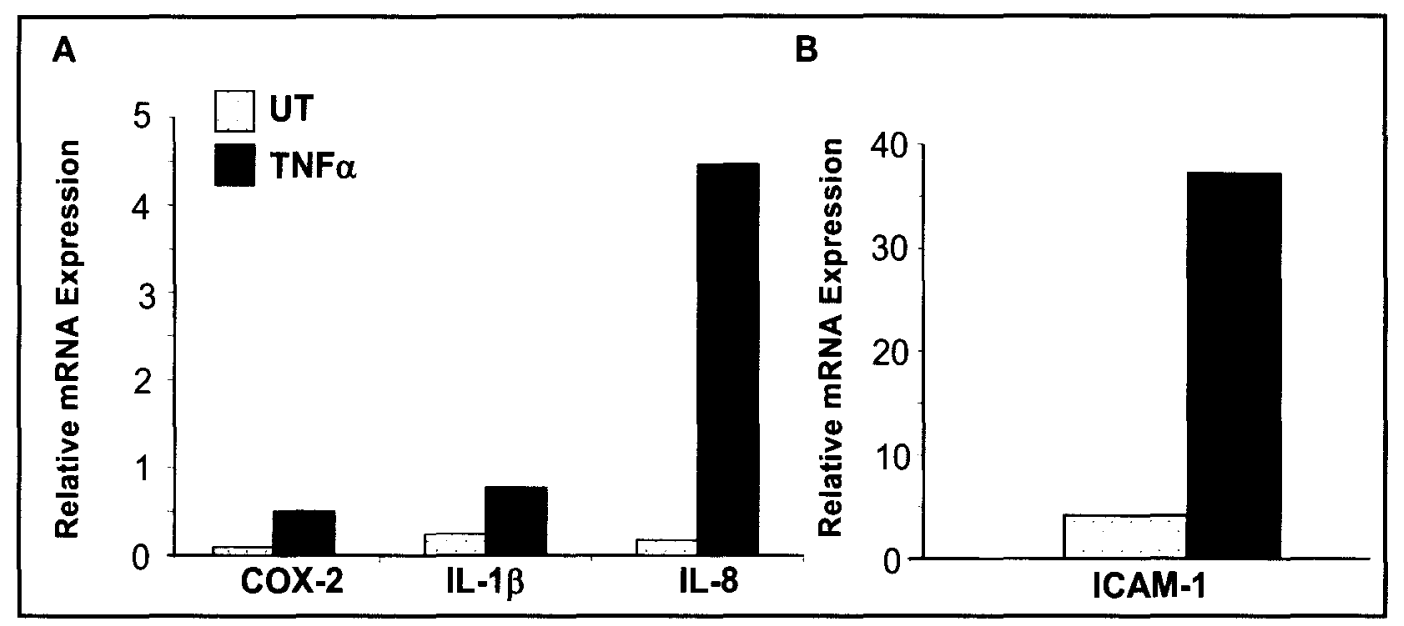

Figure 25. TNF $\alpha$ induces transcription of COX-2, IL-1 $\beta$, IL-8 and ICAM-1 in HSG cells. HSG cells were treated with $10 \mathrm{ng} / \mathrm{ml} \mathrm{TNF} \alpha$ for $4 \mathrm{~h}$. A) QRT-PCR shows that the fold induction for COX-2, IL-1 $\beta$, IL-8 and ICAM-1 compared to untreated was 5, 3, 23 and 9 respectively. B) QRT-PCR data for ICAM-1 expression. Note that the scale for the ICAM-1 graph is not identical to panel A. The fold induction for ICAM-1 in response to TNF $\alpha$ was $\sim 7$-fold 


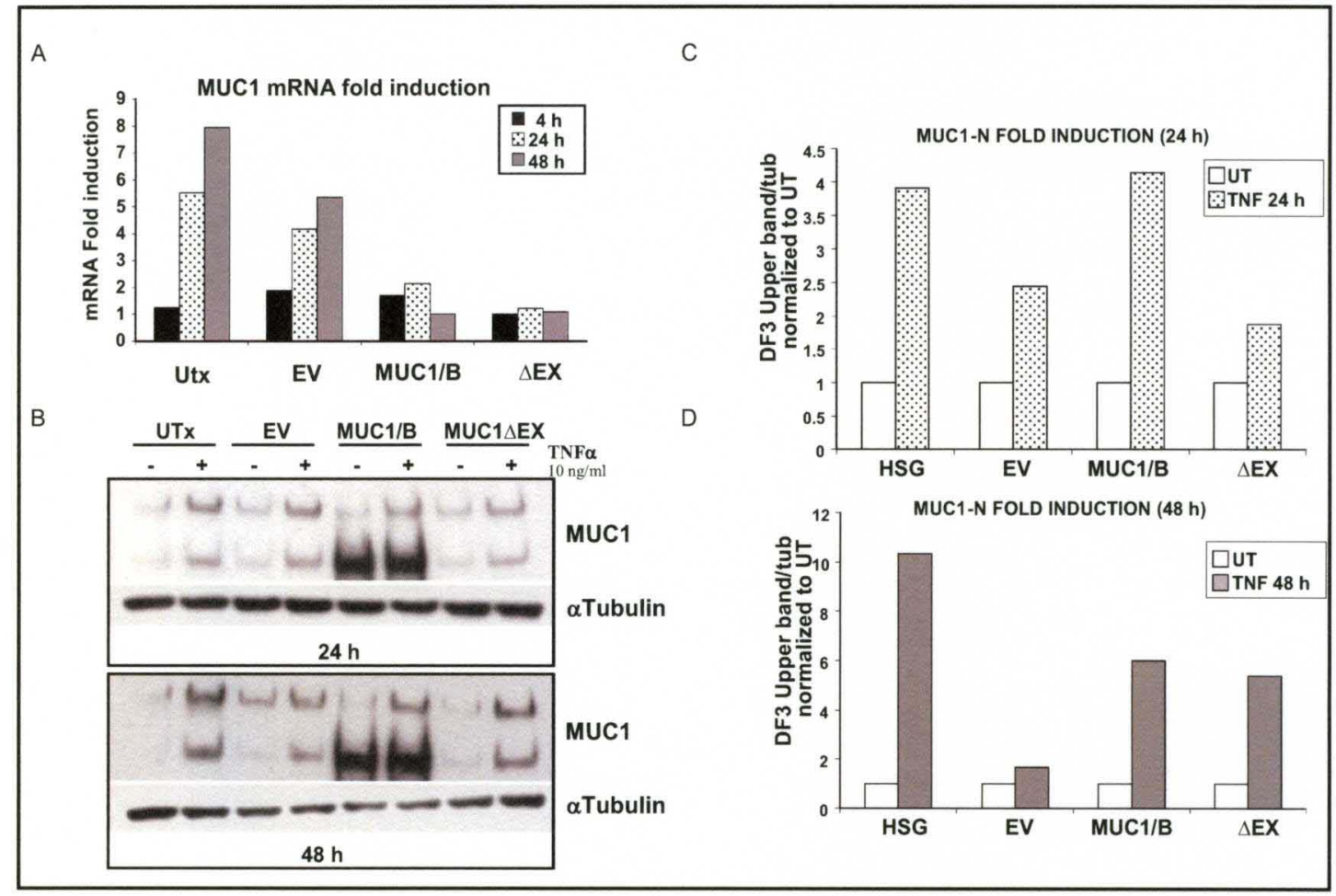

Figure 26. TNF $\alpha$ treatment increases MUC1 expression. HSG cells were left untreated or treated with $10 \mathrm{ng} / \mathrm{ml} \mathrm{TNF} \alpha$ for the indicated times. MUC1 mRNA and protein levels were analyzed. (A) MUC1 QRT-PCR in HSG cells untransfected (UTx) or expressing an EV, MUC1/B or MUC1 $\triangle \mathrm{EX}$. Cells were treated with $10 \mathrm{ng} / \mathrm{ml} \mathrm{TNF} \alpha$ for 4, 24 and $48 \mathrm{~h}$. Shown in the graph is the fold induction compared to untreated cells. (B) MUC1 protein expression in HSG cells 24 and $48 \mathrm{~h}$ after TNF $\alpha$ incubation. Briefly, $25 \mu \mathrm{g}$ total protein was separated on $3-8 \%$ Tris-Acetate gel (Invitrogen). Proteins were transferred to PVDF membranes and probed with the DF3 antibody against MUC1-N (Signet). (C) and (D) Immunoreactive MUC1 bands were quantified using UnScanIt ver. 6.1 (Silk Scientific). The graphs represent the top band of MUC1 normalized to $\alpha-$ tubulin and compared to the untreated control for each transfected construct. 


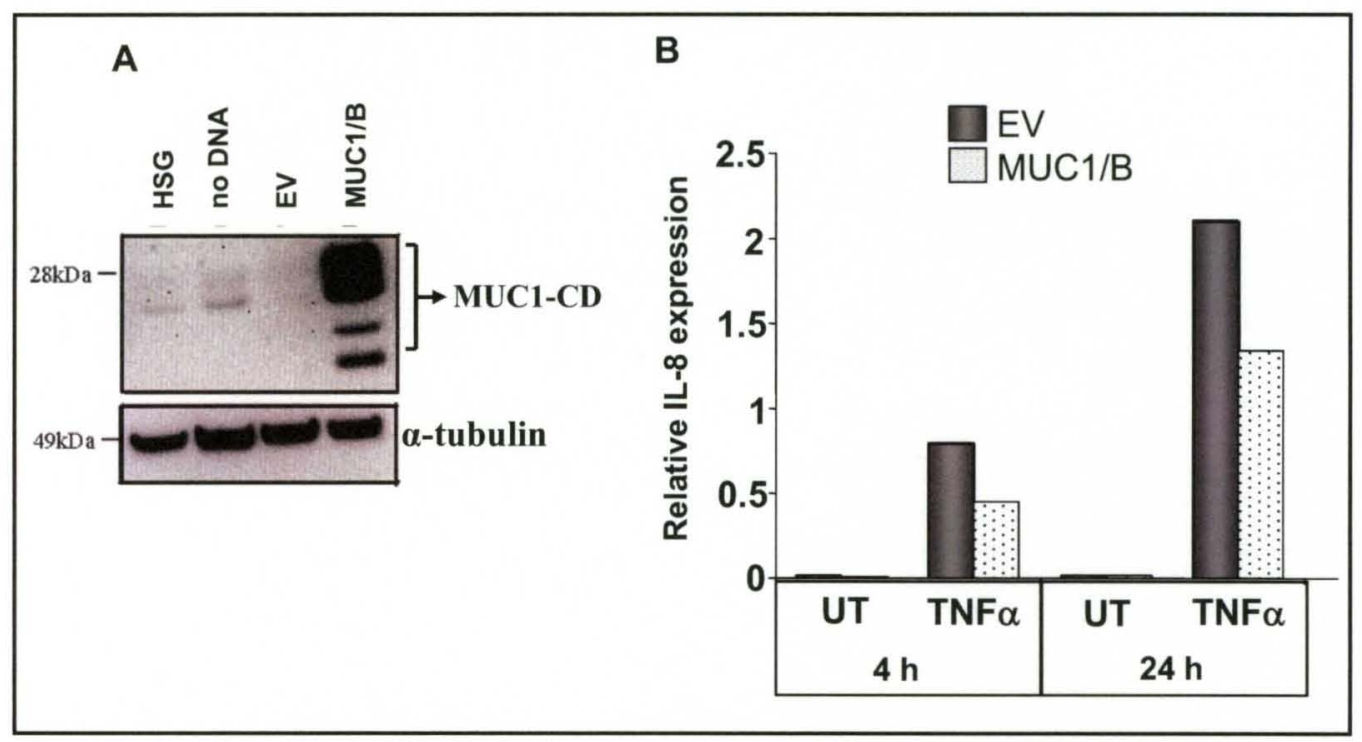

Figure 27. MUC1/B overexpression inhibits TNF $\alpha$-induced IL-8 expression in HSG cells. HSG cells were left untransfected or transfected with either no DNA (mock control), an empty vector control (EV) or MUC1/B. $48 \mathrm{~h}$ post-transfection the cells were left untreated or treated with $10 \mathrm{ng} / \mathrm{ml} \mathrm{TNF} \alpha$ for 4 or $24 \mathrm{~h}$. (A) MUC1-CD expression in HSG cells $48 \mathrm{~h}$ post-transfection. Briefly, $18 \mu \mathrm{g}$ total protein was separated on $12 \%$ BisTris gel (Invitrogen). Proteins were transferred to PVDF membranes and probed with the CT2 antibody against MUC1-CD (NeoMarkers). (B) IL-8 QRT-PCR in HSG cells expressing either an EV or MUC1/B. Cells were treated with $10 \mathrm{ng} / \mathrm{ml} \mathrm{TNF \alpha}$ for 4 and $24 \mathrm{~h}$ 


\section{APPENDIX II}

\section{ELSEVIER LICENSE TERMS AND CONDITIONS}

Oct 19,2010

This is a License Agreement hetween Yoannis Imbert ("You") and Elsevier ("Elsevier") provided by Copy right Clearance (enter " $C\left(C^{\prime \prime)}\right.$. The license consists of your order details. the terms and conditions provided by Elsevier. and the payment terms and conditions.

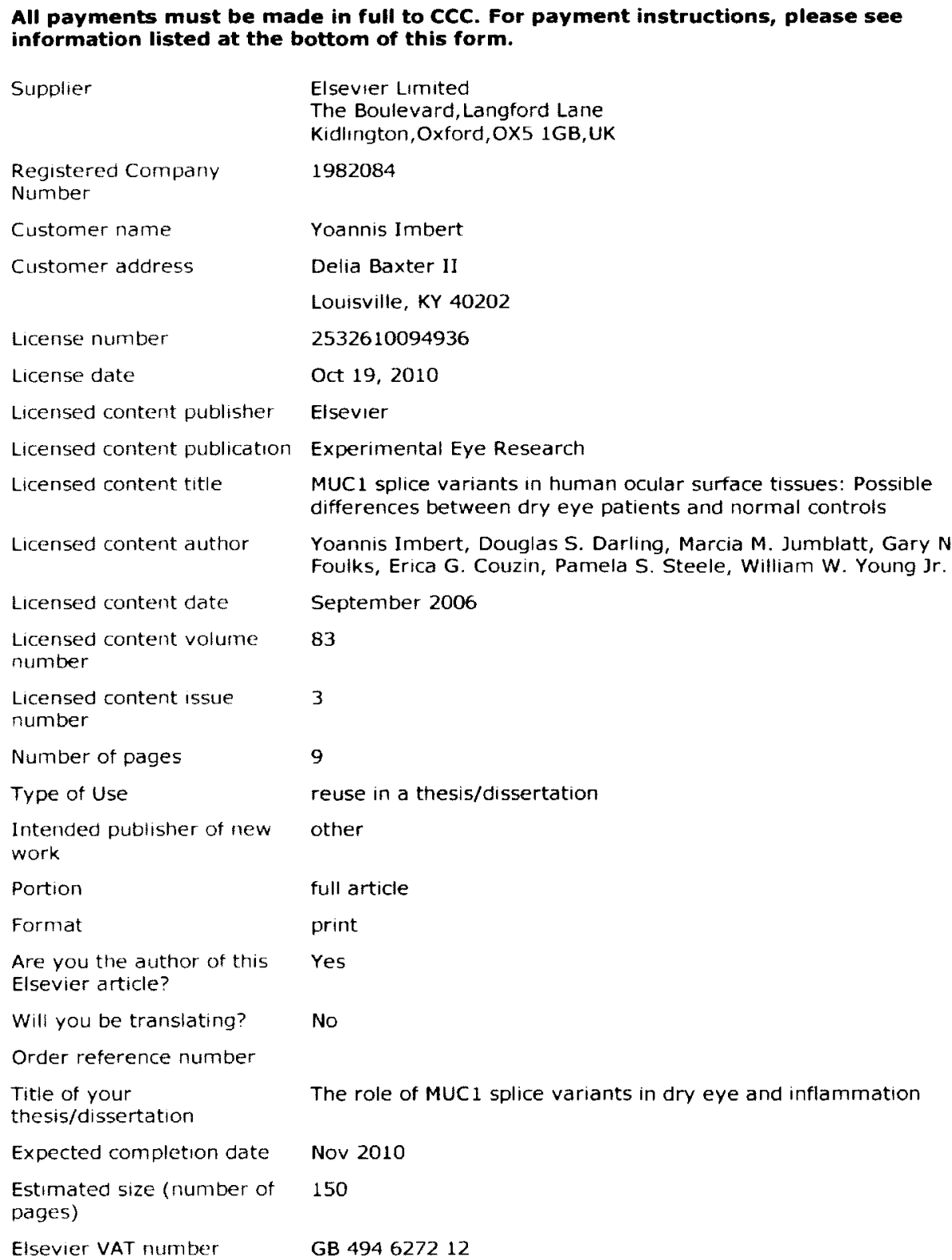

Terms and Conditions 


\section{APPENDIX III}

\section{ELSEVIER LICENSE \\ TERMS AND CONDITIONS}

Oct 19,2010

This is a License Aureement between Yoannis Imber ("You") and Elsevier ("LIsevier") provided by Copy nutht Clearance (enter ( $\mathrm{C}(\mathrm{C}$ ") The license consists of vour order details the terms and conditions provided by Hisevier. and the pay ment terms and conditions

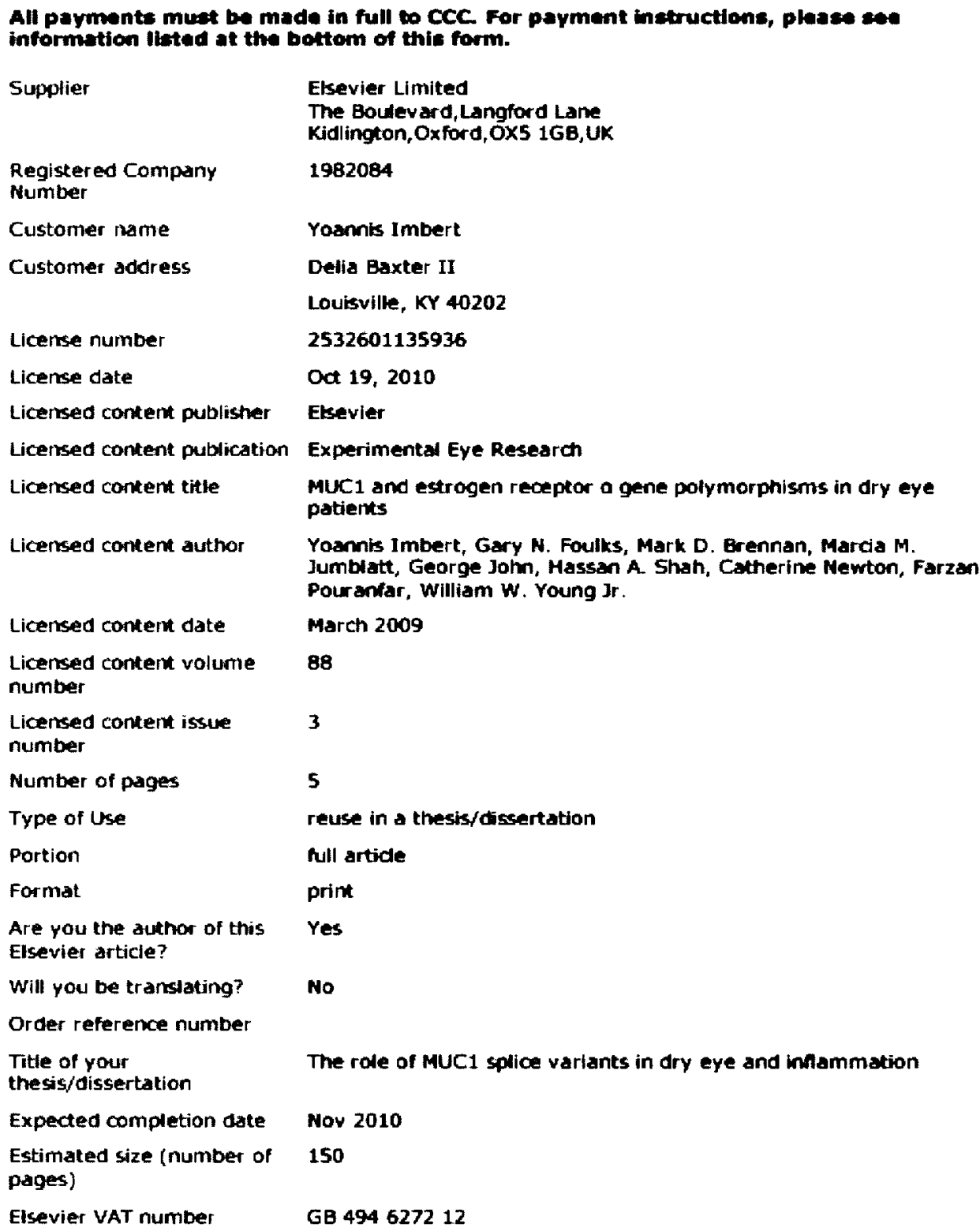

Terms and Conditions 
Personal Data:

Title:

Address:

Phone:

Fax:

Email:

\section{Education and}

Training:

\title{
Yoannis Imbert-Fernandez
}

\author{
Graduate Research Assistant, Ph.D. Candidate \\ Department Biochemistry and Molecular Biology \\ Delia Baxter Bldg, Rm 234, 580 S Preston St \\ Louisville, KY 40202 \\ (502) 852-7594 (lab), (502) 418-5846 (cell) \\ (502) 852-3659 \\ yimire01@gwise.louisville.edu
}

1998 B.S., Biochemistry

University of Havana

Havana, Cuba

GPA 3.42

2008 M.S., Biochemistry and Molecular Biology University of Louisville

Louisville, KY 40202

GPA 4.0

November 2010 anticipated Ph.D., Biochemistry and Molecular Biology

Current with radiation safety training, research ethics training and bloodbourne pathogen training

\section{Teaching Experience:}

Graduate Teaching Assistant Summer Research Students
Advanced Biochemistry I, Fall 2003

2008-2010

Awards: $\quad$ NIH Kirschstein-NRSA Minority Predoctoral Fellowship F31 EY017275 (Feb/2007-Feb/2011) 
Publications: note: Yoannis Imbert nee Yoannis Imbert-Fernandez

1. Imbert, Y., Darling, D.S., Jumblatt, M.M., Foulks, G.N., Couzin, E.G., Steele, P.S., and Young, W.W., Jr. MUCl splice variants in human ocular surface tissues: possible differences between dry eye patients and normal controls. Exp. Eye Res. 2006 Sep;83(3):493-501. Epub 2006 Apr 21. PMID: 16631167

2. Jumblatt, M.M., Imbert, Y., Young, W.W. Jr., Foulks, G.N., Steele, P.S., and Demuth, D.R. Glycoprotein 340 in normal human ocular surface tissues and tear film. Infect Immun. 2006 Jul;74(7):4058-63. PMID: 16790779

3. Imbert, Y., Jumblatt, M.M., Foulks, G.N., Couzin, E.G., Steele, P.S., Young, W.W. Jr. Expression in human ocular surface tissues of the GalNAc-transferases that initiate mucin-type O-glycosylation. Cornea. 2006 Dec;25(10):1193-9. PMID: 17172897

4. Imbert, Y., Foulks, G.N., Brennan, M.D., Jumblatt, M.M., John, G., Shah, H.A., Newton, C., Pouranfar, F., Young, W.W., Jr. MUC1 and estrogen receptor alpha gene polymorphisms in dry eye patients. Exp Eye Res. 2009 Mar;88(3):334-8. Epub 2008 Jun 20. PMID: 18619437

5. Schultz, D.J., Wickramasinghe, N.S., Ivanova, M.M., Isaacs, S.M., Dougherty, S.M., Imbert-Fernandez, Y., Cunningham, A.R., Chen, C., Klinge, C.M. Anacardic acid inhibits estrogen receptor alpha-DNA binding and reduces target gene transcription and breast cancer cell proliferation. Mol Cancer Ther. 2010 Mar;9(3):594-605. Epub 2010 Mar 2.

\section{Abstracts Presented at Scientific Meetings:}

1. Young, W.W., Jr., Imbert, Y., Jumblatt, M.M., Foulks, G.N., Ten Hagen, K. Expression of UDP-GalNAc:polypeptide N-acetylgalactosaminyltransferase isoforms at the ocular surface. The Ocular Surface 3, S129, 2005.

2. Imbert, Y., Darling, D.S., Jumblatt, M.M., Foulks, G.N., Couzin, E.G., Steele, P.S. and Young, W.W., Jr. Mucin splice variants in ocular surface tissues. (Abstract 75). Glycobiology 15, 1220, 2005.

3. Imbert, Y., Darling, D.S., Jumblatt, M.M., Foulks, G.N., Couzin, E.G., Steele, P.S. and Young, W.W., Jr. Mucin splice variants in the human ocular surface: possible differences between dry eye patients and normal controls. (Abstract GRD24) Research! Louisville, 2005.

4. Imbert, Y., Darling, D.S., Jumblatt, M.M., Foulks, G.N., Couzin, E.G., Steele, P.S. and Young, W.W., Jr. Mucin splice variants in the human ocular surface: 
possible differences between dry eye patients and normal controls. (Abstract 5596). ARVO meeting, IOVS, 2006.

5. Imbert, Y., G.N. Foulks, M.D. Brennan, M.M. Jumblatt, G. John, H.A. Shah, C. Newton, and W.W. Young, Jr. MUCl gene polymorphism in dry eye patients. (Abstract 6). TFOS meeting, 2007

6. Shah, H.A., Imbert, Y., Foulks, G.N., Brennan, M.D., Jumblatt, M.M., John, G., Newton, C., Pouranfar, F., and Young, W.W., Jr. MUC1 gene polymorphisms in patients with dry eye disease. (Abstract 5306). ARVO meeting, IOVS, 2008.

7. Imbert-Fernandez, Y., and Klinge, C.M. MUC1 splice variants differentially regulates inflammatory responses in transfected COS-7 cells. (Abstract 753). FASEB meeting, 2010.

8. Imbert-Fernandez, Y., Radde, B.N., Teng, Y. and Klinge, C.M. MUC1 splice variants differentially regulate inflammatory responses in transfected COS-7 cells. (Abstract GRD33). Research!Louisville, 2010.

9. Radde, B.N., Imbert-Fernandez, Y., Klinge, C.M. MUC1-Estrogen Receptor interaction in lung adenocarcinoma cells (Abstract RS-104). Research!Louisville, 2010 